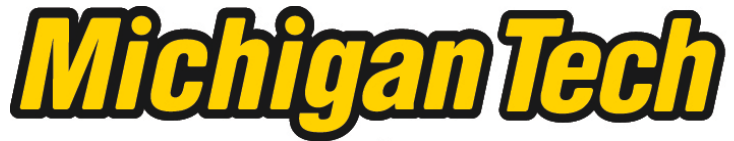 \\ Michigan Technological University Create the Future Digital Commons @ Michigan Tech
}

Regional comparisons of nano-mechanical properties of the human meniscus; structure and function

John Thomas Moyer

Michigan Technological University

Follow this and additional works at: https://digitalcommons.mtu.edu/etds

Part of the Mechanical Engineering Commons

Copyright 2012 John Thomas Moyer

\section{Recommended Citation}

Moyer, John Thomas, "Regional comparisons of nano-mechanical properties of the human meniscus; structure and function", Master's Thesis, Michigan Technological University, 2012.

https://doi.org/10.37099/mtu.dc.etds/389

Follow this and additional works at: https://digitalcommons.mtu.edu/etds

Part of the Mechanical Engineering Commons 


\title{
REGIONAL COMPARISONS OF NANO-MECHANICAL PROPERTIES OF THE HUMAN MENISCUS; STRUCTURE AND FUNCTION
}

\author{
By \\ John Thomas Moyer \\ A THESIS \\ Submitted in partial fulfillment of the requirements for the degree of \\ MASTER OF SCIENCE \\ (Mechanical Engineering) \\ MICHIGAN TECHNOLOGICAL UNIVERSITY
}

2012

@2012 John Thomas Moyer 
This thesis, "Regional Comparisons of Nano-mechanical Properties of the Human Meniscus; Structure and Function" is hereby approved in partial fulfillment of the requirements for the Degree of MASTER OF SCIENCE IN MECHANICAL ENGINEERING.

Department of Mechanical Engineering - Engineering Mechanics

Signatures:

Thesis Co - Advisor:

Tammy Haut Donahue

Thesis Co - Advisor:

Gregory Odegard

Department Chair:

William Predebon

Date 


\section{Table of Contents}

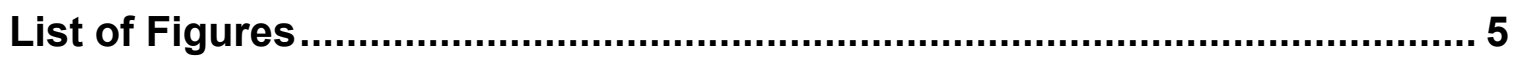

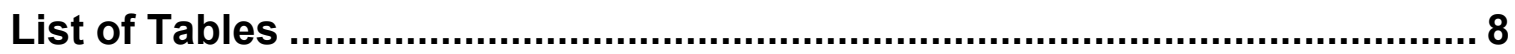

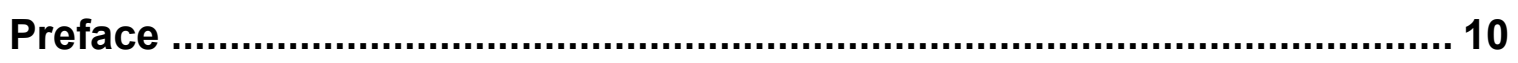

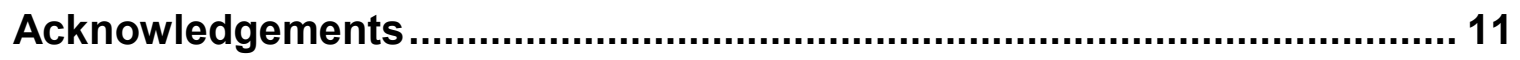

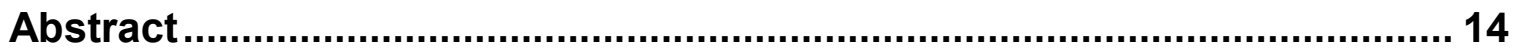

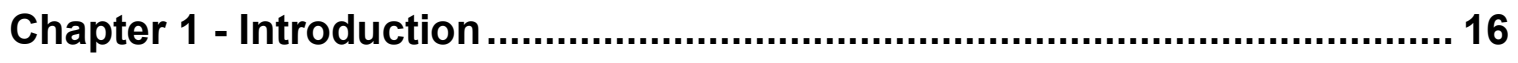

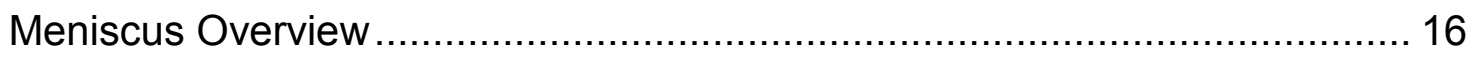

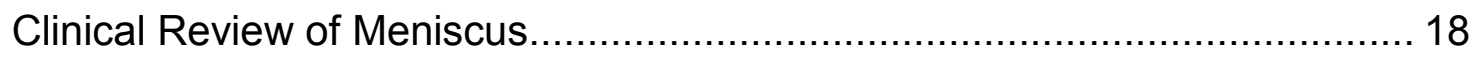

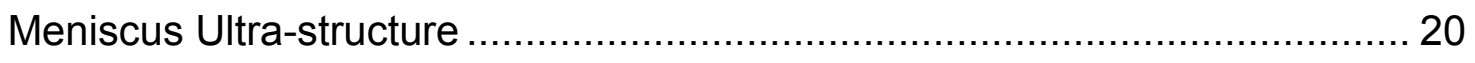

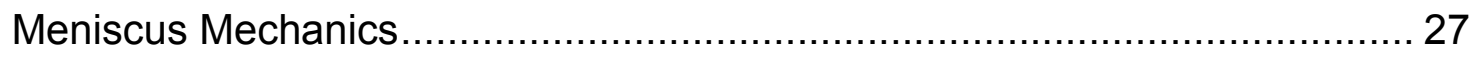



Chapter 2 - Nanoindentation of Human Meniscal Surfaces .......................... 35

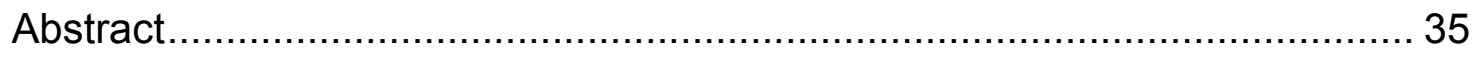

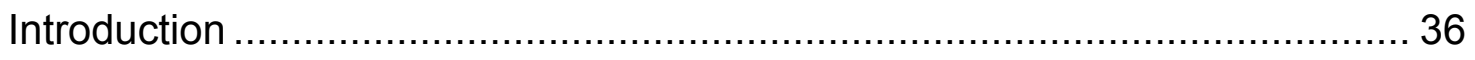





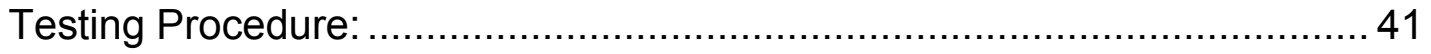



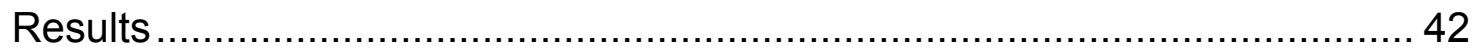

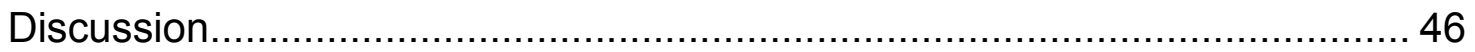

Chapter 3 - Regional Comparisons of Nano-mechanical and Histological Human Deep Zone Meniscus................................................................ 52

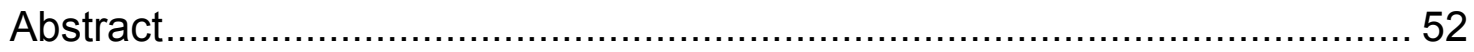

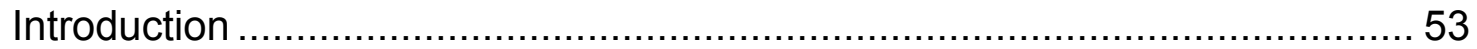

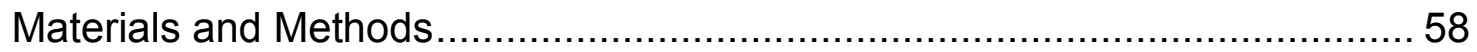



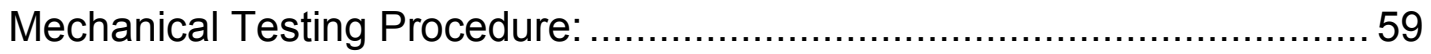



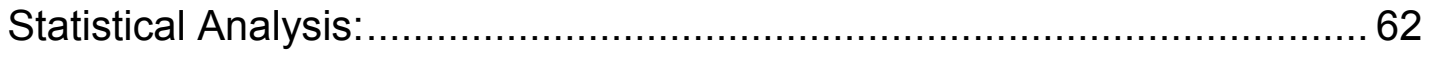

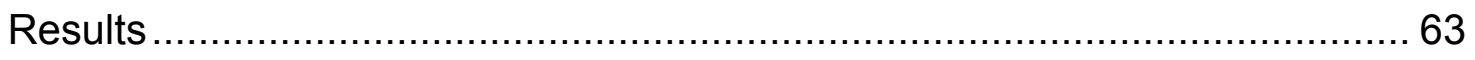

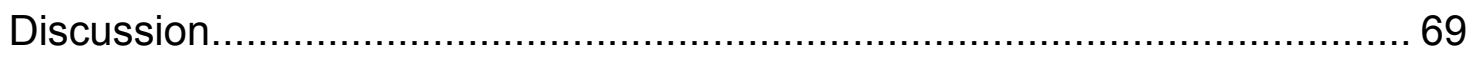


Chapter 4 - Significance of Research and Future Directions....................... 75

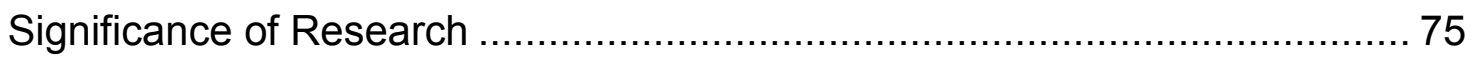

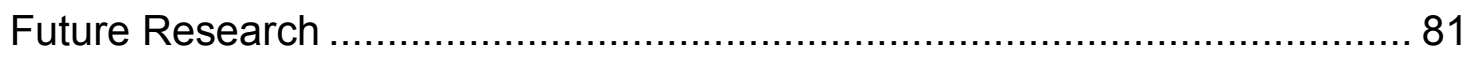

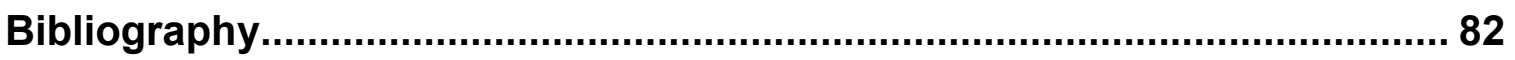

Appendix A: Standard Operating Procedure ……...................................... 91

Nanoindenting/Preparation Meniscal Tissue ................................................. 91

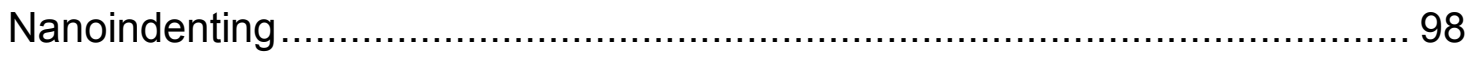

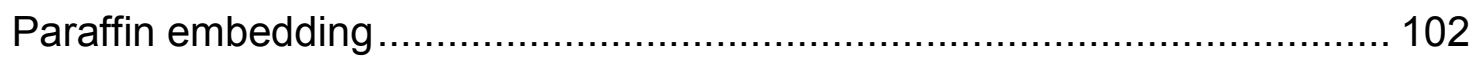

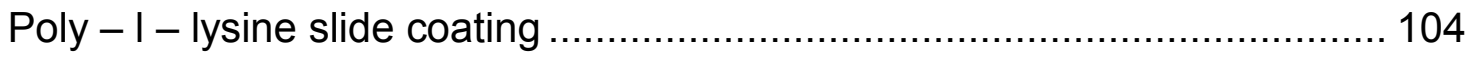

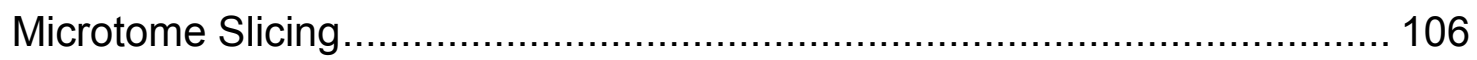

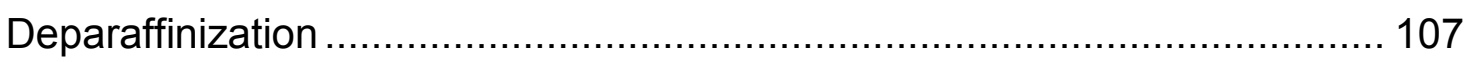

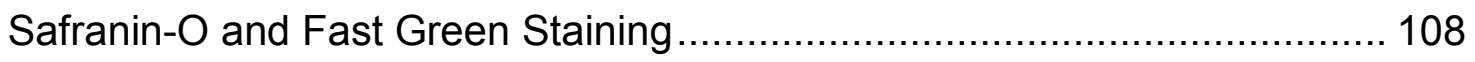

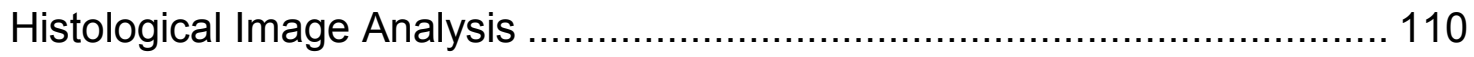

Appendix B: Supplementary Material, Raw Data and Matlab Code ........... 115

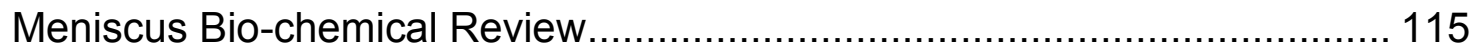

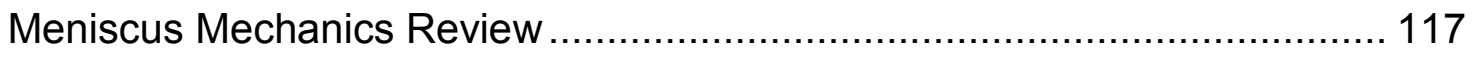

Nanoindentation Results - Deep Zone vs. Superficial layer ....................... 119

Three-way Blocked ANOVA Matlab Code ............................................... 120

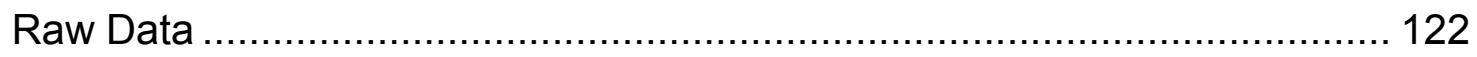

Appendix C: Copyright Clearance ........................................................ 131

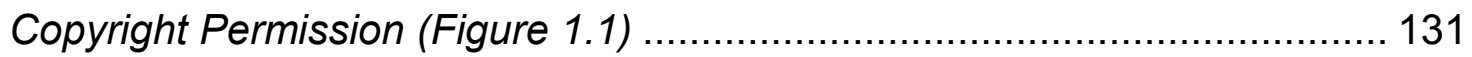

Copyright Permission (Figure 1.2) ......................................................... 132 


\section{List of Figures}

Figure 1.1: Schematic of human knee showing both lateral and medial menisci lying on tibial plateau. From El Dorado Physical Therapy with permission.

Figure 1.2: Meniscal cross-section showing hierarchal structure of collagen fibril orientations. \#1 is referencing the meniscal proximal and distal superficial layers, \#2 is in reference to the meniscal lamellar layer and \#3 designates the deep zone circumferentially aligned collagen fibrils. Arrowheads represent the location of a few radial collage fibrils that are interwoven in the circular fibril bundles. Arrows represent the loose connective tissue from the joint capsule. From (Petersen and Tillmann 1998) with kind permission from Springer Science and Business Media.

Figure 1.3: Schematic of individual proteoglycan molecule showing different glycosaminoglycan side chains (i.e. Chondroitin Sulfate) attached to hyaluronic acid. Adapted from (Hess and Herman 1986)

Figure 2.1: Schematic of human menisci showing where three regions are located and how indentation direction was normal to both the proximal and distal meniscal surface. Relative meniscal constituents compared in indenter tip size and depth are shown, all to scale with cross-section of meniscus rotated to show normal indentation direction. Dashed lines represent specimen cutting. Testing setup with meniscal sample in acrylic well puck, filled with saline solution, shows indentation direction normal to the specimen surface.

Figure 2.2: Representative displacement-time creep curve from nanoindentation on meniscal surfaces. Dots represent data points, solid line is the curve fit for the viscoelastic model used in this analysis.

Figure 2.3: A. Average steady-state elastic modulus- B. Average instantaneous elastic modulus- $C$. Average Time Dependency- values from nanoindentation conducted on both proximal and distal meniscal surfaces. Error bars represent standard error. 44

Figure 3.1: Schematic of human menisci showing where three regions are located and what testing slices resembled. Enlarged meniscal crosssection is shown. Two 2-3 mm slices were taken from each region for mechanical testing and histology analysis. Both analyses were conducted in the middle meniscus (inner, middle and outer meniscus labeled) section and nanoindentation was normal to the deep zone meniscus cut surface. Dashed lines represent specimen cutting. 
Figure 3.2: Representative histology images that have had a color threshold applied to show location of GAG content with $A$ ) showing outline of meniscal surface region without GAG content and $B$ ) showing the outline of meniscal cross-sectional area ROI and GAG cross-sectional area ROI. Figure $2 \mathrm{~A}$ was used to calculate the average distance from meniscal surface to the presence of GAG and Figure $2 B$ was used to calculate the ratio of meniscal GAG to cross-sectional area.

Figure 3.3: A. Average steady-state elastic modulus- B. Average instantaneous elastic modulus- C. Average Time Dependency- values from nanoindentation conducted on the deep zone of human meniscal samples * represents a significant difference between the connecting lines for

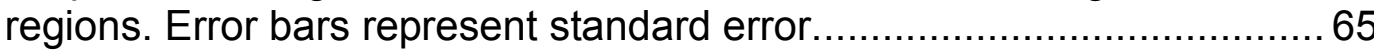

Figure 3.4: Image showing a stained medial anterior specimen. Red stain = GAG 68

Figure 3.5: Average distance from meniscal surface to GAG presence values for both proximal and distal surfaces of the anterior, central and posterior regions from lateral and medial menisci. $\boldsymbol{\nabla}$ represents a significant difference between proximal and distal surface values; \# represents a significant difference between the connecting lines for regions within respective anatomical locations and * represents a significant difference between the connecting lines between anatomical locations within respective regions. Error bars represent standard error.

Figure A.1: a) Top view of properly labeled well tray b) Iso view of the drop cloth correctly labeled. 92

Figure A.2: a) iso view of a specimen that is too high b) a side of a specimen that sticks out too much. Since the puck in the picture did not contain tape or nail polish, the specimen would stick out even more. 93

Figure A.3: Specimen painted with nail polish on the surface opposite to the surface being indented.

Figure A.4: Well-puck with double sided tape cut and inserted into it............... 94

Figure A.5: Specimens ready for transport to the sub-basement lab............... 95

Figure A.7: Images on left are original histology images. Right images are respective histology images after a threshold has been applied. 
Figure A.8: Image with applied threshold and outlines drawn to measure average thickness of non-GAG meniscal surface.

Figure A.9: Histology image with 'outer ROl' highlighted .............................112

Figure A.10: Histology image with 'inner ROl' highlighted. Making sure to overlay 'outer ROl' lines

Figure A.11: Image with both inner and outer ROI selected to show intersection 113 


\section{List of Tables}

Table 1.1: Review of previous research on glycosaminoglycans and proteoglycan content with meniscus. Supplementary biochemical studies on menisci are included in Appendix B........................................... 26

Table 1.2: Review of previous mechanical testing conducted on the meniscus, concentration on studies that examined regional inhomogeneity. Supplementary mechanical studies on menisci are included in Appendix B.

Table 2.1: Material property comparison among varying compression based mechanical tests on the meniscus

Table 2.2: Material property comparison among varying compression based mechanical tests on articular cartilage

Table 3.1: Table showing the mean \pm standard error values of GAG fraction intensity measured from histological images of regional meniscal crosssections. * represents a significant difference from the lateral - posterior region

Table 3.2: Table showing the mean \pm standard error values of Ratio of GAG - to Meniscal Area measured from thresheld histological images of regional meniscal cross-sections.

Table B.1: Review of previous research on glycosaminoglycans and proteoglycan content with meniscus

Table B.2: Supplementary review of previous mechanical testing conducted on menisci.

Table B.3: Comparison of nanoindentation results (Instantaneous Elastic Modulus) for deep zone and superficial layer of human meniscus. Superficial layer results included averaged proximal and distal surface values

Table B.4: Comparison of nanoindentation results (Steady-State Elastic Modulus) for deep zone and superficial layer of human meniscus. Superficial layer results included averaged proximal and distal surface values

Table B.5: Raw data averages for each deep-zone meniscus nanoindentation 
Table B.6: Raw data averages for each meniscal surface nanoindentation..... 123

Table B.7: Raw data from quantitative histological analysis measuring GAG

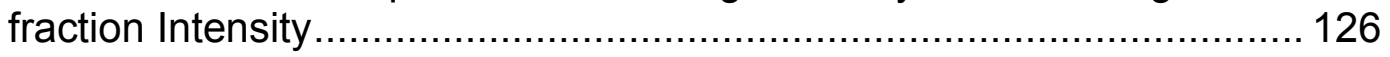

Table B.8: Raw data from quantitative histological analysis measuring distance from meniscal surface to GAG content ............................................. 127

Table B.9: Raw data from quantitative histological analysis measuring ratio of GAG area to meniscal cross-sectional area...................................... 129 


\section{Preface}

The work presented in this thesis is a compilation of my own review of the literature as well as my own work published in peer-reviewed journals (Chapter 2 has been submitted as an Original Manuscript to the Journal of Biomechanics and Chapter 3 will be submitted to a similar journal). However, it is important to note that I did not work alone on each of the following nanoindentation and histology experiments. Although, the data presented in this thesis are based on my own work and conclusions. The data presented in Chapter 2 and 3 is all my own work, from the development of the procedure to the actual testing, but both chapters will be/are submitted for publications with co-authors. These co-authors had a scientific contribution throughout the testing and experimentation. 


\section{Acknowledgements}

The work completed in this thesis would not be at all possible with the great support from several people. The past few years have been quite a rollercoaster, and I can honestly say I enjoyed 'most' of the moments. I have learned so much and hope some people have learned a thing or two from me.

I must first thank my advisor, Dr. Tammy Haut Donahue, who 'recruited' me and is responsible for starting and continually fueling my motivation to study biomechanics. I always had an interest in the field, but it was her course and attitude and encouragement that made me really want to go to graduate school and research biomechanics. Working for Dr. Donahue has been nothing but interesting and I am forever grateful that she kept me around and put up with me for these past years.

My parents have been nothing but supportive during my journey and I am so thankful that they have given me the necessary tools to succeed in this world. I would be nowhere without them constantly pushing me to maintain focus, and I truly look up to them. Hopefully I can be as great of a parent as they were to me. They have made many trips up to see me and I will never forget the great memories shared at the $\mathrm{KBC}$ ! I also want to acknowledge my great sisters; they have always had my back and were always there when I needed to talk about anything. I really am lucky to have two great sisters that I am so close to! Also, my brother-in-law has been just like a real brother to me and I must also thank him for all things he has taught me and done for me. I feel very blessed to have both sets of very supportive grandparents and my great-aunt and -uncle; they 
have given me much support and, helped with the many of life's lessons and provided a few laughs along the way. I know I would not be the man I am today without them.

I really have enjoyed my time as a research assistant, mainly due to the people I shared it with. Thank you Adam Abraham for all the knowledge you 'tried' to instill in me, and especially for all the laughs. You may be the smartest person I will ever have the privilege of knowing, but also the most interesting and straight-forward and thank you again for everything. I must also thank my other Soft Tissue Mechanics friends; Megan Killian, you have also helped me so much and will never forget the good music and many late nights for conference abstracts. Ed Knoch, I know we will be friends forever and thank you for the many memorable moments and laughs in the lab. Troy Bouman and Ryan Priest, I would probably not be graduating it wasn't for you two. Thank you very much for your hard work and great ideas, I owe both of you and am grateful you put up with me and helped me with my research. I must thank Allison Lebovsky, thank you for putting up with all my rants and varying moods every night and constantly keeping me in check, I am sure lucky to have you.

I must thank my committee, Dr. Megan Frost and Dr. Gregory Odegard, thank you very much for taking the time to serve as my committee members and help me along the way. Also, thank you to JoAnne Stimac and Karen Bess, as I have made countless trips to their desks for varying questions and they have always been kind and very helpful. And a big thank you goes out to Nancy Byers- 
Sprague and Dr. Debra D. Charlesworth for their help with my graduate school and thesis questions.

Finally, I am thankful of the financial support from Michigan Technological University, for allowing me be a teaching assistant and gain a much greater appreciation for the professors here at MTU. I also want to thank the Graduate Research Grant and Bio-Tech Research Center for providing me with multiple travel grants, allowing me to attend national conferences to present my research. Lastly I would like to thank the Michigan Space Grant Consortium and National Institute of Health for funding the majority of my research here at MTU. 


\section{Abstract}

Osteoarthritis (OA) is a debilitating disease that is becoming more prevalent in today's society. OA affects approximately 28 million adults in the United States alone and when present in the knee joint, usually leads to a total knee replacement. Numerous studies have been conducted to determine possible methods to halt the initiation of OA, but the structural integrity of the menisci has been shown have a direct effect on the progression of OA. Menisci are two C-shaped structures that are attached to the tibial plateau and aid in facilitating proper load transmission within the knee. The meniscal cross-section is wedge-like to fit the contour of the femoral condyles and help attenuate stresses on the tibial plateau. While meniscal tears are common, only the outer $1 / 3$ of the meniscus is vascularized and has the capacity to heal, hence tears of the inner $2 / 3$ rds are generally treated via meniscectomy, leading to OA. To help combat this OA epidemic, an effective biomimetric meniscal replacement is needed. Numerous mechanical and biochemical studies have been conducted on the human meniscus, but very little is known about the mechanical properties on the nano-scale and how meniscal constituents are distributed in the meniscal cross-section. The regional (anterior, central and posterior) nano-mechanical properties of the meniscal superficial layers (both tibial and femoral contacting) and meniscal deep zone were investigated via nanoindentation to examine the regional inhomogeneity of both the lateral and medial menisci. Additionally, these results were compared to quantitative histological values to better formulate a structure-function relationship on the nano-scale. These data will prove 
imperative for further advancements of a tissue engineered meniscal replacement 


\section{Chapter 1 - Introduction}

\section{Meniscus Overview}

The knee joint is important for ambulation as it encapsulates many soft tissues to allow for daily functional activities. There are four major ligaments within the knee joint (Anterior cruciate ligament- $A C L$, Posterior cruciate ligament - PCL, Medial Collateral Ligament - MCL and Lateral Collateral Ligament - LCL) and each of them act to restrain abnormal motion during common dynamic activities. Articular cartilage covers the proximal end of the tibial plateau and the distal end of the femoral condyles to provide smooth joint articulation, with two menisci located between the tibia and femur (Figure 1.1). Menisci are semi-lunar, with a concave contour on the femoral contacting surface (proximal) and a relatively flat contour on the tibial contacting surface (distal). Menisci are fibrocartilaginous structures that provide fundamental load distribution and support within the knee joint aiding to attenuate stresses at the tibiofemoral site (Walker and Erkman 1975; Shrive et al. 1978; Messner and Gao 1998; Donahue et al. 2002). The menisci are C-shaped to wrap around the architecture of the femoral condyle, and this unique shape allows the menisci to transmit axial stresses (i.e. 'body force') into hoop or radial stresses.

It has been shown that menisci may carry up to $70 \%$ of the total compressive load acting on the knee (Walker and Erkman 1975; Seedhom 1976; Ahmed and Burke 1983). While the majority of the meniscal forces are distributed 
circumferentially, the menisci are also exposed to compressive and shear stresses. Menisci help to mitigate stresses on the tibial plateau to preserve the underlying articular cartilage, thereby promoting osteoarthritis (OA) prevention (Walker and Erkman 1975; Messner and Gao 1998; Roos et al. 1998; Neuman et al. 2008; Neuman et al. 2009). With increasing prevalence of OA, it is essential to collect all relevant knowledge of the menisci, to use for meniscal replacements (Rattner et al. 2010).

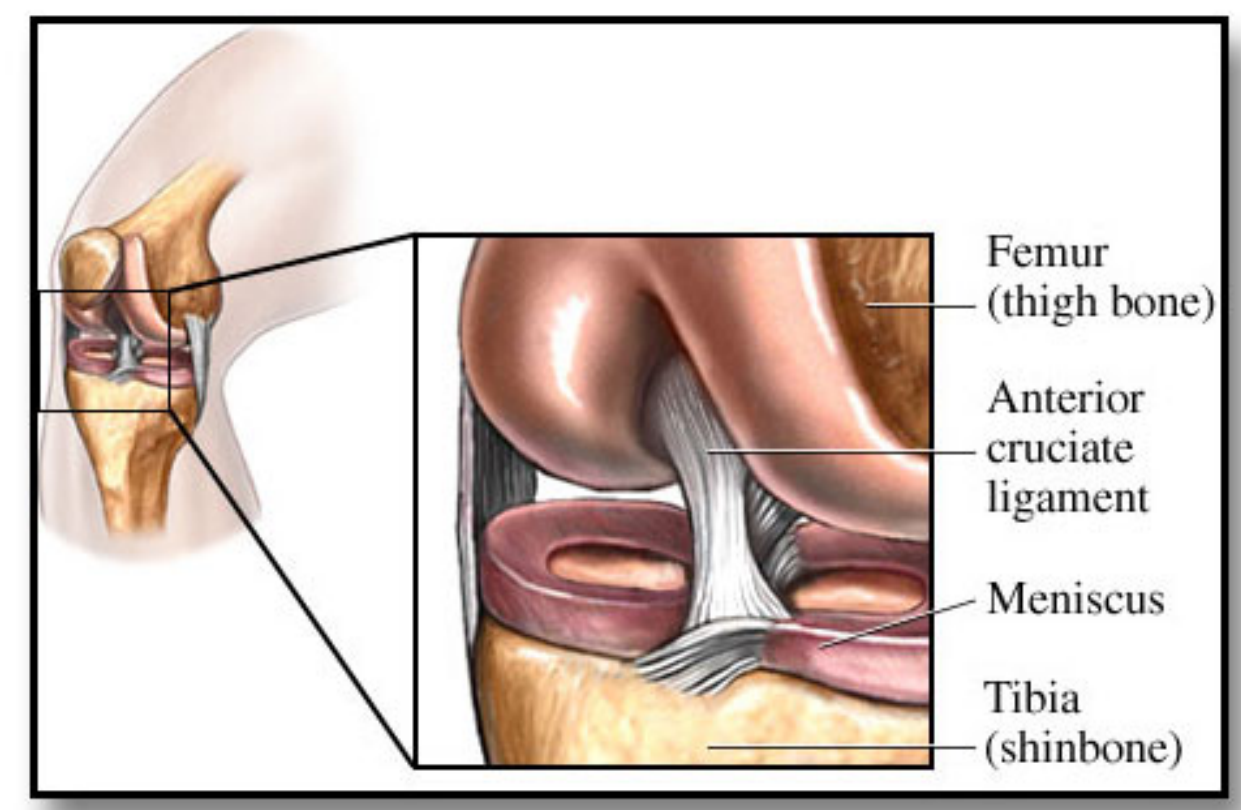

Figure 1.1: Schematic of human knee showing both lateral and medial menisci lying on tibial plateau. From El Dorado Physical Therapy with permission. 


\section{Clinical Review of Meniscus}

In the United States alone, meniscal tears represent the most common intra-articular knee injury, with annual amount of reported meniscal lesions being 66 per 100,000 people, with greater than $90 \%$ of reports resulting in meniscectomies (Baker et al. 1985; Hede et al. 1990a; Hede et al. 1990b; Rattner et al. 2010; Salata et al. 2010). Currently, surgical meniscal repair is ineffective, mainly due to the lack of necessary blood flow in the meniscal body, where only the outer $1 / 3$ of the meniscus is considered vascularized (Arnoczky et al. 1990; Messner and Gao 1998; Brindle et al. 2001; Greis et al. 2002; S. B. Adams, Jr. et al. 2005; Hoben and Athanasiou 2006). The majority of meniscal tears occur in the inner, avascular 2/3rds of the meniscus; hence, these tears do not heal well and are usually treated with a partial meniscectomies (Henning et al. 1990; Tenuta and Arciero 1994; Messner and Gao 1998). A partial meniscectomy surgically resects the torn tissue, which in turn reduces the amount of meniscal tissue, and the ability of the remaining meniscus to attenuate stresses. This procedure inevitably reduces meniscal function and is an avenue for further complications. Additionally, it has been shown that the medial posterior region of the meniscus has the highest frequency of tear occurrence (Helms et al. 1998; Choi et al. 2008; De Smet et al. 2009). Interestingly, meniscal contact pressure studies suggest the medial posterior region experiences the largest stresses, relative to the other meniscal regions (Muriuki et al. 2011). Thus, it is possible that meniscal properties and loading are not homogeneous throughout the tissue and may affect the propagation of tissue damage. 
Tissue engineered meniscal replacement efforts have been ongoing for years, with numerous questions being answered, but currently no structure can mimic the native, functioning menisci (Marsano et al. 2006; Kon et al. 2008; Makris et al. 2011). The ideal meniscal construct must excel in three main categories to properly function: mechanics (mechanical properties, geometry, anisotropy, etc.), bioactivity (cell phenotype, ECM synthesis, immunogenicity, etc.) and logistics (supply, material processability, sterilization, etc) (Makris et al. 2011). Currently there are four distinct routes to tissue engineering a meniscal replacement, with the four classes being: synthetic polymer, hydrogel, Extra Cellular Matrix (ECM) components, and tissue-derived materials (Greis et al. 2002; van Tienen et al. 2009; Rattner et al. 2010; Makris et al. 2011). Each of these classes have their pros and cons, with the tissue-derived scaffold having the best bioactivity, but the worst logistics, and the synthetic and ECM scaffolds having the best mechanics. To optimize a tissue engineering meniscal replacement, the native meniscus must be analyzed to fully understand the mechanics and how they apply to the bioactivity. 


\section{Meniscus Ultra-structure}

Menisci contain interstitial fluid, which accounts for $70 \%$ of the total weight and helps to support the menisci in compression (D.C. Fithian et al. 1989; McDevitt and Webber 1990). Interstitial fluid consists of a water solvent that contains salts, amino acids, sugars and other nutrients for the soft tissues within the knee, with many of these interstitial fluid constituents having a positive charge (net fluid charge is neutral). The remainder of the tissue is made up primarily of collagen fibrils and proteoglycans; with an array of other glycoproteins and chondrocytes.

Type I collagen accounts for approximately $90 \%$ of the meniscal collagen content, but Type II, III, V and VI collagen are also present and are mostly contained within the surface layers (Figure 1.2) (Eyre and Wu 1983; Aspden et al. 1985; Petersen and Tillmann 1998). Type I collagen fibril bundles have a diameter of approximately 10-200 $\mu \mathrm{m}$, and are composed of $35 \mathrm{~nm}$ fibrils (Aspden et al. 1985; D.C. Fithian et al. 1989; Petersen and Tillmann 1998). Not all collagen fibers are circumferentially aligned within the meniscal body, as a tight network mesh of randomized collagen fibrils contacts the tibial plateau and femoral condyles, known as the meniscal superficial layer (Figure 1.2) (100-200 $\mu m$ thick) (Petersen and Tillmann 1998; X. Li et al. 2007). The superficial layer of articular cartilage has been shown to be significantly important for both flowdependent and -independent mechanisms, and meniscal superficial layers (proximal - tibial contacting and distal - femoral contacting) are thought to be 
similar and crucial for the articular cartilage contacting interface (Beaupre et al. 1986; Setton et al. 1993). Furthermore, previous meniscal superficial zone studies have shown the layer to be structurally homogeneous, using digital image correlation and unconfined compression (Lai and Levenston 2010). 'Radial tie' fibers are also contained within the meniscus and run from the inner meniscal apex to the outer edge (Beaupre et al. 1986; Petersen and Tillmann 1998; Rattner et al. 2010). Radial fiber bundles are thought to be crucial for supporting the meniscus during shear stresses (Rattner et al. 2010; Abraham et al. 2011). Collagen fibrils are predominately oriented in the direction of the largest tensile forces, and the multiple levels of fibril orientations help maintain the intrinsic structural integrity of the meniscus (Petersen and Tillmann 1998).

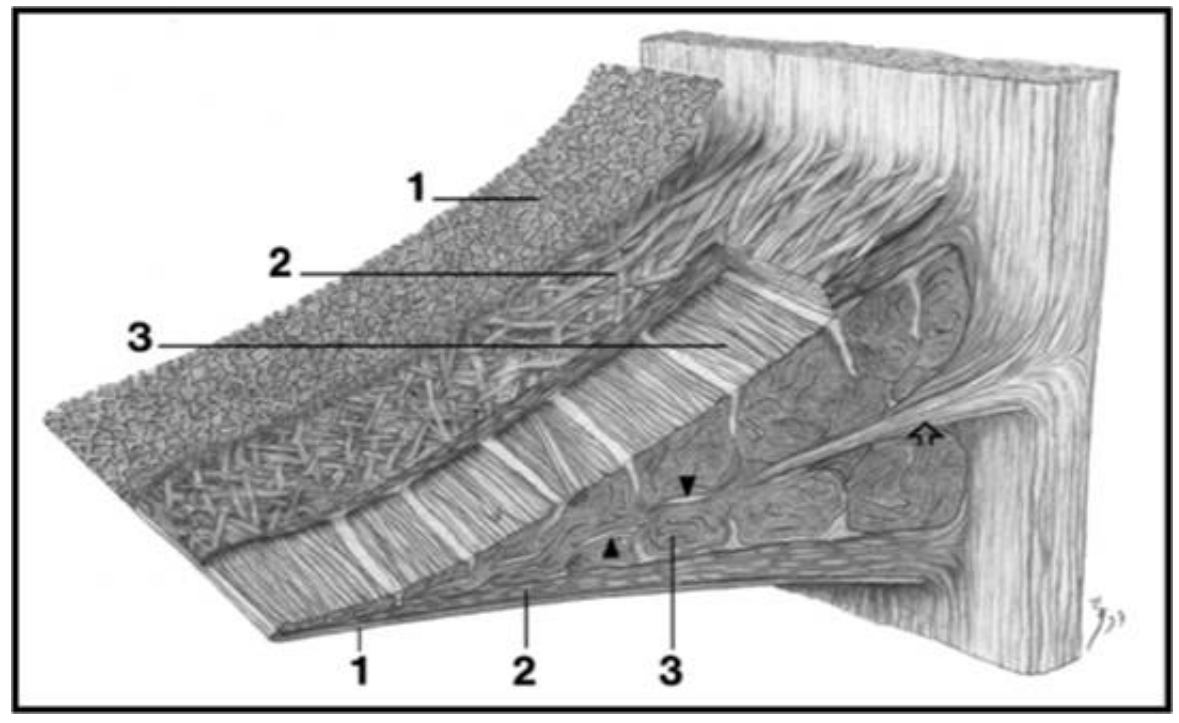

Figure 1.2: Meniscal cross-section showing hierarchal structure of collagen fibril orientations. \#1 is referencing the meniscal proximal and distal superficial layers, \#2 is in reference to the meniscal lamellar layer and \#3 designates the deep zone circumferentially aligned collagen fibrils. Arrowheads represent the location of a few radial collage fibrils that are interwoven in the circular fibril bundles. Arrows represent the loose connective tissue from the joint capsule. From (Petersen and Tillmann 1998) with kind permission from Springer Science and Business Media. 
As the meniscus is interposed between the femur and tibia, our upright posture imposes a compressive load on the tissue. This compressive load is supported by the interaction of varying meniscal constituents, namely proteoglycans and interstitial fluid (Walker and Erkman 1975; Shrive et al. 1978; McDevitt and Webber 1990; Messner and Gao 1998). Proteoglycans (PG) contain a core link protein with one or more individually attached glycosaminoglycans (GAG) (Figure 1.3). While a complete $P G$ chain is suspected to be approximately $1200 \mathrm{~nm}$ in length, this length can vary based on attached individual GAGs (McNicol and Roughley 1980; Roughley et al. 1981; M. E. Adams and Ho 1987) Menisci are known to produce a 'cartilage-like' PG in an attempt to counteract compressive loads, which is very similar to articular cartilage. However, AC has been shown to have 8 times as much PG content as the meniscus (McDevitt 1973; McNicol and Roughley 1980; Roughley et al. 1981). PG resist compressive loads via at least 2 different mechanism. First, GAG chains are inherently negatively charged (Figure 1.3) in the physiological environment and produce a swelling pressure (Donnan osmotic pressure) due to the repulsion charges (Lu et al. 2009). Along with the negative charges aiding to support the menisci in compression, the negatively charged GAGs attract the positively charged ions within the interstitial fluid, causing GAG-rich areas to retain fluid (McNicol and Roughley 1980; M. E. Adams et al. 1986). Individual GAG chains are hypothesized to have individual functional characteristics, with research showing areas that are more fibrous contain greater amounts of dermatan sulfate and areas that are more hyalinized contain more chondroitin 
sulphates. Meniscal horn attachments, which seem to be ligamentous in nature, primarily act in tension and are very fibrous; containing greater amounts of dermatan sulfate when compared to the meniscal body, which contains a greater amount of chondroitin sulfate (Table 1.1) (M. E. Adams and Muir 1981; Roughley et al. 1981; M. E. Adams et al. 1986; M. E. Adams and Ho 1987; McDevitt and Webber 1990; Roughley and White 1992; Sanchez-Adams et al. 2011).

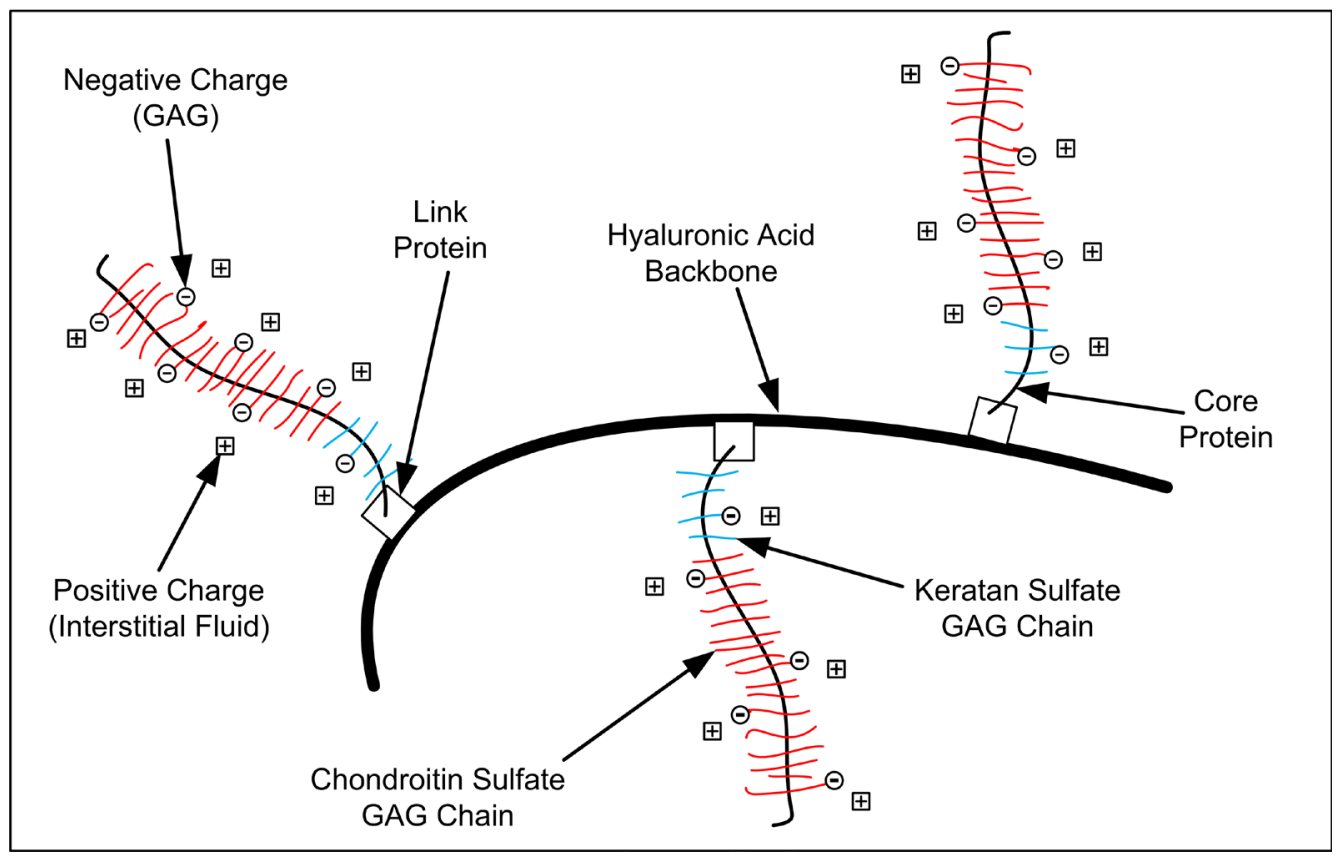

Figure 1.3: Schematic of individual proteoglycan molecule showing different glycosaminoglycan side chains (i.e. Chondroitin Sulfate) attached to hyaluronic acid. Adapted from (Hess and Herman 1986)

Previous studies have investigated how non-collagenous protein (NCP's) content is altered within the meniscus during degradation or aging (Ingman et al. 1974; Ghosh et al. 1975; Ghosh and Taylor 1987). In the human meniscus, NCP's are essentially PG's, and the ratio of collagenous proteins (CPs) to NCPs 
is shown to decrease after age 70 , which is believed to lead to a reduction in tensile strength and impair the meniscus ability to withstand normal stress (Ingman et al. 1974). However, others have shown an increased amount of hyaluronic acid retention with an increased age, which possibly indicates an overall increase in proteoglycan content with age (Ghosh et al. 1975; McNicol and Roughley 1980). Individual glycosaminoglycans attach to hyaluronic acid chains (Figure 1.3), therefore, an increased amount of hyaluronic acid may lead to an increased amount of PG content. These studies will help to understand possible measures that need to be taken into account when tissue engineering meniscal replacements.

Proteoglycan content has been shown to be relatively uniform throughout the human meniscus (D.C. Fithian et al. 1989), yet regional variations in meniscal stiffness have been shown throughout the anterior, central and posterior regions (D. C. Fithian et al. 1990; Sweigart et al. 2004; Chia and Hull 2008). Sanchez et al. examined the inner, middle, and outer regions (radial direction) of bovine meniscus to correlate GAG presence to meniscus mechanics using unconfinedcompression and tension by testing samples with and without GAG depletion (Table 1.1). Inner and middle regions, where sulfated GAGs are more abundant, showed significant changes in viscosity and modulus of relaxation between GAG depleted specimens and the unaltered native meniscus, indicating the importance of GAG in supporting compressive loads in these regions (SanchezAdams et al. 2011). Inner region tensile properties were found to increase 
following GAG depletion (Table B.1 in Appendix B); likely suggesting that GAG content can have an indirect role in determining tensile properties which are typically driven by collagen content. Others have hypothesized that GAG crosslinking tendencies may affect meniscal tensile properties (Nakano et al. 1986; Sanchez-Adams et al. 2011).

Despite previous research investigating overall GAG content in the human meniscus, it is still unknown how the GAG content varies regionally within the meniscus. Moreover, there is no published research showing how GAG content is localized in a meniscal cross-section and if that localization has regional variability. Glycosaminoglycans have been shown to have a very important role in meniscus mechanics and thus, given the aptitude for tearing in certain regions of the meniscus, regional GAG/PG coverage would be important to characterize. 
Table 1.1

Review of previous research on glycosaminoglycans and proteoglycan content with meniscus. Supplementary biochemical studies on menisci are included in Appendix B.

\begin{tabular}{|c|c|c|c|c|c|c|c|c|c|c|c|}
\hline \multicolumn{12}{|c|}{ Meniscal Glycosaminoglycans/Proteoglycan Properties } \\
\hline & & & & & & \multicolumn{6}{|c|}{ GAG content ( $\mu$ mole hexosamine/g tissue) } \\
\hline Study & $\begin{array}{c}\text { Analysi } \\
\mathrm{s}\end{array}$ & $\begin{array}{c}\text { \# of } \\
\text { samples }\end{array}$ & $\begin{array}{l}\text { Meniscus } \\
\text { Location }\end{array}$ & & $\begin{array}{l}\text { Regions } \\
\text { Studied }\end{array}$ & Hyaluronate & $\begin{array}{l}\text { Chondroitin } \\
\text { Sulfate }\end{array}$ & $\begin{array}{l}\text { Derme } \\
\text { Sulf }\end{array}$ & & $\begin{array}{c}\text { Keratan } \\
\text { Sulfate }\end{array}$ & Total \\
\hline $\begin{array}{l}\text { (Adams, } \\
\text { et al., } \\
\text { 1987) }\end{array}$ & $\begin{array}{c}\text { Histolog } \\
\mathrm{y}\end{array}$ & 4 & \multirow{4}{*}{ Medial } & & Body & $1.8 \pm 0.33$ & $7.18 \pm 1.79$ & $1.62 \pm$ & & $1.58 \pm 0.43$ & 12.18 \\
\hline & & & & \multirow{2}{*}{ Horn } & Anterior & $1.21 \pm 0.29$ & $2.68 \pm 1.43$ & \multicolumn{2}{|c|}{$1.59 \pm 0.52$} & $0.53 \pm .0 .47$ & 5.96 \\
\hline & & Human & & & Posterior & $1.56 \pm 0.63$ & $4.71 \pm 1.07$ & \multicolumn{2}{|c|}{$1.5 \pm 0.96$} & $1.12 \pm 0.49$ & 8.89 \\
\hline & & & & & Periphery & $1.14 \pm 0.40$ & $0.57 \pm 0.48$ & \multicolumn{2}{|c|}{$1.11 \pm 0.59$} & $0.05 \pm 0.13$ & 2.87 \\
\hline & & & \multirow{3}{*}{ Lateral } & & Body & $0.93 \pm 0.25$ & $4.38 \pm 0.62$ & \multicolumn{2}{|c|}{$2.28 \pm 0.55$} & $1.35 \pm 0.36$ & 8.94 \\
\hline & & & & \multirow{2}{*}{ Horn } & Anterior & $1.56 \pm 0.96$ & $2.26 \pm 0.97$ & \multicolumn{2}{|c|}{$1.74 \pm 0.79$} & $0.34 \pm 0.24$ & 5.9 \\
\hline & & & & & Posterior & $1.32 \pm 0.48$ & $2.16 \pm 1.75$ & \multicolumn{2}{|c|}{$2.05 \pm 0.59$} & $0.38 \pm 0.45$ & 5.91 \\
\hline Study & $\begin{array}{c}\text { Analysi } \\
\mathbf{s}\end{array}$ & $\begin{array}{c}\text { \# of } \\
\text { samples }\end{array}$ & $\begin{array}{l}\text { Meniscus } \\
\text { Location }\end{array}$ & & $\begin{array}{l}\text { Regions } \\
\text { Studied }\end{array}$ & \multicolumn{3}{|l|}{ Water (\%) } & \multicolumn{2}{|c|}{$\begin{array}{c}\text { Collagen } \\
\text { (dry weight } \\
\% \text { ) }\end{array}$} & \\
\hline $\begin{array}{c}\text { (D.C. } \\
\text { Fithian et } \\
\text { al. 1989) }\end{array}$ & $\begin{array}{c}\text { Histolog } \\
\mathrm{y}\end{array}$ & 4 & \multirow{3}{*}{ Lateral } & & Anterior & $75.02 \pm 2.14$ & \multicolumn{2}{|c|}{$2.40 \pm 0.67$} & \multicolumn{2}{|c|}{$93.0 \pm 24.1$} & \\
\hline & & Human & & & Central & \multicolumn{2}{|c|}{$72.99 \pm 2.40$} & $2.23 \pm 0.74$ & \multicolumn{2}{|c|}{$85.8 \pm 13.0$} & \\
\hline & & & & & Posterior & $73.99 \pm 2.44$ & \multicolumn{2}{|c|}{$2.33 \pm 0.60$} & \multicolumn{2}{|c|}{$98.8 \pm 20.2$} & \\
\hline & & & & & Anterior & $72.12 \pm 9.73$ & & $2.97 \pm 1.34$ & & $8 \pm 23.4$ & \\
\hline & & & Medial & & Central & $76.77 \pm 2.6$ & $2.74 \pm$ & 0.90 & & $4 \pm 22.1$ & \\
\hline & & & & & Posterior & $74.88 \pm 7.3$ & $2.58 \pm$ & 1.10 & & $4 \pm 23.4$ & \\
\hline
\end{tabular}




\section{Meniscus Mechanics}

Numerous mechanical tests have been conducted to observe the material properties of the menisci in all directions and in three distinct regions (anterior, central and posterior) (Table 1.2 \& Figure 2.1). Tensile tests on the menisci have been conducted using $\sim 1 \mathrm{~mm}$ wide coupon samples from meniscal body with the collagen fibers oriented parallel to the direction of loading (D.C. Fithian et al. 1989; Tissakht and Ahmed 1995; Sanchez-Adams et al. 2011). Tensile testing along the collagen fibril direction has shown the posterior region be the stiffest, with an elastic moduli value of $294.1 \pm 90.4 \mathrm{MPa}$ (D.C. Fithian et al. 1989). However, when testing meniscal samples in the radial direction, the anterior region had the largest elastic moduli with value of $48.47 \pm 25.7 \mathrm{MPa}$ (Table 1.2) (Tissakht and Ahmed 1995). Comparing tensile testing values in the circumferential and radial directions, it can be seen the meniscal body is very anisotropic in nature, making it necessary to further characterize the meniscus mechanics in compression.

To date, compressive based testing has only examined the mechanical properties of menisci on the micro-scale and larger, with compression values being multiple orders of magnitude smaller than tensile values. Compressive properties of menisci have previously been quantified on both the meniscal surface and in the deep zone (Joshi et al. 1995; Sweigart et al. 2004; X. Li et al. 2007; Chia and Hull 2008; Lai and Levenston 2010). Compression moduli values are dependent on the test conditions, which may be reflected in the values. One 
study using unconfined compression of the deep zone, resulted in aggregate moduli values an order of magnitude smaller $(\sim 0.02 \mathrm{MPa})$ than that of a microindentation study ( 0.2 MPa) (Table 1.2) (Sweigart et al. 2004; Chia and Hull 2008). Unconfined and confined compression have been used as tools for gathering mechanical properties of biological materials for many years and usually involves cylindrical or cubic specimens with a diameter of approximately 3 mm (Joshi et al. 1995; Chia and Hull 2008; Lai and Levenston 2010; SanchezAdams et al. 2011). Comparing unconfined compression results to confined compression results, it can be seen that the steady-state modulus from confined compression is approximately an order of magnitude larger than unconfined (Table 1.2) (Joshi et al. 1995; Chia and Hull 2008). With compression based testing, there are many factors that can influence the test results, such as the size of the indenter or platen, the porosity of the indenter tip, and radial confinement of the test sample.

Indentation has also been used as a compression based tool to gather mechanical properties of biological tissue, but to date, only macro- and microindentation have been utilized for meniscal tissue (Sweigart et al. 2004; X. Li et al. 2007; Sandmann et al. 2009). Sweigart et al. conducted a micro-indentation study to analyze regionally the superficial layers of the medial meniscus. This study showed no mechanical difference between the proximal and distal surfaces, but a significant difference in the anterior region for steady-state modulus, when compared to the central and posterior regions (Table 1.2) (Sweigart et al. 2004). Although this micro-indentation test was conducted on the 
two meniscal superficial zones, the underlying deep zone fibers were possibly engaged due to the indentation depth of approximately $50 \mu \mathrm{m}$ and a macro-scale indenter. Additionally, this study used a flat punch, which could possibly apply an uneven surface pressure to meniscal samples as the surface contour is known to be very inconsistent (Sweigart et al. 2004). A spherical indenter tip should be used to ensure a consistent contact area, regardless of surface contour. Indentation tests are becoming more popular among biological materials, as they offer accurate resolution and the possibility to capture the mechanical characteristics of a whole specimen surface via numerous indents. However, to date, the human meniscus has not been indented on the nano-scale to better understand meniscal mechanics and how they relate to the local meniscal constituent inhomogeneity.

Nanoindentation provides a physiologically relevant testing procedure to determine the viscoelastic material properties of the meniscus on the scale of the meniscal constituents and has been shown to be applicable for mechanical testing of hydrated cartilage-like tissues (Ebenstein et al. 2004; Ebenstein and Pruitt 2006). Mechanical testing on the nano-scale has been shown to detect changes in articular cartilage function associated with degradation, while the micro-scale could not detect these disparities (Stolz et al. 2004). Average confined/unconfined compression testing is suspected to determine how a group of constituents (i.e. proteoglycans and collagen) from the bulk meniscal body react to support compressive loading $\left(4,000,000 \mu \mathrm{m}^{2}\right.$ contact area) (Chia and Hull 2008). The results of these previous studies will be compared with those of 
nanoindentation $\left(\sim 9,000 \mu \mathrm{m}^{2}\right.$ contact area), with a smaller tip size and greater spatial resolution, to conclude how a smaller group of meniscal constituents react on the local scale to similar compressive loading situations.

Even with all the previous research conducted on meniscal surfaces and deep zone, results show large variation when comparing test parameters, making it worthwhile to characterize the meniscus on the nano-scale to see how results compare. With tissue engineered meniscal replacements relying on scaffolds to mimic the intrinsic material properties of the normal meniscus, meniscus mechanics must be studied at all depths and scales to understand its inhomogeneity and anisotropy. To date, there are no studies that investigate the regional material properties of the meniscal superficial regions (both proximal and distal) and the meniscal deep zone on the nano-scale. Previous studies have attempted to isolate the superficial regions on the micro-scale, but the use of a macro-sized flat punch and $50 \mu \mathrm{m}$ indentation depths, may result in inaccurate results of the meniscal superficial layer (Sweigart et al. 2004). The articular cartilage superficial layer, comparable to that of the meniscus, has been shown to be very important to the structure and plays a important role for the viscoelastic mechanism of cartilage (Setton et al. 1993), Data from the nanoscale can also be used to compare healthy and degenerative menisci as it has been shown that mechanical changes due to OA can be detected on the nanoscale, but not the micro-scale (Stolz et al. 2004; Stolz et al. 2009). 
Table 1.2

Review of previous mechanical testing conducted on the meniscus, concentration on studies that examined regional inhomogeneity. Supplementary mechanical studies on menisci are included in Appendix B.

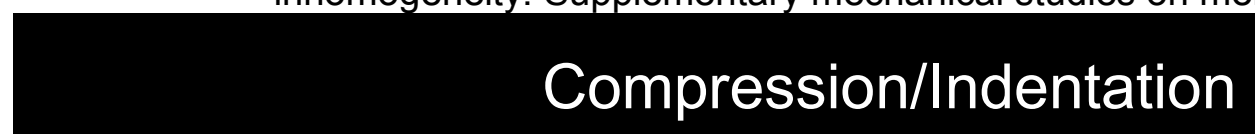

\begin{tabular}{|c|c|c|c|c|c|c|c|c|}
\hline \multirow[b]{2}{*}{ Study } & \multirow[b]{2}{*}{ Type of test } & \multirow[b]{2}{*}{$\begin{array}{c}\text { \# of } \\
\text { samples }\end{array}$} & \multirow[b]{2}{*}{$\begin{array}{l}\text { Meniscus } \\
\text { Location }\end{array}$} & \multirow[b]{2}{*}{$\begin{array}{l}\text { Surfaces } \\
\text { Studied }\end{array}$} & \multirow[b]{2}{*}{$\begin{array}{l}\text { Regions } \\
\text { Studied }\end{array}$} & \multicolumn{3}{|c|}{ Reported Material Property } \\
\hline & & & & & & $\begin{array}{l}\text { Aggregate } \\
\text { Modulus } \\
\pm S D(M P a)\end{array}$ & $\begin{array}{l}\text { Permeability } \\
\pm S D\left(10^{-15}\right. \\
\left.\mathrm{m}^{4} \mathrm{~N}^{-1} \mathrm{~s}^{-1}\right)\end{array}$ & $\begin{array}{l}\text { Shear } \\
\text { Modulus } \\
\pm \text { SD (MPa) }\end{array}$ \\
\hline $\begin{array}{l}\text { Sweigart } \\
\text { et al. }\end{array}$ & Indentation & 9 & \multirow{6}{*}{ Medial } & \multirow{3}{*}{ Proximal } & Anterior & $\begin{array}{c}0.15 \pm \\
0.03\end{array}$ & $1.84 \pm 0.64$ & $0.08 \pm 0.01$ \\
\hline \multirow{5}{*}{\multicolumn{3}{|c|}{$\begin{array}{l}\text { * Significantly different than } \\
\text { anterior region for } \\
\text { respective material } \\
\text { property }(p<0.05)\end{array}$}} & & & Central & $\begin{array}{l}0.10 \pm \\
0.03^{*}\end{array}$ & $1.54 \pm 0.71$ & $0.05 \pm 0.01^{*}$ \\
\hline & & & & & Posterior & $\begin{array}{l}0.11 \pm \\
0.02^{*}\end{array}$ & $2.74 \pm 2.49$ & $0.05 \pm 0.01^{*}$ \\
\hline & & & & \multirow{3}{*}{ Distal } & Anterior & $\begin{array}{c}0.16 \pm \\
0.05\end{array}$ & $1.71 \pm 0.48$ & $0.08 \pm 0.02$ \\
\hline & & & & & Central & $\begin{array}{l}0.11 \pm \\
0.04^{*}\end{array}$ & $1.54 \pm 0.49$ & $0.06 \pm 0.02^{*}$ \\
\hline & & & & & Posterior & $\begin{array}{l}0.09 \pm \\
0.03^{*}\end{array}$ & $1.32 \pm 0.61$ & $0.05 \pm 0.01^{*}$ \\
\hline
\end{tabular}

\begin{tabular}{|c||c||c||c||c||c|c|c|c|}
\hline \hline Study & Type of test & $\begin{array}{c}\text { \# of } \\
\text { samples }\end{array}$ & $\begin{array}{c}\text { Meniscus } \\
\text { Location }\end{array}$ & $\begin{array}{c}\text { Surfaces } \\
\text { Studied }\end{array}$ & $\begin{array}{c}\text { Regions } \\
\text { Studied }\end{array}$ & $\begin{array}{c}\text { Young's } \\
\text { Modulus } \\
(\mathbf{M P a})\end{array}$ & $\begin{array}{c}\text { Yield } \\
\text { Strength } \\
(\mathbf{M P a})\end{array}$ & $\begin{array}{c}\text { Indentation } \\
\text { Depth }(\boldsymbol{\mu})\end{array}$ \\
\hline Li et al. & Indentation & NA & NA & NA & NA & 1.30 & 0.08 & 55.00 \\
\hline
\end{tabular}


Table 1.2, continued

\begin{tabular}{|c|c|c|c|c|c|c|c|}
\hline Study & Type of test & $\begin{array}{c}\text { \# of } \\
\text { samples }\end{array}$ & $\begin{array}{l}\text { Meniscus } \\
\text { Location }\end{array}$ & $\begin{array}{l}\text { Surfaces } \\
\text { Studied }\end{array}$ & $\begin{array}{l}\text { Regions } \\
\text { Studied }\end{array}$ & $\begin{array}{c}\text { Aggregate } \\
\text { Modulus } \\
\pm S D \text { (MPa) }\end{array}$ & $\begin{array}{c}\text { Permeability } \\
\pm S D\left(10^{-15}\right. \\
\left.m^{4} N^{-1} s^{-1}\right)\end{array}$ \\
\hline $\begin{array}{c}\text { Joshi et } \\
\text { al. }\end{array}$ & $\begin{array}{c}\text { Confined } \\
\text { Compression }\end{array}$ & 5 & Medial & Distal & Posterior & $\begin{array}{c}0.22 \pm \\
0.07\end{array}$ & $2.00 \pm 0.04$ \\
\hline
\end{tabular}

\begin{tabular}{|c|c|c|c|c|c|c|c|c|c|}
\hline Study & Type of test & $\begin{array}{c}\text { \# of } \\
\text { samples }\end{array}$ & $\begin{array}{l}\text { Meniscus } \\
\text { Location }\end{array}$ & $\begin{array}{l}\text { Regions } \\
\text { Studied }\end{array}$ & $\%$ Strain & Treatment & $\begin{array}{l}\text { Coefficient } \\
\text { of Viscosity } \\
(\mu)\left(\mathrm{MPa}^{*} \mathrm{~s}\right)\end{array}$ & $\begin{array}{l}\text { Modulus of } \\
\text { Relaxation } \\
\left(E_{r}\right)(M P a)\end{array}$ & $\begin{array}{c}\text { Instantaneous }\left(E_{\mathrm{l}}\right) \\
(\mathrm{MPa})\end{array}$ \\
\hline $\begin{array}{l}\text { Sanchez- } \\
\text { Adams et } \\
\text { al } \\
\end{array}$ & $\begin{array}{l}\text { Unconfined } \\
\text { Compression }\end{array}$ & $\begin{array}{c}\text { Bovine, } \\
n=?\end{array}$ & \multirow{11}{*}{ Medial } & \multirow{4}{*}{ Outer } & \multirow[t]{2}{*}{$10 \%$} & Control & 0.20 & 0.0056 & 0.13 \\
\hline \multirow{10}{*}{\multicolumn{3}{|c|}{$\begin{array}{l}\text { CABC = GAG depletion } \\
\text { Control = normal meniscus } \\
\text { \# Significantly difference than } \\
\text { Control for representative \% } \\
\text { strain and region }(p<0.05)\end{array}$}} & & & & CABC & $0.10 \#$ & 0.0055 & 0.13 \\
\hline & & & & & \multirow{2}{*}{$20 \%$} & Control & 0.60 & 0.0059 & 0.39 \\
\hline & & & & & & CABC & $0.23 \#$ & 0.0054 & 0.40 \\
\hline & & & & \multirow{4}{*}{ Middle } & \multirow{2}{*}{$10 \%$} & Control & 0.60 & 0.0140 & 0.45 \\
\hline & & & & & & CABC & $0.25 \#$ & $0.0095 \#$ & 0.35 \\
\hline & & & & & \multirow{2}{*}{$20 \%$} & Control & 2.20 & 0.0210 & 2.20 \\
\hline & & & & & & CABC & $0.90 \#$ & 0.0130 \# & 1.65 \\
\hline & & & & \multirow{3}{*}{ Inner } & $10 \%$ & Control & 0.20 & 0.010 & 1.12 \\
\hline & & & & & \multirow[t]{2}{*}{$20 \%$} & Control & 0.60 & 0.0080 & 0.31 \\
\hline & & & & & & CABC & $0.23 \#$ & 0.0038 \# & 0.15 \\
\hline
\end{tabular}


Table 1.2, continued

\begin{tabular}{|c|c|c|c|c|c|c|c|c|c|}
\hline \multirow{2}{*}{$\begin{array}{l}\text { Study } \\
\text { Chia et } \\
\text { al. } \\
\end{array}$} & \multirow{2}{*}{$\begin{array}{c}\text { Type of test } \\
\text { Unconfined } \\
\text { Compression }\end{array}$} & \multirow{2}{*}{$\begin{array}{c}\begin{array}{c}\text { \# of } \\
\text { samples }\end{array} \\
10\end{array}$} & \multirow[t]{2}{*}{$\begin{array}{l}\text { Meniscus } \\
\text { Location }\end{array}$} & \multirow[t]{2}{*}{$\begin{array}{l}\text { Surfaces } \\
\text { Studied } \\
\end{array}$} & \multirow[t]{2}{*}{$\begin{array}{l}\text { Regions } \\
\text { Studied } \\
\end{array}$} & \multicolumn{3}{|c|}{$\begin{array}{c}\text { Equilibrium Compressive Moduli } \pm S D \\
(\mathrm{MPa})\end{array}$} & \multirow[b]{2}{*}{$12 \%$ Strain } \\
\hline & & & & & & $3 \%$ Strain & $6 \%$ Strain & $\begin{array}{c}9 \% \\
\text { Strain }\end{array}$ & \\
\hline \multirow{7}{*}{\multicolumn{3}{|c|}{$\begin{array}{l}\wedge \text { Significantly different than the } \\
\text { posterior region }(p<0.05)\end{array}$}} & \multirow{7}{*}{ Medial } & \multirow{7}{*}{ Deep Zone } & Anterior & $\begin{array}{c}0.037 \pm \\
0.034\end{array}$ & $0.052 \pm 0.047$ & $\begin{array}{c}0.073 \pm \\
0.078\end{array}$ & $0.14 \pm 0.17$ \\
\hline & & & & & Central & $\begin{array}{l}0.023 \pm \\
0.015\end{array}$ & $0.030 \pm 0.023$ & $\begin{array}{l}0.046 \pm \\
0.029\end{array}$ & $0.080 \pm 0.078$ \\
\hline & & & & & Posterior & $\begin{array}{c}0.025 \pm \\
0.047\end{array}$ & $0.012 \pm 0.0058$ & $\begin{array}{l}0.037 \pm \\
0.052\end{array}$ & $0.033 \pm 0.046$ \\
\hline & & & & & & \multicolumn{3}{|c|}{$\begin{array}{l}\text { Physiological Loading Compressive } \\
\text { Moduli } \pm \text { SD (kPa) }\end{array}$} & \\
\hline & & & & & Anterior & $0.14 \pm 0.22$ & $0.28 \pm 0.44$ & $\begin{array}{c}0.57 \pm \\
0.88\end{array}$ & $1.13 \pm 1.64^{\wedge}$ \\
\hline & & & & & Central & $\begin{array}{c}0.064 \pm \\
0.056\end{array}$ & $0.13 \pm 0.14$ & $\begin{array}{c}0.30 \pm \\
0.37 \\
\end{array}$ & $0.67 \pm 0.80$ \\
\hline & & & & & Posterior & $\begin{array}{c}0.041 \pm \\
0.061\end{array}$ & $0.084 \pm 0.16$ & $\begin{array}{l}0.184 \pm \\
0.38\end{array}$ & $0.36 \pm 0.74$ \\
\hline
\end{tabular}




\section{Research Aims and Hypotheses}

Hypothesis 1: It is hypothesized that the proximal and distal meniscal surfaces will have no regional differences as previous structural studies suggest a very homogenous superficial layer

Aim 1: Hypothesis 1 will be accomplished via nanoindentation of the three distinct regions (anterior, central and posterior) of the lateral and medial menisci, on both the proximal and distal surfaces

Hypothesis 2: It is hypothesized that the posterior region of deep zone menisci will have a smaller elastic modulus when compared to the anterior and central regions due to the increased tear frequency and contact pressures in the posterior region.

Aim 2: Hypothesis 2 will be accomplished by nano-indenting the three distinct regions of human menisci in the deep zone of the menisci and comparing the results to GAG presence 


\section{Chapter 2 - Nanoindentation of Human Meniscal Surfaces ${ }^{1}$}

\section{Abstract}

Menisci are crescent shaped fibrocartilaginous structures which support load distribution of the knee. The menisci are specifically designed to fit the contour of the femoral condyles, aiding to disperse the stresses on the tibial plateau and in turn safeguarding the underlying articular cartilage. The importance of the meniscal superficial layer has not been fully revealed and it is suspected that this layer plays a pivotal role for meniscal function. In this study, both femoral (proximal) and tibial (distal) contacting meniscal surfaces were mechanically examined on the nano-level among three distinct regions (anterior, central and posterior) of the lateral and medial menisci. Nanoindentation testing showed no significant differences among regions, surfaces or anatomical locations, possibly elucidating the homogeneity of the meniscal superficial zone structure. Nano-mechanical modulus values were approximately an order of magnitude greater than micro-scale testing derived modulus values. These findings validate the structural homogeneity of the meniscal superficial zone, showing that material properties are statistically similar regardless of meniscal surface and region. Understanding the mechanical behavior of meniscal surfaces is imperative to properly design an effective meniscal replacement.

\footnotetext{
${ }^{1}$ The material contained in this chapter has been submitted for publication to the Journal of Biomechanics
} 


\section{Introduction}

Human knee menisci are semi-lunar shaped fibrocartilaginous structures that provide support, load distribution, and lubrication within the joint, ultimately aiding to attenuate stresses at the tibiofemoral site (Walker and Erkman 1975;

Shrive et al. 1978; Messner and Gao 1998). The structural integrity of the menisci has been shown to be instrumental in conserving the underlying articular cartilage $(A C)$ thereby slowing the progression of osteoarthritis (OA) (Andriacchi et al. 2004). Menisci transmit approximately $70 \%$ of the load through the knee by supporting hoop/circumferential stresses as well as axial stresses (Walker and Erkman 1975; Seedhom 1976; Ahmed and Burke 1983).

Meniscal composition is inhomogeneous and biphasic, consisting of varying types of collagen fibrils and proteoglycans within the solid matrix of the meniscal body (Roughley et al. 1981; McDevitt and Webber 1990; Petersen and Tillmann 1998), and $70 \%$ interstitial fluid (D.C. Fithian et al. 1989; Brindle et al. 2001). Type I collagen fibrils are predominately circumferentially oriented within the menisci, however additional varying collagen fiber orientation layers help maintain the intrinsic structure of the meniscus (Aspden et al. 1985; McDevitt and Webber 1990; Petersen and Tillmann 1998). The superficial layer (tibial and femoral AC contacting surfaces), of the meniscus is approximately $100-200 \mu \mathrm{m}$ thick (Ling and Levenston 2012) and is composed of a tight meshwork of randomly oriented collagen fibrils, which are $10 \mu \mathrm{m}$ or greater in diameter (Figure 2.1). This network of taut, 'mat-like' collagen fibrils is believed to be similar to that 
of the AC tangential fiber layer (Aspden et al. 1985; Setton et al. 1993; Petersen and Tillmann 1998). It has previously been shown that both flow-dependent and independent viscoelastic mechanisms rely on the strength of the cartilage superficial zone (Setton et al. 1993). Moreover, recent investigations of the meniscal superficial layer suggest a stiffer superficial layer in meniscus compared to cartilage, with meniscal samples showing constant strains through the superficial layer to the deep layer (Lai and Levenston 2010). Others have suggested that the contacting meniscal superficial layer may serve a major role to uphold meniscal integrity (Walker and Erkman 1975; Newman et al. 1989; Andriacchi et al. 2004). 


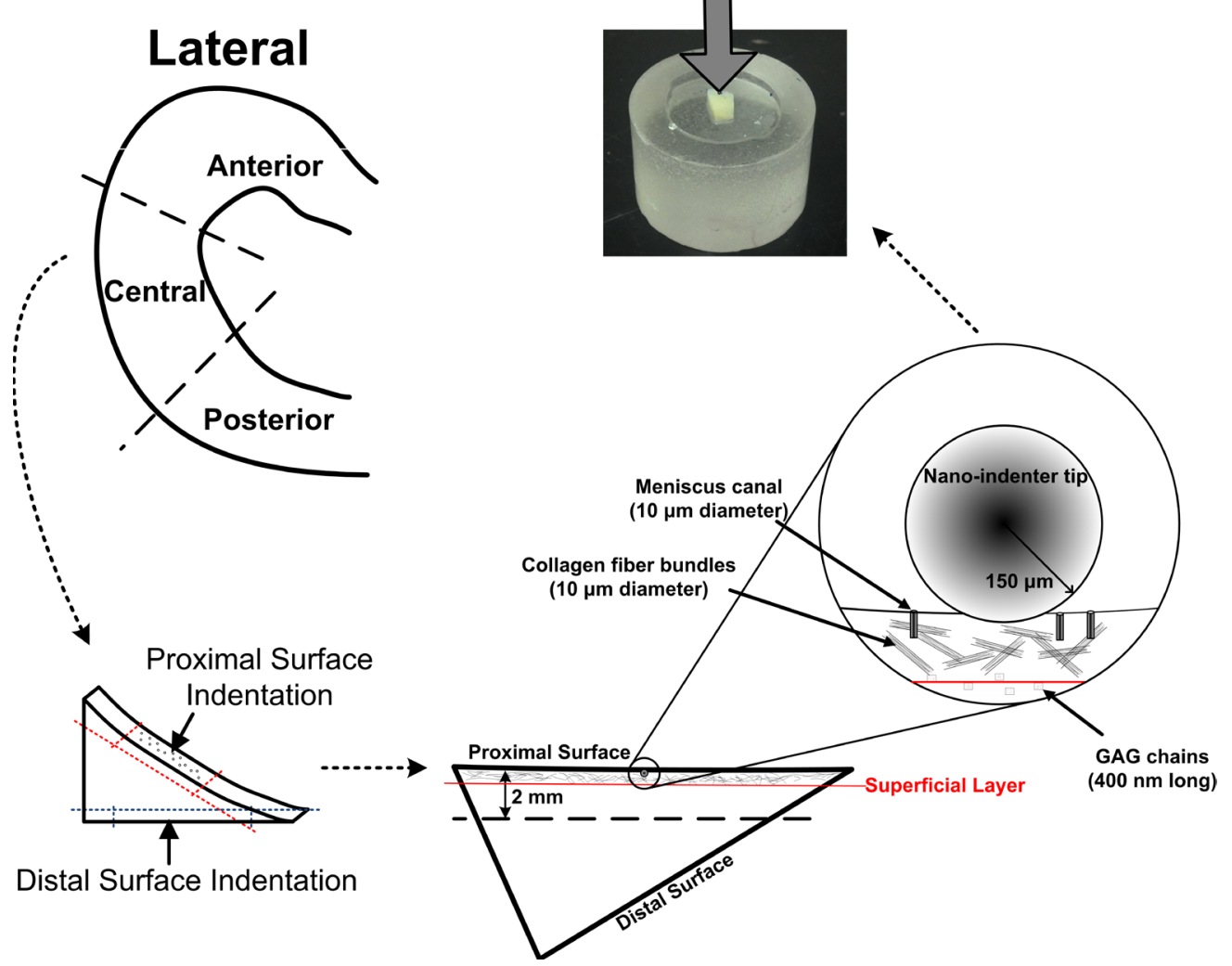

Figure 2.1: Schematic of human menisci showing where three regions are located and how indentation direction was normal to both the proximal and distal meniscal surface. Relative meniscal constituents compared in indenter tip size and depth are shown, all to scale with cross-section of meniscus rotated to show normal indentation direction. Dashed lines represent specimen cutting. Testing setup with meniscal sample in acrylic well puck, filled with saline solution, shows indentation direction normal to the specimen surface.

Previous mechanical testing on human menisci has been performed on the macro-level, either using fiber aligned coupon samples for tension tests or meniscal disc samples for confined/unconfined compression (Whipple et al. 1985; D. C. Fithian et al. 1990; Tissakht and Ahmed 1995; Chia and Hull 2008). It is unknown if this macro-scale testing can isolate the superficial zone behavior to determine a structure-function relationship at a local level. Nanoindentation 
provides a physiologically relevant testing procedure to determine the viscoelastic material properties of the meniscus on the scale of the meniscal constituents and has been shown to be applicable for mechanical testing of cartilage-like hydrated tissues (Ebenstein et al. 2004; Ebenstein and Pruitt 2006). Studying cartilage material properties on the nanometer scale, rather than the micrometer scale has been shown to be effective in detecting mechanical variations due to collagen fiber orientations and proteoglycan changes (Stolz et al. 2004).

To date, human menisci have not been characterized on the nano-scale. Sweigart et al. examined regional (anterior, central and posterior) differences in the proximal and distal medial meniscal surfaces at the micro-scale (Sweigart et al. 2004). They reported no differences in proximal versus distal layer, but significant differences did exist in material properties among regions (Sweigart et al. 2004). Given the importance of the superficial zone and previous investigations on the structure of this zone in the human meniscus, the objective of this study was to quantify and compare the viscoelastic nano-mechanical properties of human menisci on both the proximal (femoral contacting) and distal (tibial contacting) surface. While it has been shown that there are significant regional differences when testing meniscal surfaces on the micro-level, it is hypothesized that the proximal and distal meniscal surfaces will have no regional differences as previous structural studies suggest a homogenous superficial layer (Petersen and Tillmann 1998; Lai and Levenston 2010; Ling and Levenston 2012). To isolate the superficial zone nanoindentation will be used on both the 
proximal and distal surfaces of the anterior, central and posterior regions of lateral and medial human menisci. Nanoindentation will provide an improved understanding of the mechanical behavior at the nano-scale and thus given additional insight into the behavior and role of this superficial zone.

\section{Materials and Methods}

\section{Specimen Preparation:}

Eight healthy cadaveric knees (7 males, 1 female, ages 50-77, avg. age 59) (NDRI, Philadelphia, PA) were procured (Office of Research Integrity and Compliance approval \#M0145), wrapped in $0.9 \%$ saline solution soaked gauze and frozen at $-20^{\circ} \mathrm{C}$ until the time of dissection. Both lateral and medial menisci were refrigeration thawed and then cut at the meniscal attachment site, and trisected into anterior, central and posterior regions for regional comparisons (Figure 2.1) (Whipple et al. 1985; D. C. Fithian et al. 1990; Tissakht and Ahmed 1995; Sweigart et al. 2004; Chia and Hull 2008). Once each meniscus had been trisected, $2 \mathrm{~mm}$ wide sections were cut through the cross-section from each region; one sample for proximal mechanical testing and one for distal mechanical testing. Samples were trimmed so that they could be placed under the nanoindenter tip such that indentation was perpendicular to the surface (Figure 2.1). Nitrocellulose was applied to the face opposite of indentation followed by double-stick tape to facilitate adhesion between the sample and the well puck. 
Saline solution was filled into the well to keep the specimen fully hydrated throughout the test.

\section{Testing Procedure:}

Nanoindentation was performed at room temperature on both proximal and distal meniscal surfaces using a Nano Indenter (Agilent Technologies, Santa Clara, CA) with a $300 \mu m$ diameter spherical ruby tip (Agilent Nano Measurements, Indianapolis, IN). Fifteen indents were performed on each meniscal sample, spatially randomizing indent locations, normal to the surface (Figure 2.1). Indents were spaced at least $250 \mu \mathrm{m}$ apart to avoid effects from subsequent indents (Ebenstein et al. 2004). Creep nanoindentation was performed using a trapezoidal loading sequence with a 5 second rise time and 1 $\mathrm{mN}$ hold for 70 seconds. These testing parameters were chosen based on preliminary testing results and to limit surface penetration to approximately 10 $\mu \mathrm{m}$.

Resultant displacement-time data (Figure 2.2), was curve-fit, using Matlab Optimization toolbox (Mathworks, Natick, MA), to determine both instantaneous and steady-state material properties. Shear and elastic modulus were calculated for all three regions, on both proximal and distal meniscal surfaces using a viscoelastic model developed by Oyen et al. (Oyen 2005; Oyen and Cook 2009). This analysis was based on the assumption that Poisson's ratio of the human meniscus is 0.38 (Hu et al. 2001). Furthermore, a 'time-dependency' material property was calculated by taking the ratio between steady-state and 
instantaneous elastic modulus. Material property values from each indent were calculated and then averaged to gain an overall average material property value from each sample to encompass the meniscal surface.

\section{Statistical Analysis:}

A three-way Analysis of Variance (ANOVA) was performed to determine differences in material properties (shear and elastic moduli) among meniscal surface (proximal/distal), anatomical location (medial/lateral) and meniscal region (anterior/central/posterior), for both instantaneous and steady-state moduli. A post-hoc statistical power analysis was conducted.

\section{Results}

Nano-indents produced a displacement-time curve with a linear region during ramp loading followed by a horizontally asymptotic curve during the held load (Figure 2.2), indicative of steady-state behavior. The average indenter contact radius was $53.61 \pm 3.53 \mu \mathrm{m}$, as the displacement into the meniscal surface was approximately $10 \mu \mathrm{m}$ for each indent (Figure 2.1). 


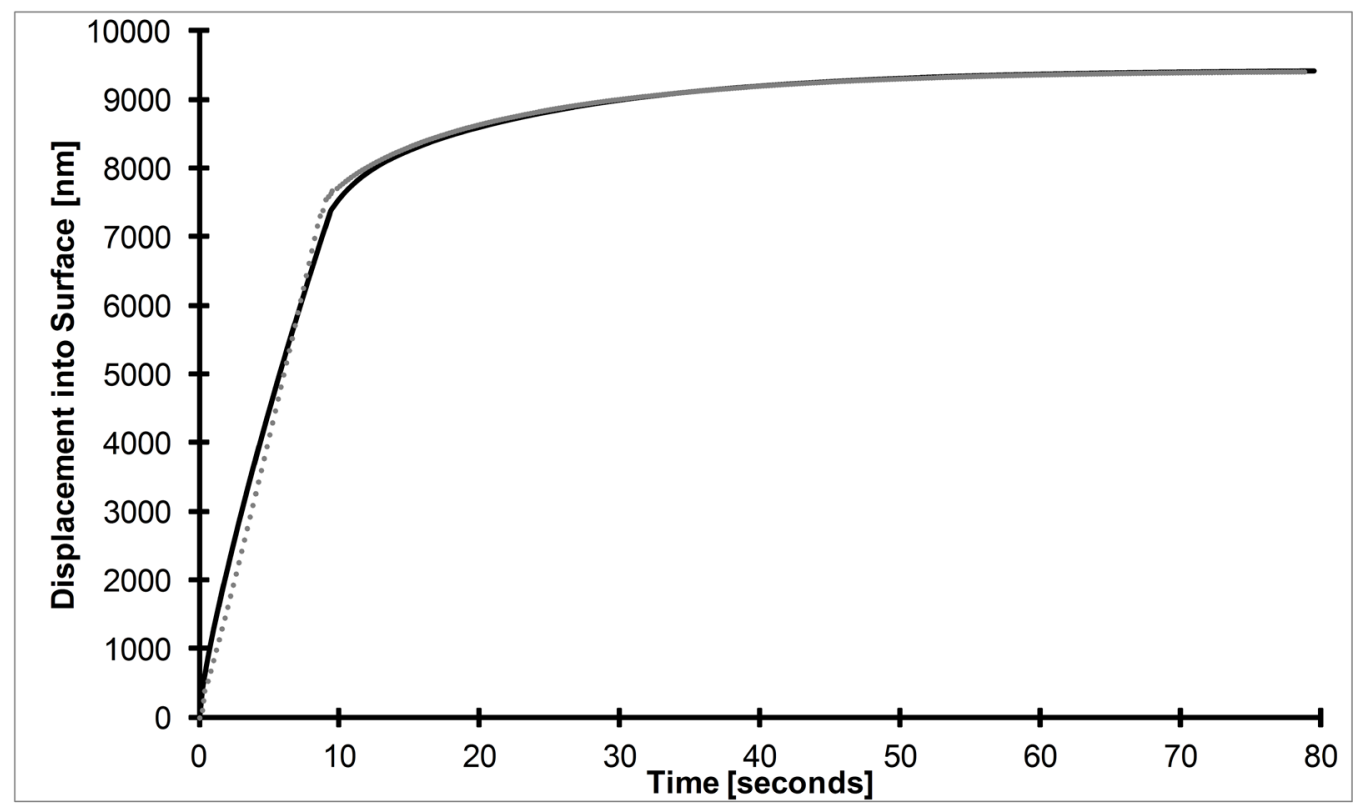

Figure 2.2: Representative displacement-time creep curve from nanoindentation on meniscal surfaces. Dots represent data points, solid line is the curve fit for the viscoelastic model used in this analysis.

All meniscal samples, regardless of contacting surface, region or anatomical location, exhibited statistically similar behavioral mechanics, when nano-indented (Figure 3.3). Variation among individual indents was less than $5 \%$ of the overall average material property value for each specimen, indicating the homogeneity among individual indents on each meniscal sample. The statistical power analysis revealed a power of $95 \%$, given an expected difference from the calculated material property value was $25 \%$. The anterior and posterior regions showed a decrease in steady-state elastic modulus on the distal surface when moving from lateral to medial and an increase when between the later on the proximal surface. Additionally, instantaneous shear and elastic moduli do not demonstrate any noticeable trends and all surfaces and regions appear to be very comparable (Figure 2.3 A \& B). 

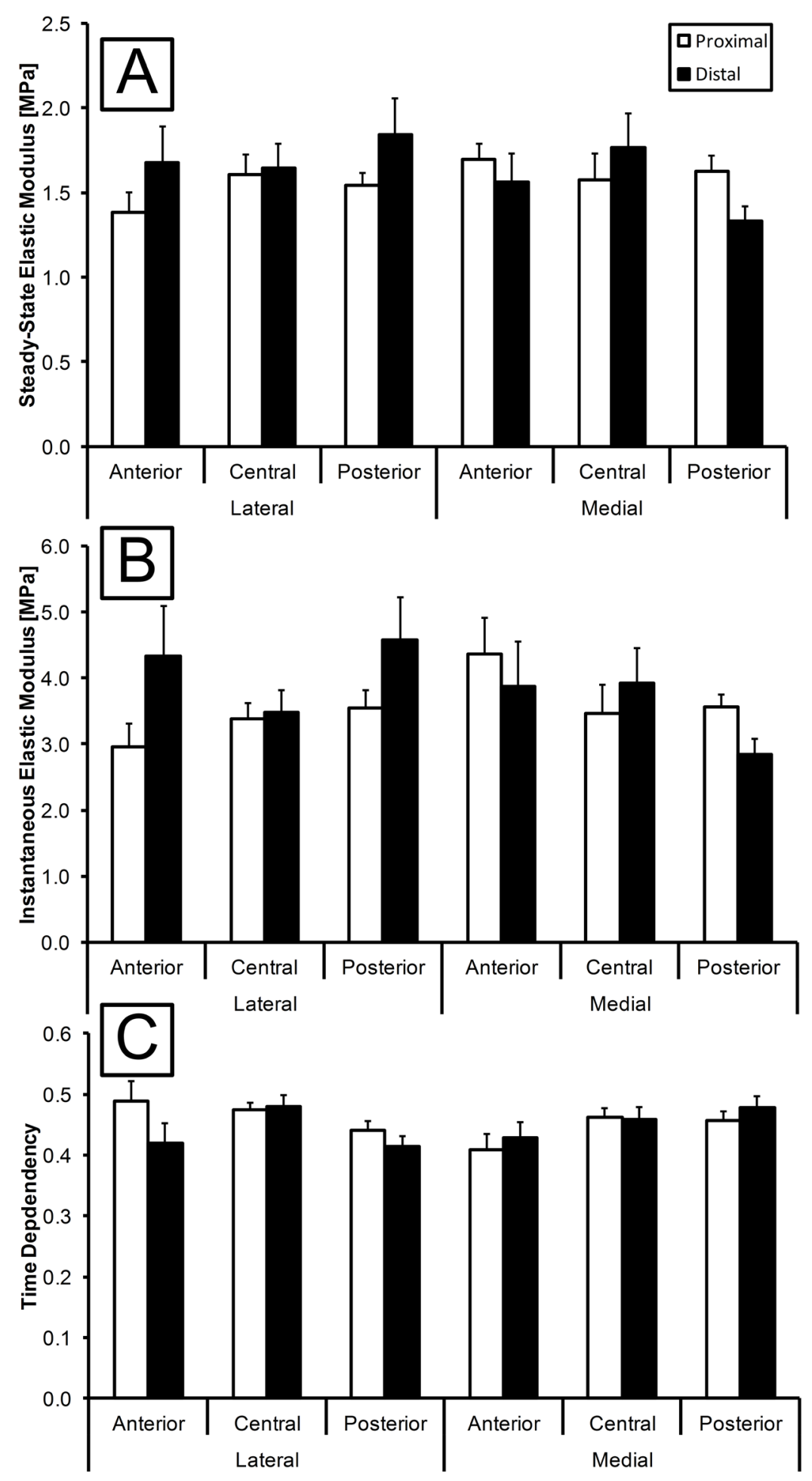

Figure 2.3: A. Average steady-state elastic modulus- $B$. Average instantaneous elastic modulus- C. Average Time Dependency- values from nanoindentation conducted on both proximal and distal meniscal surfaces. Error bars represent standard error. 
When grouping meniscal surfaces (proximal and distal) together, it can be seen that the elastic moduli (steady-state and instantaneous) was greater in the medial meniscus for both anterior (medial steady-state $=1.63 \pm 0.09 \&$ medial instantaneous $=4.12 \pm 0.42 \mathrm{MPa}$ vs. lateral steady-state $=1.52 \pm 0.12$ \& lateral instantaneous $=3.59 \pm 0.43 \mathrm{MPa}$ ) and central (medial steady-state $=1.67 \pm 0.13$ \& medial instantaneous $=3.70 \pm 0.33 \mathrm{MPa}$ vs. lateral steady-state $=1.62 \pm 0.09$ \& lateral instantaneous $=3.43 \pm 0.20 \mathrm{MPa}$ ) regions, but the opposite trend is true for the posterior region (medial steady-state $=1.47 \pm 0.07$ \& medial instantaneous $=3.17 \pm 0.18 \mathrm{MPa}$ vs. lateral steady-state $=1.69 \pm 0.12 \&$ lateral instantaneous $=4.06 \pm 0.37 \mathrm{MPa}$ ), whereas the lateral meniscus displays a larger elastic moduli than the medial. This same trend occurs when evaluating the time dependency values (meniscal surfaces averaged). Despite interesting trends, the time dependency values displayed no statistically significant differences between regions, anatomical locations or meniscal surface (Figure $2.3 C)$.

When only examining meniscal regions, the anterior $(3.86 \pm 0.30 \mathrm{MPa})$ and central $(3.56 \pm 0.19 \mathrm{MPa})$ region displayed the largest and smallest instantaneous elastic modulus, respectively. The opposite was true for the steady-state elastic modulus, as the central region $(1.65 \pm 0.07 \mathrm{MPa})$ had the largest value and the anterior region $(1.58 \pm 0.08 \mathrm{MPa})$ was the smallest. 
The three-way blocked ANOVA revealed no significant differences for steadystate and instantaneous material property values between meniscal regions, surface or anatomical locations.

\section{Discussion}

While other studies have investigated the compressive properties of mammalian menisci (Joshi et al. 1995; Sweigart et al. 2004; X. Li et al. 2007; Chia and Hull 2008), this is first study to nanoindent both human meniscal surfaces and regionally analyze the three distinct regions (anterior, central and posterior). Literature has shown that freezing and thawing for 1 cycle had no impact on the biochemical or material property values of meniscus or cartilage (X. Li et al. 2007; Lewis et al. 2008; Szarko et al. 2010). Nanoindentation was used rather than other compression-based methods (micro-indentation, confined compression, etc.) for both the increased spatial resolution and the aspiration of illustrating single meniscal surface material properties rather than gathering material properties from bulk constituents. A spherical nanoindentation tip was used to ensure consistent contact area (Oyen 2005) given the uneven meniscal surface contour. Also, nanoindentation was utilized to isolate the meniscal superficial layer by only penetrating approximately 10 microns into the specimen surface, whereas the superficial layer is suspected to be $100-200$ microns thick (Petersen and Tillmann 1998; Ling and Levenston 2012).. 
The results from this study indicate there are no significant nanomechanical differences among meniscal regions, surfaces or anatomical locations. It is very important to note that the proximal and distal meniscal surfaces both behave similarly, as the fluid interaction with the tibial and femoral articular cartilage is crucial for decreasing friction and allowing for proper joint articulation. The material property similarities may be expected, given the collagen fiber orientation at the meniscal superficial layer is a random fibril mesh, but with fibrils coplanar to the surface (Aspden et al. 1985; Petersen and Tillmann 1998). Additionally, meniscal composition within the superficial layer, other than a collagen fiber network, is not well characterized, and it is known that other meniscal constituents, i.e. proteoglycans, have a direct correlation with mechanical strength and viscosity in compression (Sanchez-Adams et al. 2011). Further investigation of meniscal composition in the superficial zone may help form a better understanding of the structure-function relationship at the superficial zone.

$\mathrm{Li}$ et al. conducted a very similar indentation study on mini-pig menisci, using a $500 \mu \mathrm{m}$ diameter conospherical tip and using a peak indentation load of $10 \mathrm{mN}$. Although anatomical location, region or surface was not specified, Young's modulus values were reported to be approximately $1.3 \mathrm{MPa}$, the same order of magnitude of results shown in the current study (X. Li et al. 2007). Other studies have also analyzed the human meniscus to gather regional mechanical properties (compressive and tensile); however, these tests were completed on a 
micro-scale or greater (Table 2.1) (Whipple et al. 1985; D.C. Fithian et al. 1989; Joshi et al. 1995; Tissakht and Ahmed 1995; Sweigart et al. 2004; Chia and Hull 2008). Evaluating the meniscus on a larger scale (micro-indentation, confined compression, etc.), may result in mechanical properties that represent the bulk constituents of the menisci, rather than using small-scale investigations (nanoindenting) to isolate specific features.

Other compression based studies, focusing on the medial meniscus and also conducted at room temperature, have shown the meniscus to be weakest in the posterior region (Table 2.1), possibly elucidating why the majority of meniscal tears occur in the posterior meniscus (Singson et al. 1991; Helms et al. 1998; Brody et al. 2006; Choi et al. 2008; Ahn et al. 2009; De Smet et al. 2009; Lykissas et al. 2010). These macro-scale test results are approximately an order of magnitude smaller than what is seen here from nanoindentation. This discrepancy is possibly due to engagement of specific meniscal constituents, rather than bulk material, or differences in test modalities. By limiting surface penetration to approximately $10 \mu \mathrm{m}$, only the tightly woven superficial collagen is engaged rather than spatially averaging between the structurally unique superficial and deep zones. The ramifications of this testing indicate that the surface layer is specifically adapted at supporting compressive loading and perhaps pivotal for allowing fluid movement while maintaining basic function. Also, cartilage superficial zone has been shown to be crucial for fluid flow (Setton et al. 1993) and each different test may influence the varying fluid flow patterns of the meniscus. Nanoindentation, with a rigid tip, may cause the solid and fluid 
phases of the meniscal surface to behave differently than when compressed with a 1-2 mm porous platen (Joshi et al. 1995; Sweigart et al. 2004), as contact areas are altered, and fluid movement through meniscal canals differ for fluid evacuation (Bird and Sweet 1988).

Table 2.1

Material property comparison among varying compression based mechanical tests on the meniscus

\begin{tabular}{|c|c|c|c|c|c|}
\hline & \\
\hline & & \multicolumn{4}{|c|}{ Steady-State Modulus $\pm S D$ (MPa) } \\
\hline $\begin{array}{l}\text { Meniscus } \\
\text { Location }\end{array}$ & $\begin{array}{l}\text { Regions } \\
\text { Studied }\end{array}$ & $\begin{array}{l}\text { Nanoindentation } \\
\text { (current study) }\end{array}$ & $\begin{array}{c}\text { Micro- } \\
\text { indentation } \\
\text { (Sweigart } \\
\text { et al. 2004) }\end{array}$ & $\begin{array}{l}\text { Unconfined } \\
\text { Compression } \\
\text { (Chia and } \\
\text { Hull 2008) }\end{array}$ & $\begin{array}{c}\text { Confined } \\
\text { Compression } \\
\text { (Joshi et al. } \\
\text { 1995) }\end{array}$ \\
\hline \multirow{3}{*}{ Medial } & Anterior & $1.63 \pm 0.10$ & $0.16 \pm 0.04$ & $0.14 \pm 0.17$ & NA \\
\hline & Central & $1.67 \pm 0.13$ & $0.11 \pm 0.04$ & $0.080 \pm 0.078$ & NA \\
\hline & Posterior & $1.47 \pm 0.07$ & $0.10 \pm 0.03$ & $0.033 \pm 0.046$ & $0.22 \pm 0.07$ \\
\hline
\end{tabular}

When comparing varying compression based testing methods for articular cartilage, it can be seen that the same relationship for macro- and nano-scale testing applies for the meniscus as for articular cartilage (Table 2.2). Unconfined and confined compression based methods, both utilizing larger platens for compression, exhibit nearly order of magnitude smaller values than nanoindentation type tests. This further affirms the close comparison between articular cartilage and meniscus fibrocartilage. 
Table 2.2

Material property comparison among varying compression based mechanical tests on articular cartilage

\begin{tabular}{|c|c|c|}
\hline Type of Study & Study & $\begin{array}{c}\text { Steady-State } \\
\text { Modulus } \pm \text { SD } \\
(\mathrm{MPa}) \\
\end{array}$ \\
\hline \multirow{3}{*}{ Nanoindentation } & (Franke et al. 2007) & $2.25 \pm 0.25$ \\
\hline & (Thambyah et al. 2006) & $3.64 \pm 1.23$ \\
\hline & (X. Li et al. 2007) & $2.80 \pm 0.45$ \\
\hline $\begin{array}{l}\text { Unconfined } \\
\text { Compression } \\
\end{array}$ & $\begin{array}{l}\text { (DiSilvestro et al. 2001a; } \\
\text { DiSilvestro et al. 2001b) } \\
\end{array}$ & $0.55 \pm 0.11$ \\
\hline \multirow{2}{*}{ Confined Compression } & (C. Y. Huang et al. 2005) & $0.15 \pm 0.05$ \\
\hline & (Setton et al. 1993) & $0.54 \pm 0.25$ \\
\hline
\end{tabular}

These material properties on the nano-scale coupled with other larger scale tensile, compressive and shear properties of the meniscus (D.C. Fithian et al. 1989; Sweigart et al. 2004; Chia and Hull 2008) will help accurately model the meniscus for the ultimate goal of creating an effective meniscal replacement that can mimic the native human menisci (Donahue et al. 2002; Maes and Haut Donahue 2006; Hauch et al. 2009; Abraham et al. 2011). As this is the first study to regionally isolate and compare meniscal surfaces, it is essential to chronicle the fact that the meniscal surface layer has been shown to be structurally homogenous, and now this has been validated by showing the material properties of the meniscal superficial zone do not vary among regions or contacting surface. It has been shown that there is an order of magnitude difference between meniscal surface material property values when examined on the nano-scale compared to the micro-scale. This discrepancy may prove vital when attempting to recreate human meniscal replacements. Additionally, these 
data are imperative to thoroughly understand regional menisci interaction with articular cartilage contacting surfaces in relation to the meniscus mechanics and constituents on the nano-scale. 


\section{Chapter 3 - Regional Comparisons of Nano-mechanical and Histological Human Deep Zone Meniscus ${ }^{2}$}

\section{Abstract}

Menisci are two semi-lunar shaped fibrocartilaginous structures that provide fundamental load distribution and support within the knee joint aiding to attenuate stresses at the tibiofemoral site. The menisci are C-shaped to wrap around the contour of the femoral condyle, and this unique shape allows the menisci to transmit axial stresses (i.e. 'body force') into hoop or radial stresses. The menisci are composed of an aggregate of glycosaminoglycans (GAGs) supporting bulk compression and Type I collagen fibrils upholding tension. It has been shown that the meniscal superficial layers are functionally homogeneous throughout the three distinct regions (anterior, central and posterior) on the nanoscale, but the deep zone of the meniscus has yet to be mechanically characterized on the nano-scale. Furthermore, the distribution and intensity of GAG throughout the meniscal cross-section has not been examined. This study investigated the nano-mechanical properties, via nanoindentation, of the human deep zone meniscus among three regions of the lateral and medial menisci and compared these results to quantitative histological results to develop a structurefunction relationship. Nano-mechanical results on the deep zone of the meniscus showed the medial posterior region to be significantly different than the central region for both instantaneous elastic modulus and time dependency; with all steady-state elastic modulus values showing no statistical differences.

\footnotetext{
${ }^{2}$ The material contained in this chapter will be submitted for publication in a biomechanical journal
} 
Histological results revealed that the GAG content is not present until at least $\sim 600 \mu \mathrm{m}$ from the meniscal surface and that the lateral anterior region had a significantly greater GAG intensity fraction than that of the posterior region. Understanding the role and distribution of GAG within the human meniscus and how they affect the material properties of the meniscus will aid in the design of tissue engineered meniscal replacements.

\section{Introduction}

Human menisci are two crescent shaped fibrocartilaginous structures that serve numerous functions within the knee; aiding in load transmission and providing a frictionless joint congruity between the tibia and femur (Walker and Erkman 1975; Shrive et al. 1978; Messner and Gao 1998). The menisci are specifically designed to fit around the architecture of the femoral condyles and disperse stresses on the tibial plateau, thereby safeguarding the underlying articular cartilage and preventing Osteoarthritis (OA) (Roos et al. 1998; Andriacchi et al. 2004; Neuman et al. 2008; Neuman et al. 2009). Menisci diffuse approximately $70 \%$ of the load in the knee as hoop/circumferential stresses, but compressive and shear forces are also present due to the dynamic nature of the knee joint (Walker and Erkman 1975; Seedhom 1976; Ahmed and Burke 1983). To uphold meniscal structural integrity under this complex loading environment, meniscal composition is inhomogeneous, with multiple solid constituents and interstitial fluid (D.C. Fithian et al. 1989; McDevitt and Webber 1990). As the incidence of OA continues to rise in today's society, and clinical treatment for 
meniscal injuries is only effective in the vascular zone, a better understanding of meniscal structure-function will likely aid development of tissue engineered meniscal replacements (Rattner et al. 2010).

Type I collagen fibers have been shown to be predominately circumferentially aligned within the deep zone of the menisci $(>200 \mu \mathrm{m}$ deep from superficial layers) and bolster meniscal strength in tension. Proteoglycans and interstitial fluid provide a supportive matrix to supplement the menisci under compressive loads (Roughley et al. 1981; McDevitt and Webber 1990; Petersen and Tillmann 1998; Sanchez-Adams et al. 2011). Meniscal structure and function has been shown to be both depth and circumferentially inhomogeneous, as there are multiple hierarchal levels of collagen fibril orientations within the menisci (Aspden et al. 1985; D.C. Fithian et al. 1989; Petersen and Tillmann 1998; Sweigart et al. 2004; Chia and Hull 2008). However, less is known about the depth dependent distribution of proteoglycans within human menisci, and to date only one study has documented regional sulfated GAG content, showing no regional differences (D.C. Fithian et al. 1989). Water-affine sulfated glycosaminoglycans (GAGs), a proteoglycan side-chain, contribute to supporting the menisci in compression due to their inherent negative charges (McNicol and Roughley 1980; Roughley et al. 1981; Lu et al. 2009). Recently, it has been shown that the depletion of sulfated GAG has a significant effect on the biphasic mechanical behavior of the bovine meniscus, further clarifying the structure-function relationship of GAG in the meniscus (Sanchez-Adams et al. 2011). 
Mechanical testing has investigated the regional inhomogeneity of the human menisci and significant differences have been identified among the three distinct regions of the lateral and medial menisci when tested in tension, compression and shear (Figure 3.1) (D.C. Fithian et al. 1989; Tissakht and Ahmed 1995; Sweigart et al. 2004; Chia and Hull 2008; Abraham et al. 2011). The deep zone of human medial meniscus has been shown to vary significantly between regions, with the posterior region having a significantly smaller compressive modulus (at physiological loading rate) than the anterior region (Chia and Hull 2008). The meniscal surface has previously been studied on the nano- and micro-scale, both utilizing a creep-indentation test (Sweigart et al. 2004; Moyer et al. 2012). The nanoindentation study, which had an indentation depth of approximately $10 \mu \mathrm{m}$, yielded no significant differences among regions or meniscal surfaces, while the micro-indentation study, with an indentation depth of $50 \mu \mathrm{m}$, resulted in anterior region being statistically greater than the central and posterior regions for the medial meniscus when comparing aggregate moduli. The steady-state elastic modulus from nanoindentation (Moyer et al. 2012) was also an order of magnitude greater than that of the microindentation study (Sweigart et al. 2004). As the nanoindentation study isolated the superficial layer of the meniscus, the micro-indentation study may have engaged the superficial and deep zone conjunction within the meniscus; therefore, it is necessary to isolate the deep zone on the nano-scale to investigate regional meniscal properties. 
To date, previous studies on the mechanical properties of meniscal tissue have been conducted on the macro- or micro-scale (D.C. Fithian et al. 1989; Joshi et al. 1995; Tissakht and Ahmed 1995; Sweigart et al. 2004; Chia and Hull 2008; Sanchez-Adams et al. 2011), whereas nano-scale material properties of articular cartilage have been shown to be effective in detecting stiffness disparities due to collagen fiber orientations and proteoglycan changes (Stolz et al. 2004). Nanoindentation can be utilized to better understand meniscus mechanics and how they relate meniscal constituent inhomogeneity on a relevant scale. This indentation technique has been shown to be successful at capturing local material properties of hydrated biological materials and the size-scale is on the level of meniscal constituents (Ebenstein et al. 2004; Ebenstein and Pruitt 2006).

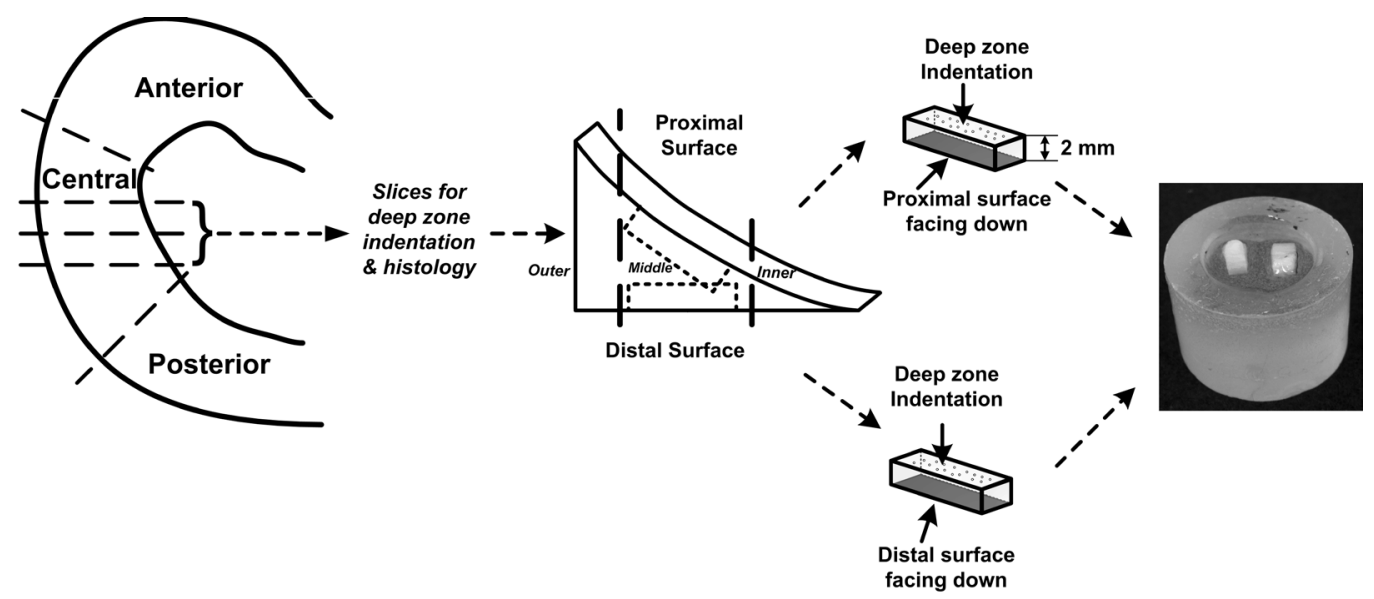

Figure 3.1: Schematic of human menisci showing where three regions are located and what testing slices resembled. Enlarged meniscal cross-section is shown. Two 2-3 $\mathrm{mm}$ slices were taken from each region for mechanical testing and histology analysis. Both analyses were conducted in the middle meniscus (inner, middle and outer meniscus labeled) section and nanoindentation was normal to the deep zone meniscus cut surface. Dashed lines represent specimen cutting. 
A complete proteoglycan chain is suspected to be approximately $1.2 \mu \mathrm{m}$ in length, while most Type I collagen fibril bundles have a diameter $>10 \mu \mathrm{m}$, and are composed of $35 \mathrm{~nm}$ diameter fibrils (Aspden et al. 1985; Carney and Muir 1988; McDevitt and Webber 1990; Petersen and Tillmann 1998). Therefore, the objective of this study was to quantify and compare the viscoelastic nanomechanical properties of the human meniscus in the deep zone and compare the mechanical results to quantitative histological GAG measures to formulate an accurate structure-function relationship at the nano-scale, where the contact area of indentation will be approximately $9000 \mu \mathrm{m}^{2}$. To accomplish this, nanoindentation of the anterior, central and posterior regions of the lateral and medial human meniscus will be completed. Nanoindentation will provide an improved understanding of the mechanical behavior at the nano-scale and will lead to advancements in tissue engineering of meniscal replacements. 


\section{Materials and Methods}

\section{Specimen preparation:}

Eight human male non-arthritic knees (ages 50-65, avg. age 58) (NDRI, Philadelphia, PA), were procured (Office of Research Integrity and Compliance approval \#M0145), the lateral and medial menisci were harvested, placed in a $0.9 \%$ saline solution and frozen at $-20^{\circ} \mathrm{C}$ until the time of testing. It has previously been proven that meniscus and cartilage do not have significantly different material properties following a freeze-thaw cycle, and histology corroborated this by showing biochemical content did not significantly change following freezethaw (X. Li et al. 2007; Lewis et al. 2008; Szarko et al. 2010). Each meniscus was refrigeration thawed and then trisected into anterior, central and posterior sections for regional material testing and two adjacent 2-3 $\mathrm{mm}$ wide crosssectional slices were cut from each region, one for mechanical testing and the other for a histological analysis (Figure 3.1). For the histological samples, India ink was applied to the proximal surface for designation during imaging. Two rectangular sections were then cut out of the meniscal cross-sections, one from the proximal surface (femoral contacting) and another from the distal surface (tibial contacting) to expose the deep zone of the meniscus, each $2 \mathrm{~mm}$ deep from the meniscal surface (Figure 3.1). Samples were trimmed on non-testing face, to ensure nanoindentation was conducted normal to the meniscal deep zone. Nitrocellulose was applied to the face opposite of indentation (either proximal or distal meniscal superficial layer) followed by double-stick tape to facilitate adhesion between the sample and the well puck (Figure 3.1). Saline 
solution was filled in around the well to keep the specimen fully hydrated throughout the test.

Meniscal cross-sections from each region (for the histological analysis) were processed for paraffin embedding, to then undergo a histological analysis for GAG distribution. Meniscal cross-sections were labeled with region and anatomical location, dehydrated in formalin and concentrations of ethanol then embedded in paraffin (Villegas et al. 2008). Once samples were processed with paraffin, $6 \mu \mathrm{m}$ thick sections were sliced using a microtome (Shandon AS325, Thermo Electron Corop., Waltham, MA) and stained to identify GAG content. Specimens were first stained in Weigert's iron hematoxylin working solution for 10 minutes, followed by a 10 minute water rinse. Samples were then stained using Fast Green FCF solution for 5 minutes with a 10 second rinse of $1.0 \%$ acetic acid rinse following. Lastly, each sample was stained with $0.1 \%$ SafraninO for 10 minutes and cleared using $95 \%$ and $100 \%$ ethanol and Xylene (Rosenberg 1971; Clark 1973; Kiviranta et al. 1985).

\section{Mechanical Testing Procedure:}

Nanoindentation was performed at room temperature on the deep zone of the meniscus, on both samples (proximal - deep and distal - deep) from each region with, using a nanoindenter (Agilent Technologies, Santa Clara, CA) with a $300 \mu \mathrm{m}$ diameter spherical ruby tip (Agilent Nano Measurements, Indianapolis, IN). Ten spatially randomized indents were performed on each meniscal sample, 
ensuring each indent was normal to the surface (Figure 3.1). Indents were spaced at least $250 \mu \mathrm{m}$ apart to avoid possible residual effects from prior indents (Ebenstein et al. 2004). Creep nanoindentation was performed using a trapezoidal loading sequence with a 5 second rise time and $1 \mathrm{mN}$ hold for 90 seconds. These testing parameters were chosen based on preliminary testing results.

Resultant displacement-time data was curve-fit, using the matlab optimization toolbox (Mathworks, Natick, MA), to determine both instantaneous and steady-state material properties. Shear and elastic modulus were calculated for all three regions, on both deep-proximal and deep-distal meniscal surfaces using a viscoelastic model developed by Oyen et al. (Oyen 2005; Oyen and Cook 2009). This analysis was based on the assumption that Poisson's ratio of the human meniscus is 0.38 ( $\mathrm{Hu}$ et al. 2001). Furthermore, a 'time-dependency' material property was calculated by taking the ratio between steady-state and instantaneous elastic modulus, which helped to describe the viscosity of each sample. Material property values from each indent were calculated and then averaged to gain an overall average material property value from each sample to encompass the meniscal surface. 


\section{Histological Analysis:}

Histological slides of meniscal cross-sections were analyzed to measure three relative quantitative properties: 1 . the average distance from the meniscal surface to the initiation of staining for GAG content (Figure 3.2A), 2. the ratio of the GAG cross-sectional area to the meniscal cross-sectional area for the meniscus (Figure 3.2B) and 3. the binding intensity fraction of GAG within the meniscal cross-section. Before measurements analyses 1 \& 2 were accomplished, images had a color threshold applied using Image J (Abramoff et al. 2004) to signify where GAG content was present. Average thickness of the meniscal surface - to - GAG was performed using commercial software (BIOQUANT Image Analysis Corporation, Nashville, TN) with sectioned lines drawn along the meniscus articulating surface and where GAG was present (Figure 3.2A).

The ratio of GAG to meniscal cross-section area was performed using Image J (Abramoff et al. 2004). A region of interest (ROI) was first drawn around a section of the meniscal cross-section to encompass the area from meniscal proximal surface to distal surface and the area was calculated. A second ROI only surrounding the GAG content was then measured (Figure 3.2B). The ratio of meniscal GAG content area to meniscal cross-sectional area was then determined. 


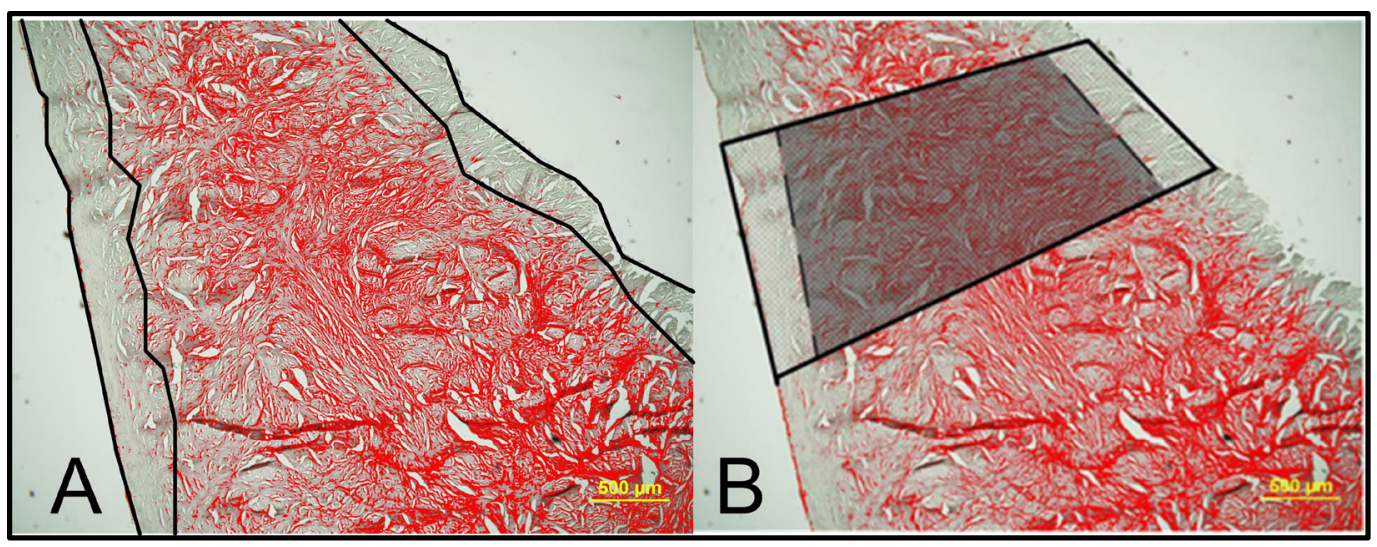

Figure 3.2: Representative histology images that have had a color threshold applied to show location of GAG content with A) showing outline of meniscal surface region without GAG content and B) showing the outline of meniscal cross-sectional area $\mathrm{ROI}$ and GAG cross-sectional area ROI. Figure $2 \mathrm{~A}$ was used to calculate the average distance from meniscal surface to the presence of $G A G$ and Figure $2 B$ was used to calculate the ratio of meniscal GAG to cross-sectional area.

The binding intensity of the GAG stain was measured by selecting a ROI around a portion of the inner meniscal GAG content. Image $\mathrm{J}$ (Abramoff et al. 2004) was used to measure the intensity values of red (R), green (G) and blue (B), with values from 0 to 255 assigned. The proportion of red color (GAG stain) was of interest, and using the equation $r=R /\left(R^{2}+G^{2}+B^{2}\right)^{1 / 2}$, the intensity fraction of red ( $r$ ) with respect to the other primary colors was quantified (Q. Huang et al. 2002; Villegas et al. 2008).

\section{Statistical Analysis:}

One way Analysis of Variance (ANOVA) was performed to determine differences among meniscal regions for quantitative values from nanoindentation and histological analyses. When significant results were identified by ANOVA, a post-hoc Student's two-tailed $t$-test was conducted to compare individual regional 
values amongst one another. Additionally, material properties from nanoindentation, GAG fraction intensity and $G A G / m e n i s c a l$ area ratio values were all analyzed for significant differences using a Student's two tailed t-test to determine significant differences between same regions in the lateral and medial menisci. Quantitative histological values measuring the distance from meniscal surface to GAG content were statistically analyzed with the Student's two tailed ttest to compare proximal and distal surface values for respective regions and anatomical locations $(p<0.05)$.

\section{Results}

Individual nano-indents resulted in a displacement-time curve with a typical linear region during the ramp loading phase, followed by a horizontally asymptotic curve during the held load, indicative of steady-state behavior. Steady-state was defined when a change in displacement was $<0.01 \%$. The average time to steady-state behavior was measured to be approximately 67.5 seconds. In a previous study conducted on the superficial zone of the human meniscus, under the same conditions, the average time to steady state was recorded to be 57.6 seconds (Moyer et al. 2012).

No significant difference was seen between deep zone nanoindentation results from proximal or distal cut samples, so values from the two samples were averaged together. This was expected, as the deep zone is thought to be consistent and not vary spatially from the proximal side to the distal side. 
Variation among the numerous indents on each sample was less than $4 \%$ of the respective material property value, indicating homogeneity among individual indents on the deep zone middle menisci. The average indenter contact radius was $56.15 \pm 2.58 \mu \mathrm{m}$, as the displacement into the meniscal surface was approximately $11 \mu \mathrm{m}$ for each indent. 

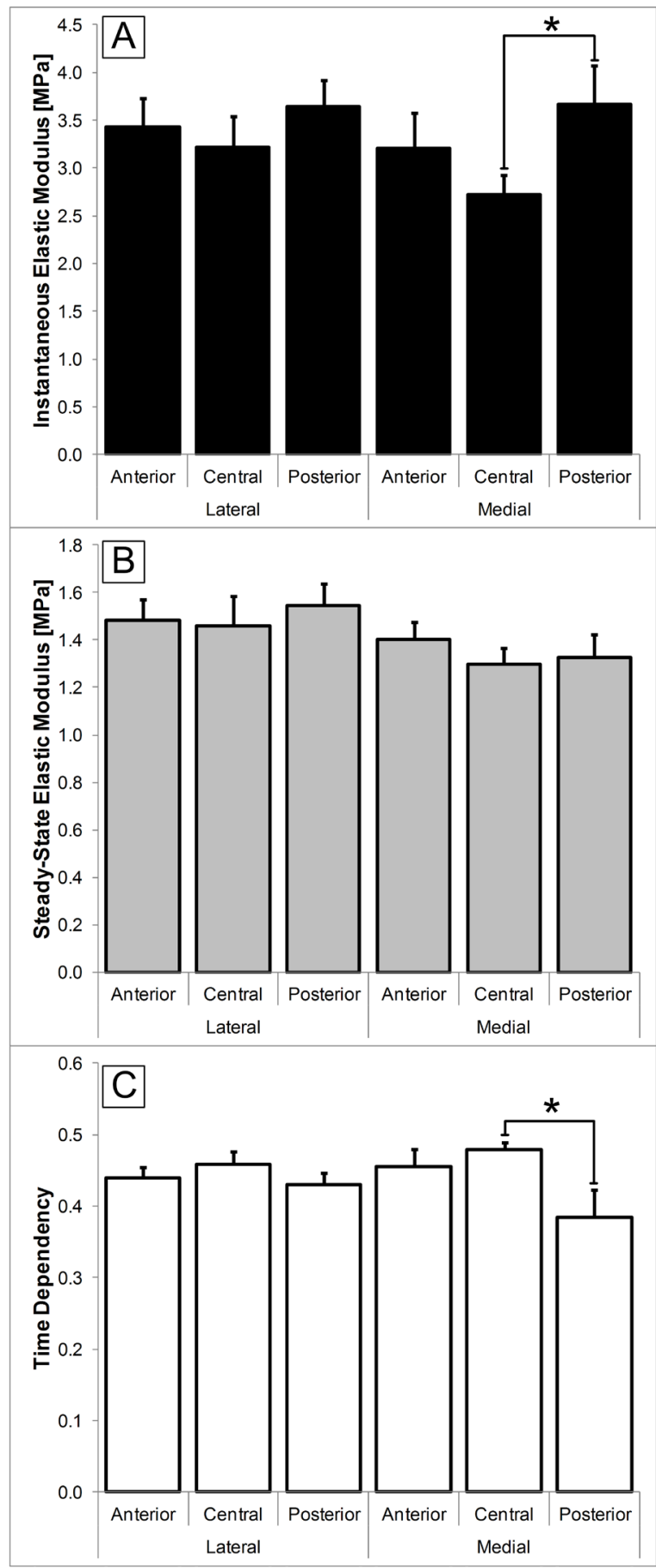

Figure 3.3: A. Average steady-state elastic modulus- B. Average instantaneous elastic modulus- C. Average Time Dependency- values from nanoindentation conducted on the deep zone of human meniscal samples * represents a significant difference between the connecting lines for regions. Error bars represent standard error. 
The regional (anterior vs. central vs. posterior) results from nanoindentation on the deep zone meniscus showed no significant differences for the lateral meniscus for the any of the material properties, whereas the medial-central meniscal region was significantly different than posterior region for both the instantaneous and time-dependency material properties (Figure 3.3A \& C). There were no significant differences between respective lateral or medial regions for steady-state elastic modulus (Figure 3.3B). The posterior region of the medial menisci had the largest instantaneous elastic modulus and the nearly the smallest steady-state elastic modulus (Figure 3.3A \& B), suggestive of the largest amount of relaxation (Figure $3.3 \mathrm{C}$ ). It is worth noting that the instantaneous elastic modulus values and time dependency values seem to have an opposite trend, with the central regions having low instantaneous modulus values and large time dependency values, where the anterior and posterior regions tended to have larger instantaneous moduli values and low time dependency values (Figure 3.3A \& C).

Table 3.1

Table showing the mean \pm standard error values of GAG fraction intensity measured from histological images of regional meniscal cross-sections. * represents a significant difference from the lateral - posterior region

\begin{tabular}{||c||c|c|c||}
\hline \hline \multicolumn{1}{|c||}{} & \multicolumn{3}{c||}{ GAG fraction Intensity } \\
\hline \hline & Anterior & Central & Posterior \\
\hline \hline Lateral & $0.64 \pm 0.011 *$ & $0.65 \pm 0.027$ & $0.60 \pm 0.019$ \\
\hline \hline Medial & $0.61 \pm 0.021$ & $0.63 \pm 0.026$ & $0.60 \pm 0.017$ \\
\hline \hline
\end{tabular}


Generally speaking, visible inspection displayed that GAG stain was weak along the proximal and distal meniscal surfaces (Figure 3.4). The central region for both the lateral and medial menisci had the largest GAG fraction intensity values when compared to the anterior and posterior regions (Table 3.1). No significant differences among all regions and anatomical locations were seen for the ratio of GAG area -to- meniscal area (Table 3.2).

The distance from meniscal surface to the initiation of GAG staining ranged from approximately 500 to $1500 \mu \mathrm{m}$, with the medial meniscus having greater distance values than the lateral region (Figure 3.5). Only the lateral posterior region displayed a significant difference between the two meniscal surfaces $(607.67 \pm 37.78 \mu \mathrm{m}$ on the distal surface compared to $826.11 \pm 82.88 \mu \mathrm{m}$ on the proximal surface). Distal surface posterior values were significantly different between lateral and medial menisci, while proximal surface values were significantly different between the anterior and posterior regions for the lateral menisci (Figure 3.5). Additionally, it can be seen that the medial menisci displayed a much higher variability throughout all regions when compared to the lateral menisci for both proximal and distal values (Figure 3.5). 


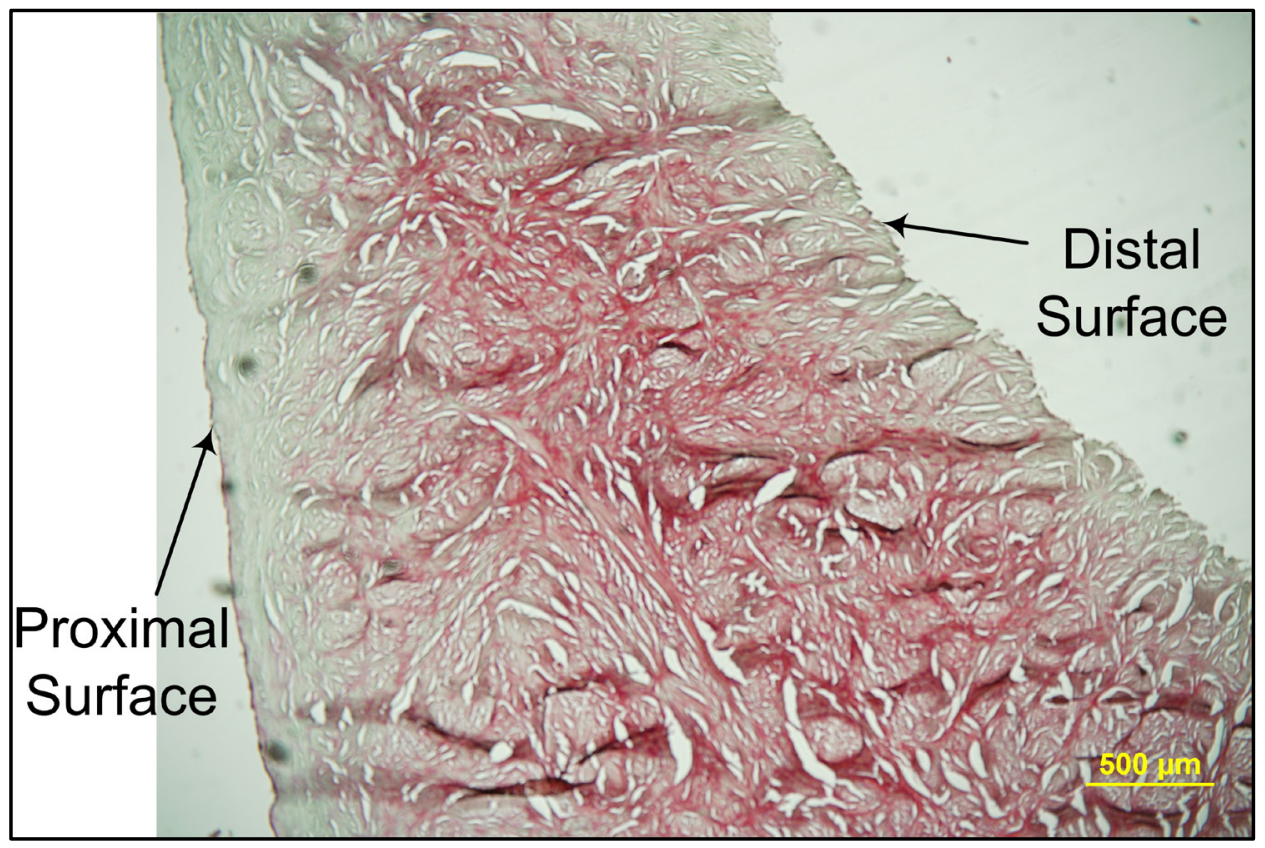

Figure 3.4: Image showing a stained medial anterior specimen. Red stain = GAG

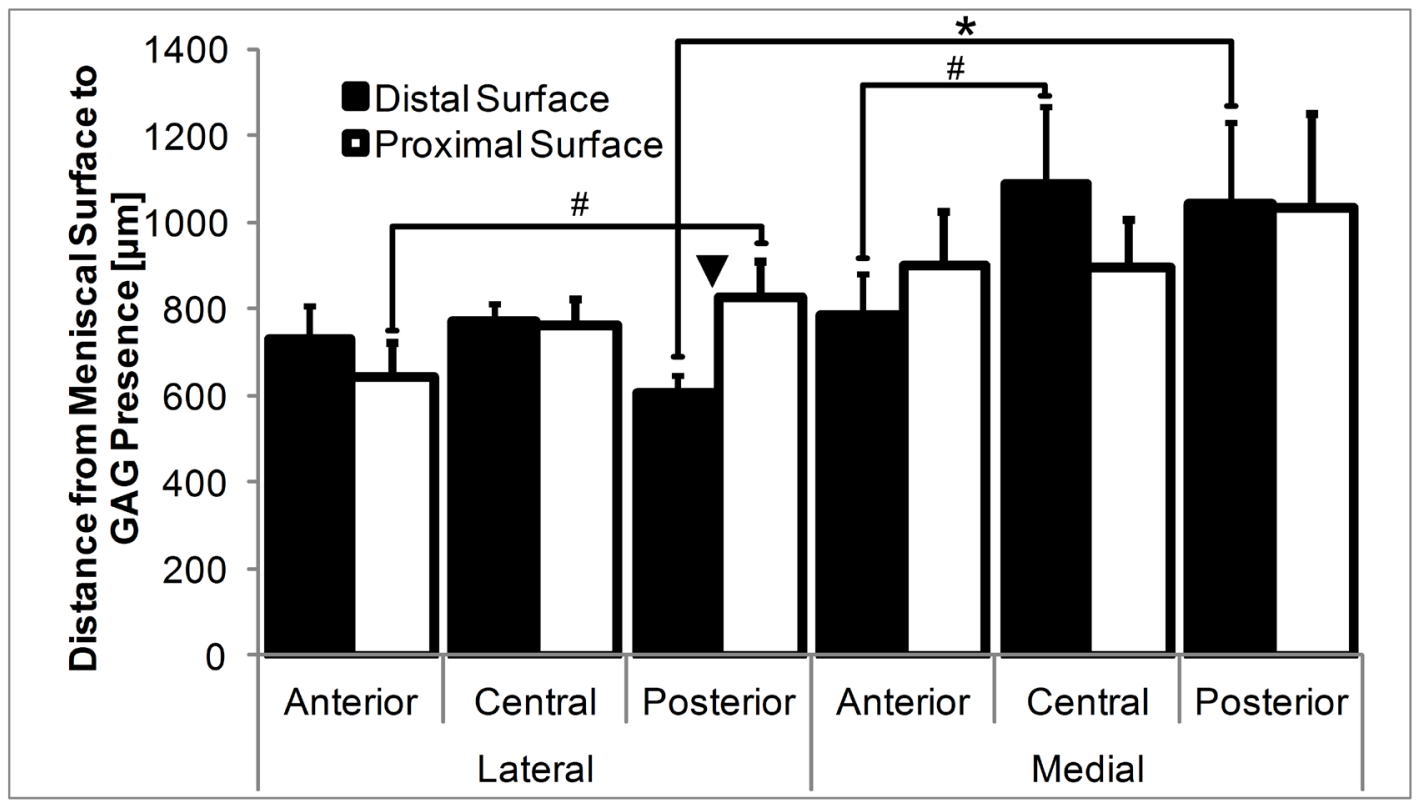

Figure 3.5: Average distance from meniscal surface to GAG presence values for both proximal and distal surfaces of the anterior, central and posterior regions from lateral and medial menisci. $\boldsymbol{\nabla}$ represents a significant difference between proximal and distal surface values; \# represents a significant difference between the connecting lines for regions within respective anatomical locations and * represents a significant difference between the connecting lines between anatomical locations within respective regions. Error bars represent standard error. 
Table 3.2

Table showing the mean \pm standard error values of Ratio of GAG - to - Meniscal Area measured from thresheld histological images of regional meniscal cross-sections.

\begin{tabular}{||c||c|c|c||}
\hline \hline \multicolumn{1}{|c||}{} & \multicolumn{3}{c|}{ Ratio of GAG - to - Meniscal Area } \\
\hline \hline & Anterior & Central & Posterior \\
\hline \hline Lateral & $0.60 \pm 0.042$ & $0.58 \pm 0.087$ & $0.50 \pm 0.053$ \\
\hline \hline Medial & $0.50 \pm 0.058$ & $0.46 \pm 0.085$ & $0.45 \pm 0.087$ \\
\hline
\end{tabular}

\section{Discussion}

This is the first study to examine the deep zone of the human meniscus on the nano-scale. Nanoindentation proved to be a viable option to gather local mechanical properties from the deep zone of human menisci and results were repetitive for each proximal-side and distal-side meniscal deep zone sample. Material property results from this study are approximately two orders of magnitude larger than another compressive based study, also conducted at room temperature (1.5 MPa vs. $0.03 \mathrm{MPa}$ ) (Chia and Hull 2008). Despite these differences in properties between previous macro-scale meniscal tissue testing and the current nano-scale meniscal testing, properties measured in this study (Figure 3.3) are on the same order of magnitude as previous nanoindentation results for both articular cartilage and meniscus, with similar testing parameters and environments (Thambyah et al. 2006; Franke et al. 2007; X. Li et al. 2007; Moyer et al. 2012). Interestingly, the previous nano-scale meniscal data is on the 
superficial zone (Moyer et al. 2012). Thus, it is surprising that the material properties are similar given that the deep zone and superficial layer have very different collagen fiber orientations and GAG content. It is important to note though, significant regional variations existed for the deep zone, whereas no statistical differences were present regionally for surface zone measurements. For both the superficial and deep zones, steady-state moduli are approximately $1.51 \pm 0.04$ and instantaneous moduli are $3.50 \pm 0.12$ (Moyer et al. 2012). This surprising result warrants further investigation as to the structures that are engaged during nanoindentation.

Results from this study indicate that there are significant regional differences in the material properties of the human meniscus in the deep zone. The central region of the meniscus has proven to be significantly different than the posterior region for both the instantaneous elastic modulus and time dependency on the medial meniscus, but not for steady-state elastic modulus (Figure 3.3A - C). In the current study, the medial-posterior region had the lowest time dependency value (Figure 3.3C), in agreement with a previous indentation study showing the medial posterior region to have a lower aggregate modulus compared to the anterior region (Sweigart et al. 2004). In contrast to our current study, an unconfined compression study on cubic shaped human meniscal samples by Chia et al., 2008 showed the medial anterior region to have a statistically greater instantaneous elastic modulus when compared to the posterior region. Clinically, the medial posterior region is torn most frequently (Singson et al. 1991; Helms et al. 1998; Brody et al. 2006; Choi et al. 2008; Ahn 
et al. 2009; De Smet et al. 2009; Lykissas et al. 2010). The relationship between lower indentation modulus and increased tear frequency is interesting and may provide insight into meniscal injury mechanics.

Given that mechanical properties of musculoskeletal tissues are often times linked to morphology and biochemical composition, nano-mechanical results can be compared to biochemical studies to elucidate structure-function characteristics of the human meniscus. Only one other study has reported regional sulfated GAG values, although no regional variations in sulfated GAG were reported; however, the study did not isolate GAG from the deep zone, but rather the entire cross-section (D.C. Fithian et al. 1989). Thus, our study is unique in that GAG intensity was measured for deep zones of each region of the meniscus main body (anterior, central and posterior). Comparing the current nano-mechanical data to our histological measurements of GAG, results showed an inverse relationship between the instantaneous elastic modulus (Figure 3.3C) and GAG fraction intensity (Table 3.1). Of all six regions studied, the medial posterior region had a lower GAG intensity measurement, but a high instantaneous elastic modulus. Thus, as discussed earlier, it would again appear as if GAG intensity within the meniscus does not contributed to nano-scale compressive properties as was indicated when comparing superficial versus deep zone properties. To further support the discontinuity between GAG and nano-scale indentation modulus, the medial posterior region had the lowest GAG-to-meniscal area (Table 3.2). It is interesting to note that while articular cartilage is known to have roughly 8 times as much proteoglycan content as the 
meniscus, the nano-scale indentation moduli are very similar (McDevitt 1973; McNicol and Roughley 1980; M. E. Adams and Muir 1981; Herwig et al. 1984). Previous nanoindentation studies on articular cartilage reported steady-state elastic modulus values of approximately $2.90 \pm 0.40 \mathrm{MPa}$, while it has been shown here that the steady-state elastic modulus for meniscus (superficial and deep) is $1.51 \pm 0.04 \mathrm{MPa}$ (C. Li et al. 2006; Thambyah et al. 2006; Franke et al. 2007; Moyer et al. 2012) While on the macro-level proteoglycan and water are typically thought to control the instantaneous and equilibrium modulus, it would appear that indentation at a smaller scale does not directly relate to PG levels, or at least sulfated GAG intensities.

While previous studies have quantified total sulfated GAG content for the anterior/central/posterior regions on the meniscus (D.C. Fithian et al. 1989), this is the first study to our knowledge which presents relative quantitative GAG fraction intensity results of the deep zone, and quantify the thickness of the superficial zone that is essentially void of GAG. The central deep region displayed the highest GAG fraction intensity values for both lateral and medial menisci, although not significant, whereas the lateral anterior region displays a significant difference from the lateral posterior region (Table 3.1). While our data shows a significant difference between the lateral anterior and posterior regions for GAG fraction intensity, and the previous study (D.C. Fithian et al. 1989) does not, it may be that the current study isolated the deep zone. Our data also shows a significant difference in thickness of the GAG superficial zone between the 
anterior and posterior regions of the lateral meniscus. Neither this study nor the previous reported statistical variations in sulfated GAG for the medial meniscus.

It can be seen that GAG presence is not seen until approximately $600 \mu \mathrm{m}$ from the meniscal surface (Figure 3.5 ) and only encompasses approximately $50 \%$ of the meniscus area (Table 3.2). This discovery suggests that GAG within the meniscus does not have the same depth dependency as collagen fibrils. The meniscal superficial layer, a taut network of collagen fibrils oriented parallel to meniscal surface is suspected to be approximately $100-200 \mu \mathrm{m}$ throughout each meniscal region (Petersen and Tillmann 1998; Ling and Levenston 2012). GAG content has been shown to be localized in a circumscribed area, $600 \mu \mathrm{m}$ deep into the meniscus, possibly demonstrating macro-scale compressive resistance is dependent on the deep zone meniscal constituents.

Sulfated GAG and interstitial fluid are known to support the menisci in compression, by holding in fluid and using negative charges to create a resisting pressure (Roughley et al. 1981; Lu et al. 2009; Sanchez-Adams et al. 2011). The current study shows that the bulk of GAG is concentrated in the deep zone of the meniscal cross-section. Taken together with the GAG-less superficial zone, this may explain why nanoindentation testing required a longer time to achieve a steady-state condition as compared to the GAG-less meniscal surface (Moyer et al. 2012). The GAG-less meniscal surface will likely not retain as much interstitial fluid as the GAG-rich deep zone, giving the meniscal superficial layer less resistance to a compressive force and quicker to reach equilibrium. 
Both histological and mechanical results from this work will prove imperative to better form a structure-function relationship on the nano-scale and effectively tissue engineer meniscal replacements. Showing how the nanomechanical properties of the meniscus regionally vary will help understand the circumferential and radial inhomogeneity of the human menisci and lead to advancements in meniscal replacement design. Lastly, results from this study coupled with nanoindentation on meniscal superficial layers will also be used to better understand the depth inhomogeneity of the meniscus (Moyer et al. 2012). 


\section{Chapter 4 - Significance of Research and Future Directions}

\section{Significance of Research}

In today's hectic environment, humans are constantly moving, relying on their knees to provide them with the necessary stability and comfort for daily activities. Osteoarthritis $(\mathrm{OA})$ is a crippling joint disease which deteriorates the articular cartilage and subchondral bone, ultimately limiting mobility and causing severe discomfort (Andriacchi et al. 2004; Neuman et al. 2008; Neuman et al. 2009). This disease is estimated to affect approximately 28 million adults in the United States alone, with numbers continually on the rise. It is common in the human knee joint and if left untreated, can lead to a total knee replacement (TKR), thus further studies are needed to control this disease, whereby limiting the need for TKR. It has been shown articular cartilage preservation is most important for stopping the initiation of OA.

Articular cartilage protection in the human knee joint is contingent on the structural integrity of the menisci. The menisci are fibrocartilaginous structures which are crucial for proper load distribution in the knee. The menisci are specifically designed to fit the contour of the femoral condyles, aiding to disperse the stresses on the tibial plateau and in turn safeguarding the underlying articular cartilage. Additionally, the circumferentially and depth inhomogeneity of the 
menisci has yet to be characterized on the nano-level to better understand the how meniscal constituents contribute to meniscus mechanics.

In the United States alone, meniscal tears are responsible for the greatest amount of intra-articular knee injuries, with annual amount of reported meniscal fissures being 66 per 100,000 people, with greater than $90 \%$ of reports resulting in some form of meniscus surgical procedure (Baker et al. 1985; Hede et al. 1990a; Hede et al. 1990b; Rattner et al. 2010; Salata et al. 2010). Currently, surgical meniscal repair is deemed ineffective, as only the outer $1 / 3$ of the meniscal body is considered vascularized (Arnoczky et al. 1990; Messner and Gao 1998; Brindle et al. 2001; Greis et al. 2002; S. B. Adams, Jr. et al. 2005; Hoben and Athanasiou 2006). Due to the smaller area and higher stress concentrations, the majority of meniscal tears occur in the inner, avascular $2 / 3$ rds of the meniscus; hence, these tears do not heal well and are usually treated with a partial meniscectomies (Henning et al. 1990; Tenuta and Arciero 1994; Messner and Gao 1998). Clinical treatment of meniscal tears usually involves partial meniscectomies, where a portion of the injured meniscus is removed, and limiting meniscal functionality.

Given current state of clinical meniscal injury treatment, there is a strong need for improved meniscal replacements. A greater understanding of the mechanical properties on the nano-level of the menisci will lead to advanced meniscal replacement design and further OA prevention. Research has shown that the mechanical properties of meniscal fibrocartilage greatly vary when it is compressed on different size-scales, making it necessary to better understand 
the meniscus mechanics all size-scales, especially the local nano-scale. Moreover, meniscal constituent, collagen fibrils and proteoglycans, are measured on the nano-scale; therefore direct structure-function comparisons can be made to better understand the inhomogeneous nature of the meniscus and how it functions. Tissue engineering will greatly benefit with a better understanding of the meniscus mechanics on the nano-scale and how the mechanics are influenced by specific meniscal constituents, specifically how GAG contribute to nano-scale compression.

Tissue engineered meniscal replacements are a promising route to suppress OA, however, a better interpretation of meniscal microstructure composition is required to construct these scaffolds. As proteoglycans and interstitial fluid are suspected to reinforce the menisci in compression, it is possible that individual glycosaminoglycans chains have a direct effect on the meniscal structure during compression. Furthermore, a better grasp of the how nano-structural components, such as glycosaminoglycans, relate to meniscal functionality, is required to better formulate a structure-function relationship.

To effectively create a biomimetric meniscal replacement that will properly function, a structure function relationship on all size-scale is necessary. Results from these nano-scale studies on the human deep zone and superficial layer of the meniscus are essential for meniscal replacement design. To properly design or tissue engineering a meniscal replacement, it is necessary to know how individual constituents function to support the structure on all levels. These studies demonstrate how the meniscal superficial layers and deep zone nano- 
scale material properties directly compare quantitative values corresponding to GAG content. Comparing the regional mechanical and histological-GAG values of the meniscus will prove essential, possibly leading to advancements in meniscal replacements. This data will better explain the regional and depth inhomogeneity of the human meniscus on the nano-scale.

The meniscal superficial layer has been show to be very important and its homogeneous network of coplanar collagen fibrils may aid in protecting the structural integrity of the meniscus (Setton et al. 1993; Petersen and Tillmann 1998; Ling and Levenston 2012). Nanoindentation results on the meniscal superficial layer shows that the meniscal superficial layers (both proximal and distal) are functionally homogeneous (no statistical difference) throughout all meniscal regions and anatomical locations. Showing the meniscal superficial layer has a homogeneous structure-function relationship through each meniscal surface and region will lead to advancements in tissue engineered meniscal replacements. However, it is necessary to compare mechanical results to histological images of meniscal cross-sections to better understand the results.

Histology images of meniscus showed the bulk concentration of GAG localized in the middle of the cross-section, at least $600 \mu \mathrm{m}$ away from either the proximal or distal superficial layer. This bulk concentration of GAG possibly alludes to the fact that the central zone of the meniscal cross-section is crucial for retaining interstitial fluid, supporting the meniscus in compression. This is validated after nanoindentation results show that the deep zone meniscus required a longer time to reach a steady-state displacement, when compared to 
the GAG-less superficial region (both with the same loading parameters). Nanomechanical results from the deep zone meniscus did identify significant differences among regions, showing the medial central region to be statistically different then the posterior region for instantaneous elastic modulus and time dependency, while the steady-state elastic modulus displayed no significant differences. This regional variation further corroborates the thought that the medial posterior meniscus is significantly different and requires further investigation.

As previously mentioned, this is the first time any of this meniscal nanoscale information has been reported and these data will prove to be a novel contribution for the continuous improvement of meniscal replacements. It has been shown here that the nano-scale compressive properties of both the meniscal superficial layers and deep zone are on the same order of magnitude, yet the deep zone of the meniscus is shown to be GAG-rich, while the meniscal superficial layer is GAG-less. This is very interesting, as it has always been suspected that GAG is the main contributor to supporting the meniscus in compression (Sanchez-Adams et al. 2011). These data may show that GAG is engaged during bulk compressive loading and has a minimal affect during nanoscale loading situations. It was shown that GAG-rich meniscus deep zone reached a steady-state displacement (via nanoindentation) after approximately 67 seconds, while the GAG-less meniscal superficial layer only took approximately 55 seconds. This may be attributed to deep-zone GAG retaining interstitial fluid, allowing the meniscal deep zone to sustain a compressive load 
for a longer time until all the fluid was evacuated. This leads us to believe that meniscal compressive resistance on the nano-scale is structurally driven by collagen fibril bundles and interstitial water. Furthermore, as the role of fluid flow and its support of meniscus functionality are understood, it is presumed that collagen fibrils contribute most to the GAG-depleted surface layer mechanics. These data, combined with other research conducted on the human meniscus, will be used to mimic the native human menisci to someday create a successful meniscal replacement to help combat Osteoarthritis. 


\section{Future Research}

Future applicable research should investigate the nano-mechanical properties of the meniscal cross-sections (nanoindenting normal to a transverse meniscal slice) and compare results directly to histological images. Instead of nano-indenting on meniscal surfaces or deep zone layers (as done in Chapter 2 \& 3); indentation should be conducted directly on the cross-section to show possibly radial variation (inner to outer) of the meniscus mechanics and constituents. Additionally, if using matched face specimens, it could be possible to directly indent where there is a high concentration of GAG to show how if the higher concentration affects the mechanical results on the nano-scale; as previous research has shown that GAG have a minimal contribution on the nanoscale. Furthermore, digestion of GAG and/or collagen could directly show what meniscal constituent is supporting the extra-cellular matrix on the nano-scale. These analyses will really show an unequivocal structure-function relationship for an enhanced meniscal replacement design.

To date, it has been shown that GAGs directly affect meniscal strength and viscosity in bulk compression, but individual GAGs, such as dermatan sulfate or chondroitin sulfate, have not been investigate to show their function in mechanical strength. Using immuno-histology or other biochemical techniques, individual GAG chains could be identified and compared results to nanoindentation. These structure-function analyses could also greatly improve tissue engineering efforts for meniscal replacements. 


\section{Bibliography}

Abraham AC, Edwards CR, Odegard GM, Donahue TL. 2011. Regional and fiber orientation dependent shear properties and anisotropy of bovine meniscus. Journal Mechanical Behavahior Biomedical Materials 4(8):2024-30.

Abramoff M, Magalhaes Martins PJ, Ram SJ. 2004. Image Processing with Image J. Biophotonics International 11(7):36-42.

Adams ME, Muir H. 1981. The glycosaminoglycans of canine menisci. Biochemical Journal 197(2):385-9.

Adams ME, McDevitt CA, Ho A, Muir H. 1986. Isolation and characterization of high-buoyant-density proteoglycans from semilunar menisci. Journal of Bone and Joint Surgery American 68(1):55-64.

Adams ME, Ho YA. 1987. Localization of glycosaminoglycans in human and canine menisci and their attachments. Connective Tissue Research 16(3):269-79.

Adams SB, Jr., Randolph MA, Gill TJ. 2005. Tissue engineering for meniscus repair. Journal of Knee Surgery 18(1):25-30.

Ahmed AM, Burke DL. 1983. In-vitro measurement of static pressure distribution in synovial joints--Part I: Tibial surface of the knee. Journal Biomechical Engineering 105(3):216-25.

Ahn JH, Lee YS, Chang JY, Chang MJ, Eun SS, Kim SM. 2009. Arthroscopic all inside repair of the lateral meniscus root tear. Knee 16(1):77-80.

Andriacchi TP, Mundermann A, Smith RL, Alexander EJ, Dyrby CO, Koo S. 2004. A framework for the in vivo pathomechanics of osteoarthritis at the knee. Annals Biomedical Engineering 32(3):447-57.

Arnoczky SP, Warren RF, McDevitt CA. 1990. Meniscal replacement using a cryopreserved allograft. An experimental study in the dog. Clinical Orthopaedic Relatated Research (252):121-8.

Aspden RM, Yarker YE, Hukins DW. 1985. Collagen orientations in the meniscus of the knee joint. Journal of Anatomy 140 ( Pt 3):371-80. 
Baker BE, Peckham AC, Pupparo F, Sanborn JC. 1985. Review of meniscal injury and associated sports. American Journal of Sports Medicine 13(1):1-4.

Beaupre A, Choukroun R, Guidouin R, Garneau R, Gerardin H, Cardou A. 1986. Knee menisci. Correlation between microstructure and biomechanics. Clinical Orthopaedic Related Research(208):72-5.

Bird MD, Sweet MB. 1988. Canals in the semilunar meniscus: brief report. Journal of Bone and Joint Surgery Britain 70(5):839.

Brindle T, Nyland J, Johnson DL. 2001. The meniscus: review of basic principles with application to surgery and rehabilitation. Journal of Athletic Training 36(2):160-9.

Brody JM, Lin HM, Hulstyn MJ, Tung GA. 2006. Lateral meniscus root tear and meniscus extrusion with anterior cruciate ligament tear. Radiology 239(3):805-10.

Brunelle BW, Nicholson TL. 2007. Microarray-based approach for genome-wide survey of nucleotide polymorphisms. Methods of Molecular Biology 396:267-79.

Camplejohn KL, Allard SA. 1988. Limitations of safranin 'O' staining in proteoglycan-depleted cartilage demonstrated with monoclonal antibodies. Histochemistry 89(2):185-8.

Carney SL, Muir H. 1988. The structure and function of cartilage proteoglycans. Physiological Reviews 68(3):858-910.

Chia HN, Hull ML. 2008. Compressive moduli of the human medial meniscus in the axial and radial directions at equilibrium and at a physiological strain rate. Journal of Orthopaedic Research 26(7):951-6.

Choi NH, Son KM, Victoroff BN. 2008. Arthroscopic all-inside repair for a tear of posterior root of the medial meniscus: a technical note. Knee Surgery, Sports Traumatology, Arthroscopy 16(9):891-3.

Clark G. 1973. Staining Procedures. Baltimore: Williams and Wikins. p. 40.

De Smet AA, Blankenbaker DG, Kijowski R, Graf BK, Shinki K. 2009. MR diagnosis of posterior root tears of the lateral meniscus using arthroscopy as the reference standard. American Journal of Roentgenology 192(2):480-6. 
DiSilvestro MR, Zhu Q, Suh JK. 2001a. Biphasic poroviscoelastic simulation of the unconfined compression of articular cartilage: II--Effect of variable strain rates. Journal of Biomechanical Engineeing 123(2):198-200.

DiSilvestro MR, Zhu Q, Wong M, Jurvelin JS, Suh JK. 2001b. Biphasic poroviscoelastic simulation of the unconfined compression of articular cartilage: I--Simultaneous prediction of reaction force and lateral displacement. Journal of Biomechanical Engineeing 123(2):191-7.

Donahue TL, Hull ML, Rashid MM, Jacobs CR. 2002. A finite element model of the human knee joint for the study of tibio-femoral contact. Journal of Biomechanical Engineeing 124(3):273-80.

Ebenstein D, Kuo A, Rodrigo J, Reddi A, Ries M, Pruitt L. 2004. A nanoindentation technique for functional evaluation of cartilage repair tissue. Journal of Materials Research 19:273-281.

Ebenstein D, Pruitt L. 2006. Nanoindentation of biological materials Nanotoday 1(2):26-33.

Eyre DR, Wu JJ. 1983. Collagen of fibrocartilage: a distinctive molecular phenotype in bovine meniscus. FEBS Letters 158(2):265-70.

Fithian DC, Schmidt MB, Ratcliffe A, Mow VC. 1989. Human Meniscus Tensile Properties: Regional Variation and Biochemical Correlation. Preceedings of 35th Orthopaedic Research Society Annual Meeting.

Fithian DC, Kelly MA, Mow VC. 1990. Material properties and structure-function relationships in the menisci. Clinical Orthopaedic Related Research (252):19-31.

Franke O, Durst K, Maier V, Goken M, Birkholz T, Schneider H, Hennig F, Gelse K. 2007. Mechanical properties of hyaline and repair cartilage studied by nanoindentation. Acta Biomaterialia 3(6):873-81.

Ghosh P, Ingman AM, Taylor TK. 1975. Variations in collagen, non-collagenous proteins, and hexosamine in menisci derived from osteoarthritic and rheumatoid arthritic knee joints. Journal of Rheumatology 2(1):100-7.

Ghosh P, Taylor TK. 1987. The knee joint meniscus. A fibrocartilage of some distinction. Clinical Orthopaedic Related Research (224):52-63.

Greis PE, Bardana DD, Holmstrom MC, Burks RT. 2002. Meniscal injury: I. Basic science and evaluation. Jornal of the American Academy of Orthopaeic Surgeons 10(3):168-76. 
Hauch KN, Oyen ML, Odegard GM, Haut Donahue TL. 2009. Nanoindentation of the insertional zones of human meniscal attachments into underlying bone. Journal of Mechanical Behavior of Biomedical Materials 2(4):33947.

Hede A, Hempel-Poulsen S, Jensen JS. 1990a. Symptoms and level of sports activity in patients awaiting arthroscopy for meniscal lesions of the knee. Journal of Bone and Joint Surgery American 72(4):550-2.

Hede A, Jensen DB, Blyme P, Sonne-Holm S. 1990b. Epidemiology of meniscal lesions in the knee. 1,215 open operations in Copenhagen 1982-84. Acta Orthopaedica Scandinavica 61(5):435-7.

Helms CA, Laorr A, Cannon WD, Jr. 1998. The absent bow tie sign in buckethandle tears of the menisci in the knee. American Journal Roentgenology 170(1):57-61.

Henning CE, Lynch MA, Yearout KM, Vequist SW, Stallbaumer RJ, Decker KA. 1990. Arthroscopic meniscal repair using an exogenous fibrin clot. Clinical Orthopaedic Related Research (252):64-72.

Herwig J, Egner E, Buddecke E. 1984. Chemical changes of human knee joint menisci in various stages of degeneration. Annals of the Rheumatic Diseases 43(4):635-40.

Hess B, Herman D. 1986. Cartilage metabolism and anti-inflammatory drugs in osteoarthritis. The American Journal of Medicine 81(5B).

Hoben GM, Athanasiou KA. 2006. Meniscal repair with fibrocartilage engineering. Sports Medicine and Arthroscopy 14(3):129-37.

Hu K, Radhakrishnan P, Patel RV, Mao JJ. 2001. Regional structural and viscoelastic properties of fibrocartilage upon dynamic nanoindentation of the articular condyle. Journal of Structural Biology 136(1):46-52.

Huang CY, Stankiewicz A, Ateshian GA, Mow VC. 2005. Anisotropy, inhomogeneity, and tension-compression nonlinearity of human glenohumeral cartilage in finite deformation. Journal of Biomechanics 38(4):799-809.

Huang Q, Opstelten D, Samman N, Tideman H. 2002. Experimentally induced unilateral tooth loss: histochemical studies of the temporomandibular joint. Journal of Dental Research 81(3):209-13. 
Ingman AM, Ghosh P, Taylor TK. 1974. Variation of collagenous and noncollagenous proteins of human knee joint menisci with age and degeneration. Gerontologia 20(4):212-23.

Joshi MD, Suh JK, Marui T, Woo SL. 1995. Interspecies variation of compressive biomechanical properties of the meniscus. Journal of Biomedical Materials Research 29(7):823-8.

Kahveci Z, Minbay FZ, Cavusoglu L. 2000. Safranin O staining using a microwave oven. Biotechnic \& Histochemistry 75(6):264-8.

Kiviranta I, Tammi M, Jurvelin J, Saamanen AM, Helminen HJ. 1985. Demonstration of chondroitin sulphate and glycoproteins in articular cartilage matrix using periodic acid-Schiff (PAS) method. Histochemistry 83(4):303-6.

Kon E, Chiari C, Marcacci M, Delcogliano M, Salter DM, Martin I, Ambrosio L, Fini M, Tschon M, Tognana $E$ et al. . 2008. Tissue engineering for total meniscal substitution: animal study in sheep model. Tissue Engineering Part A 14(6):1067-80.

Lai JH, Levenston ME. 2010. Meniscus and cartilage exhibit distinct intra-tissue strain distributions under unconfined compression. Osteoarthritis Cartilage 18(10):1291-9.

Lewis PB, Williams JM, Hallab N, Virdi A, Yanke A, Cole BJ. 2008. Multiple freeze-thaw cycled meniscal allograft tissue: A biomechanical, biochemical, and histologic analysis. Journal of Orthopaedic Research 26(1):49-55.

Li C, Pruitt LA, King KB. 2006. Nanoindentation differentiates tissue-scale functional properties of native articular cartilage. Journal of Biomedical Materials Research Part A 78(4):729-38.

Li X, An YH, Wu YD, Song YC, Chao YJ, Chien CH. 2007. Microindentation test for assessing the mechanical properties of cartilaginous tissues. Journal of Biomedical Materials Research B Applied Biomaterials 80(1):25-31.

Ling CH, Levenston ME. 2012. Measurement of Meniscal Layer Thickness Using Optical Coherence Tomography. Preceedings of ORS Annual Meeting.

Lu XL, Mow VC, Guo XE. 2009. Proteoglycans and mechanical behavior of condylar cartilage. Journal of Dental Research 88(3):244-8.

Lykissas MG, Mataliotakis GI, Paschos N, Panovrakos C, Beris AE, Papageorgiou CD. 2010. Simultaneous bicompartmental bucket-handle 
meniscal tears with intact anterior cruciate ligament: a case report. Journal of Medical Case Reports 4:34.

Maes JA, Haut Donahue TL. 2006. Time dependent properties of bovine meniscal attachments: stress relaxation and creep. Journal of Biomechanics 39(16):3055-61.

Makris EA, Hadidi P, Athanasiou KA. 2011. The knee meniscus: structurefunction, pathophysiology, current repair techniques, and prospects for regeneration. Biomaterials 32(30):7411-31.

Marsano A, Vunjak-Novakovic G, Martin I. 2006. Towards tissue engineering of meniscus substitutes: selection of cell source and culture environment. Conference Proceedings IEEE Engineering Medical Biololgy Society 1:3656-8.

McDevitt CA. 1973. Biochemistry of articular cartilage. Nature of proteoglycans and collagen of articular cartilage and their role in ageing and in osteoarthrosis. Annals of the Rheumatic Diseases 32(4):364-78.

McDevitt CA, Webber RJ. 1990. The ultrastructure and biochemistry of meniscal cartilage. Clinical Orthopaedics and Related Research (252):8-18.

McNicol D, Roughley PJ. 1980. Extraction and characterization of proteoglycan from human meniscus. Biochemical Journal 185(3):705-13.

Messner K, Gao J. 1998. The menisci of the knee joint. Anatomical and functional characteristics, and a rationale for clinical treatment. Journal of Anatamoy 193 ( Pt 2):161-78.

Moyer JT, Abraham AC, Haut Donahue TL. 2012. Nanoindentation of Human Meniscal Surfaces. Journal of Biomechanics in review.

Muriuki MG, Tuason DA, Tucker BG, Harner CD. 2011. Changes in tibiofemoral contact mechanics following radial split and vertical tears of the medial meniscus an in vitro investigation of the efficacy of arthroscopic repair. Journal of Bone and Joint Surgery American 93(12):1089-95.

Nakano T, Thompson JR, Aherne FX. 1986. Distribution of glycosaminoglycans and the nonreducible collagen crosslink, pyridinoline in porcine menisci. Canadian Journal of Veterinary Research 50(4):532-6.

Neuman P, Englund M, Kostogiannis I, Friden T, Roos H, Dahlberg LE. 2008. Prevalence of tibiofemoral osteoarthritis 15 years after nonoperative 
treatment of anterior cruciate ligament injury: a prospective cohort study. American Journal of Sports Medicine 36(9):1717-25.

Neuman P, Kostogiannis I, Friden T, Roos H, Dahlberg LE, Englund M. 2009. Patellofemoral osteoarthritis 15 years after anterior cruciate ligament injury--a prospective cohort study. Osteoarthritis Cartilage 17(3):284-90.

Newman AP, Anderson DR, Daniels AU, Dales MC. 1989. Mechanics of the healed meniscus in a canine model. American Journal of Sports Medicine 17(2):164-75.

Oyen ML. 2005. Spherical indentation creep following ramp loading. Journal of Materials Research 20(8):6.

Oyen ML, Cook RF. 2009. A practical guide for analysis of nanoindentation data. Jouranl of Mechanical Behavior of Biomedical Materials 2(4):396-407.

Petersen W, Tillmann B. 1998. Collagenous fibril texture of the human knee joint menisci. Anatomy and Embryology Berlin 197(4):317-24.

Rattner JB, Matyas JR, Barclay L, Holowaychuk S, Sciore P, Lo IK, Shrive NG, Frank CB, Achari Y, Hart DA. 2010. New understanding of the complex structure of knee menisci: Implications for injury risk and repair potential for athletes. Scandinavian Journal of Medicine \& Science in Sports.

Roos EM, Roos HP, Lohmander LS, Ekdahl C, Beynnon BD. 1998. Knee Injury and Osteoarthritis Outcome Score (KOOS)--development of a selfadministered outcome measure. Journal of Orthopaedic and Sports Physical 28(2):88-96.

Rosenberg L. 1971. Chemical basis for the histological use of safranin $O$ in the study of articular cartilage. Journal of Bone and Joint Surgery American 53(1):69-82.

Roughley PJ, McNicol D, Santer V, Buckwalter J. 1981. The presence of a cartilage-like proteoglycan in the adult human meniscus. Biochemical Journal 197(1):77-83.

Roughley PJ, White RJ. 1992. The dermatan sulfate proteoglycans of the adult human meniscus. Journal of Orthopaedic Research 10(5):631-7.

Salata MJ, Gibbs AE, Sekiya JK. 2010. A systematic review of clinical outcomes in patients undergoing meniscectomy. American Journal of Sports Medicine 38(9):1907-16. 
Sanchez-Adams J, Willard VP, Athanasiou KA. 2011. Regional variation in the mechanical role of knee meniscus glycosaminoglycans. Journal of Applied Physiology.

Sandmann GH, Eichhorn S, Vogt S, Adamczyk C, Aryee S, Hoberg M, Milz S, Imhoff AB, Tischer T. 2009. Generation and characterization of a human acellular meniscus scaffold for tissue engineering. Journal of Biomedical Materials Research Part A 91(2):567-74.

Seedhom BB. 1976. Loadbearing function of the menisci. Physiotherapy 62(7):223.

Setton LA, Zhu W, Mow VC. 1993. The biphasic poroviscoelastic behavior of articular cartilage: role of the surface zone in governing the compressive behavior. Journal of Biomechanics 26(4-5):581-92.

Shrive NG, O'Connor JJ, Goodfellow JW. 1978. Load-bearing in the knee joint. Clinical Orthopaedics and Related Research (131):279-87.

Singson RD, Feldman F, Staron R, Kiernan H. 1991. MR imaging of displaced bucket-handle tear of the medial meniscus. Ameican Journal of Poentgenology 156(1):121-4.

Stolz M, Raiteri R, Daniels AU, VanLandingham MR, Baschong W, Aebi U. 2004. Dynamic elastic modulus of porcine articular cartilage determined at two different levels of tissue organization by indentation-type atomic force microscopy. Biophysical Journal 86(5):3269-83.

Stolz M, Gottardi R, Raiteri R, Miot S, Martin I, Imer R, Staufer U, Raducanu A, Duggelin M, Baschong W et al. . 2009. Early detection of aging cartilage and osteoarthritis in mice and patient samples using atomic force microscopy. National Nanotechnology 4(3):186-92.

Sweigart MA, Zhu CF, Burt DM, DeHoll PD, Agrawal CM, Clanton TO, Athanasiou KA. 2004. Intraspecies and interspecies comparison of the compressive properties of the medial meniscus. Annals of Biomedical Engineering 32(11):1569-79.

Szarko M, Muldrew K, Bertram JE. 2010. Freeze-thaw treatment effects on the dynamic mechanical properties of articular cartilage. BMC Musculoskeletal Disorders 11:231.

Tenuta JJ, Arciero RA. 1994. Arthroscopic evaluation of meniscal repairs. Factors that effect healing. American Journal of Sports Medicine 22(6):797-802. 
Thambyah A, Nather A, Goh J. 2006. Mechanical properties of articular cartilage covered by the meniscus. Osteoarthritis Cartilage 14(6):580-8.

Tissakht M, Ahmed AM. 1995. Tensile stress-strain characteristics of the human meniscal material. Journal of Biomechanics 28(4):411-22.

Tran D, Golick M, Rabinovitz H, Rivlin D, Elgart G, Nordlow B. 2000. Hematoxylin and safranin $O$ staining of frozen sections. Dermatology Surgery 26(3):197-9.

van Tienen TG, Hannink G, Buma P. 2009. Meniscus replacement using synthetic materials. Clinical Sports Medicine 28(1):143-56.

Villegas DF, Hansen TA, Liu DF, Donahue TL. 2008. A quantitative study of the microstructure and biochemistry of the medial meniscal horn attachments. Annals of Biomedical Engineeing 36(1):123-31.

Walker PS, Erkman MJ. 1975. The role of the menisci in force transmission across the knee. Clinical Orthopaedics and Related Research (109):18492.

Whipple RR, Wirth CR, Mow VC. 1985. Anisotropic and zonal variations in the tensile properties of the meniscus. Orthopaedic Transactions10(367). 


\section{Appendix A: Standard Operating Procedure}

\section{Nanoindenting/Preparation Meniscal Tissue}

\begin{tabular}{|c|c|}
\hline Item & Location \\
\hline $\begin{array}{l}\text { Samples Embedded in Acrylic } \\
\text { Pucks }\end{array}$ & $\begin{array}{r}\begin{array}{l}\text { Prepared in } 1004 \\
\text { Specimen }\end{array}\end{array}$ \\
\hline Portable Hard Drive & $\begin{array}{l}\text { Top-Right Drawer in Center Desk (Rm } \\
\text { 1004) }\end{array}$ \\
\hline Indenter Tip of Choice & Spherical Indenter Tip (Rm 1004) \\
\hline $\begin{array}{l}\text { Nail Polish-Sally Hansen Insta-dry } \\
\text { (320- Blue) }\end{array}$ & Flammables Cabinet (Rm 1004) \\
\hline $\begin{array}{l}\text { Double Sided Tape } \\
\text { Scissors }\end{array}$ & $\begin{array}{l}\text { Top Drawer in Small Filing Cabinet } \\
(\mathrm{Rm} 1004)\end{array}$ \\
\hline Personal Notebook & $\begin{array}{l}\text { Usually in The Top of The Large Filing } \\
\text { Cabinet (Rm 1004) }\end{array}$ \\
\hline $\begin{array}{l}\text { Keys to The SB } 005 \text { Nanoindenter } \\
\text { Lab }\end{array}$ & $\begin{array}{l}\text { Hanging Near The Fire Extinguisher } \\
(\mathrm{Rm} 1004)\end{array}$ \\
\hline $\begin{array}{l}0.9 \% \text { Saline Solution }-10 \mathrm{ml} \\
\text { Syringe }\end{array}$ & $\begin{array}{l}\text { Bottom Right Cabinet of Histology } \\
\text { Bench (Rm 1004) }\end{array}$ \\
\hline Well Tray $(2 \times 3)$ & Cabinet in Room 1006 \\
\hline Scalpel & Dissection Table (Rm 1004) \\
\hline Moyer SOP & $\begin{array}{l}\text { Purple SOP Binder Near Door in Room } \\
1004\end{array}$ \\
\hline $\begin{array}{l}\text { Tweezers } \\
\text { Indenter Tip C }\end{array}$ & \multirow[t]{2}{*}{$\begin{array}{ccc}\text { Tan } & \text { Cabinet } & \text { (Sub-Basement } \\
\text { Nanoindenter room) } & \end{array}$} \\
\hline Ethyl Alcohol & \\
\hline Sonic Bath & $\begin{array}{l}\text { On The Table Farthest From The Door } \\
\text { (SB 005) }\end{array}$ \\
\hline Puck Holder & $\begin{array}{ccc}\text { In Nanoindenter } & \text { (Sub-Basement } \\
\text { Nanoindenter Room) } & \\
\end{array}$ \\
\hline Nanoindenter with Computer & Sub-Basement Nanoindenter Room \\
\hline Kim & $\begin{array}{l}\text { On The Table Farthest From The Door } \\
\text { (SB 005) }\end{array}$ \\
\hline
\end{tabular}


Throughout whole procedure: When nanoindenting, the main thing to remember is to keep the specimens hydrated with $0.9 \%$ saline as much as possible. If the specimens do not stay hydrated their material properties will change i.e. they won't be representative of what the test is testing for. Below are the steps followed when nanoindenting the deep zone of the human meniscus.

Note: This procedure is for previously prepared meniscal samples; meaning the human meniscus has been harvested, sectioned for regional testing and labeled as they have been previously tested on the superficial zone.

1) Thaw specimens

a. Put a well tray of specimens (from freezer) in the refrigerator for a day before testing

2) Lay $1^{\text {st }}$ column from well tray out on a drop cloth. (Figure A.1)

a. Use gloves and tweezers

b. Label drop cloth with specimen ID in a coordinate system you can remember (Figure A.1b)

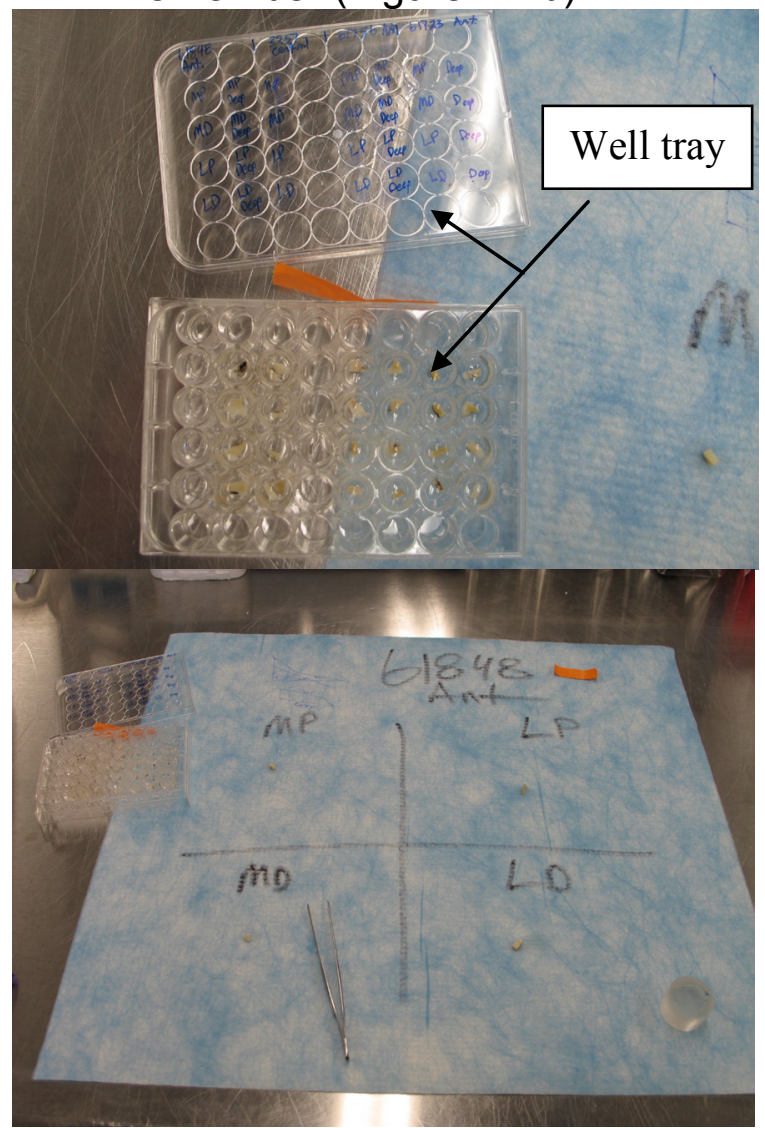

Figure A.1: a) Top view of properly labeled well tray b) Iso view of the drop cloth correctly labeled

c. Size the specimen so that the surface is flat with the well-puck. (Figure A.2)

i. Includes tape + nail polish thickness 
d. Use a scalpel to resize as needed

i. Remember to cut material off the side you are NOT indenting on

E.g. In the case of deep zone testing, material was cut off the non-surface side. This allowed the surface to remain intact for later testing. Due to have thick the well tray is there were no concerns that the test was leaving the deep zone.

Figure A.2: a) iso view of a specimen that is too high b) a side of a specimen that sticks out too much. Since the puck in the picture did not contain tape or nail polish, the specimen would stick out even more.

3) Put nail polish on the opposite side you are testing

a. We used Sally Hansen insta-dry nail polish (320 Cobolt Blue), located in the flammables cabinet.

b. Use a conservative amount just so the specimen can stick to tape (creates a barrier between sample and tape to stick). (Figure A.3)

c. Give it 10 minutes to dry (the more time the better) 


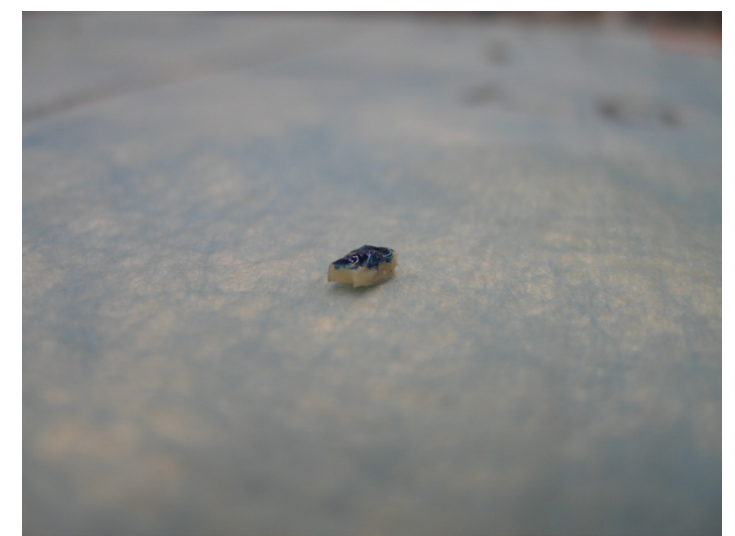

Figure A.3: Specimen painted with nail polish on the surface opposite to the surface being indented.

4) While the nail polish is drying, cut a circle from double sided tape and place it in the puck. (Figure A.4)

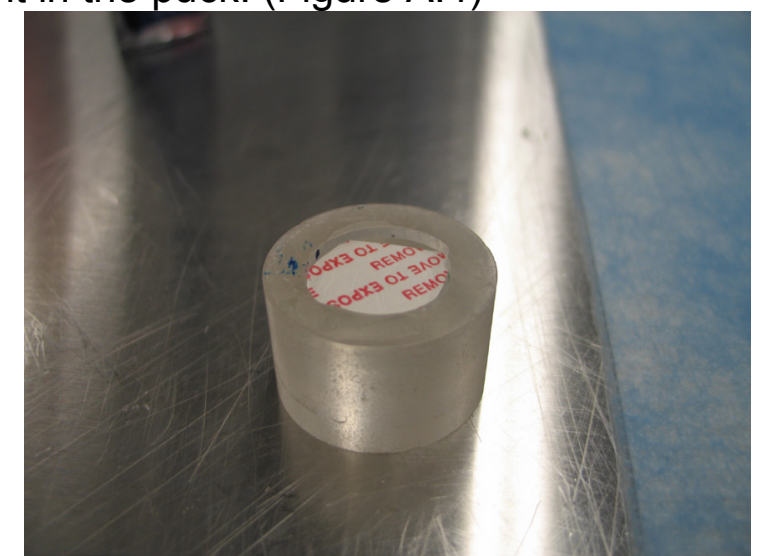

Figure A.4: Well-puck with double sided tape cut and inserted into it.

5) The next step is to bring everything to the nanoindenter is the subbasement, Room S005

a. Tape, scissors, nail polish, specimens in well tray with a small bubble of saline (Figure A.5), tweezers, notebook, pencil, saline, lab keys, a flash drive, and the well-puck. 


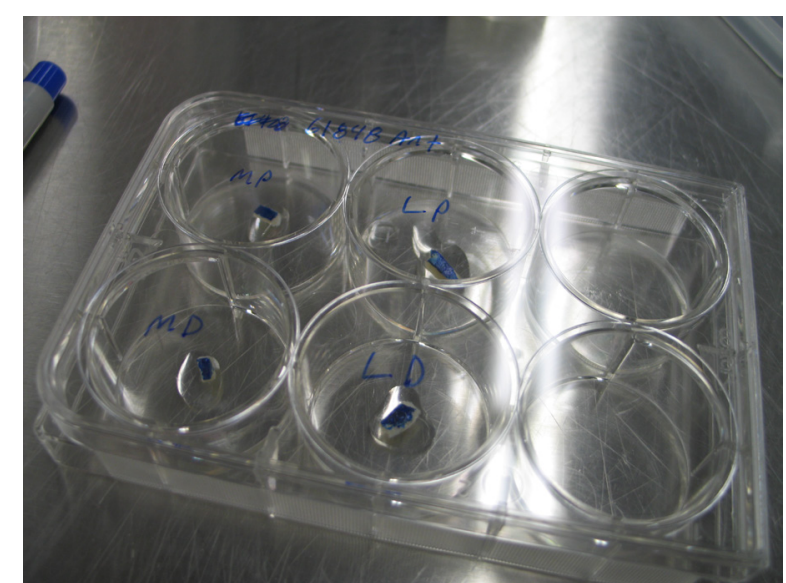

Figure A.5: Specimens ready for transport to the sub-basement lab

6) Once you're in the lab, log into the computer and sign in on the paper log

a. If someone else was running a test and their test is complete, export all of their data to excel. Any questions regarding how to run the nanoindenter should be directed to Moyer's SOP for the nanoindenter

7) "Load sample tray" to get the tray out

a. Take other person's samples out if needed

8) Clean tip if needed

a. You know if the tip needs to be cleaned when you are calibrating. If the calibration dots are not distinct, then the tip needs to be cleaned. This can also be visually inspected. Always make sure pins are inserted if cleaning tip!

b. Clean tip by removing the tip (referrer to SOP) and rinsing it in a sonic bath filled with 190 proof ethyl alcohol for a minute or two. (Insert: Top then Bottom)

9) Load puck with no specimens on it into the tray

a. The best way to do this is place the tray upside down on the table, place the puck in the hole, and tighten the allen wrench. This ensures the puck and tray are flush.

i. If the tray and puck are not flush, the indenter could crash on the puck. THIS IS VERY BAD.

10)Remove the backing from the tape

11)Dry specimen nail polish surface with a kim wipe

a. Do this by just setting the kim wipe on the table and gently rolling the specimen over the wipe. 
12)Place the specimen on the tape

a. Record the location of where you put what specimen in your notebook

i. You can run more than 1 specimen per puck, if they fit

b. Once the specimen is located lightly push down (generally with just the weight of the allen wrench) on the specimen to secure it

c. Place 1 small drop of saline on each specimen

13)Place tray back into nanoindenter

14)Check the table height of the indenter

15)Initialize the indenter

16)Calibrate the machine

a. Moyer SOP

17)Setup the test in Testworks

a. See Moyer's SOP for the nanoindenter

18)Fill the puck with saline

19)Check the table height of the indenter

20)Start the test

21)Once the test is complete, export the data to excel for the successful runs

22)Take the puck out of the tray ("Load sample tray")

23)Shutdown the machine

a. Load the tray back into the machine

b. Initialize the machine

c. Put pins in after initialization

i. Top then Bottom

d. Record on many indents were successful in the log

24)Now place the specimens back in to the well tray (rehydrate!)

25)Go back upstairs for data analysis

26)Run program Nanoripper to make all excel files .csv files

27)Run program CurveFitGuiV2

a. Make sure figure file is in the same folder

b. Add batch process 
c. Select one of the .csv files created

d. Under process:

i. NI Creep

ii. Function Order $=2$

iii. Indenter tip radius $=150$ [nanometers]

iv. Additional argument: .38 [obtained from literature]

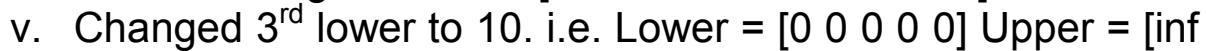
inf 10 inf inf]

vi. Hit "Process"

28)Next type $x x=$ cell2mat(Results. Coeff') into the Matlab command prompt

29)Copy the first four columns of $x x$ in the workspace to the last four columns of the data in the material properties excel file

a. These are the coefficients

30)Fill in the first 5 columns of the material properties excel file with the information about the specimen

test 


\section{Nanoindenting}

Equipment Needed:

1. Tweezers

2. Indenter tip changer tool

3. Embedded specimen pucks

4. Puck holder

5. Equipment in Nanoindenter room

Steps for Setup/Testing:

1. Insert sample and calibration pucks into holder

a. Place holder with rails on glass

b. Slide pucks into respective holes, face down

c. Apply pressure and tighten set screws

2. Turn isolation table on by toggling black switch On below nanoindenter case door

3. Put holder into nanoindenter slot

a. If isolation table reads High/Low

i. Rotate handle inside machine below table CCW (moves table down)

ii. Rotate handle inside machine below table CW (moves table up)

b. Rotate handle until indicator light reads $\underline{\mathbf{O K}}$

4. Power on MTS Nanoindenter (white box)

5. Power on computer and screen

6. On computer, open Test Works 4

a. Most of the remaining steps will be conducted within the Test Works program

b. Italics indicate steps not done using the program

7. Open Method

a. KN Hauch $>$ XP Load, Disp, Time

b. Unless reference holes are need, chose this pre-set method

c. OK

8. Take out locking pins and set on isolation table (first bottom, then top pin)

a. Load Disp should $=0.000$

9. Right-click the Test screen

a. Click Initialize

i. This step will set the machine up (Home, position, etc.)

10. If lights in the lower-right are blinking red 
a. Get Adam

b. Steps will need to be taken to correct

11. The following steps are used to Change the Tip (if needed)

12. Click Tip (from Menu Bar)

a. Click Change Indenter Tip

B. REPLACE LOCKING PINS (FIRST THE TOP, THEN BOTTOM PIN)

13. Use Indenter tip changer tool to remove current tip head and replace new tip

a. Be very careful!

14. Take pins back out!

a. Head may drop (that's OK)

15. Click Tip > Select new indenter tip

16. Conduct Microscope to Calibration

a. Right-click the Test Screen $>$ Mode $>$ Microscope

b. Move Microscope to Calibration Puck

c. Right-click point $>$ Move to Target

17. Right-click the Test Screen $>$ Nano Video Handset View

18. Turn machine light on

19. Use Focus Tools (below Test Screen) to focus and find clean area on calibration pad

20. Right-click the Test Screen > Microscope to Indenter Calibration

a. Click Next (10X)

b. Right-click Test Screen > Remove Backlash

c. Click Next (Indent 5 times)

d. Light can be turned off during calibration

21. Once finished with calibration

a. Click crosshair to the middle of the 5 indents

b. Click Finish

22. Right-click the Test Screen > Go back to Nano Handset

23. Move point back to specimen of interest

a. Use the Move to Target command

\section{Enable Nano Video Handset}

25. Move around specimen area and use Focus tools to find clean area to indent

26. Click Batch Mode Icon on top icon tool bar

a. Batch control must be used when KN Hauch Method is enabled

27. Clear Batch samples in right window pane

a. Right-click samples in pane to remove 
28. Click the Define tab in the Test screen

a. You will now set up the parameters for the testing procedure

29. Click the Next button until the Sample Name is requested

30. A new Sample Name may need to be used for each new indent

a. Cannot just perform one test using a grid of indents

b. Click Next once Sample Name is specified

31. Delta $X$ and Delta $Y$

a. These two values are the distances that the indenter will move away from the current indention location to find the surface

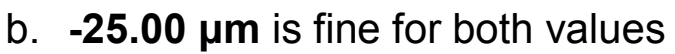

32. Allowable Drift

a. This is the allowable amount of thermal drift in the system

i. This is can be set smaller when machine has been on for awhile

33. Find surface at Test Location

a. Distance: $1000 \mathrm{~nm}$

b. Surface Sensitivity: $10 \%$ change in load/disp curve is needed to indicate surface contact

c. Velocity: slower the better $=5 \mathrm{~nm} / \mathrm{s}$ is as low as you can go

d. To store: $1000 \mathrm{~nm}$ (match distance)

e. Click Next

34. Now you can enter your specific settings for your nanoindent test

a. Want to conduct tests to get a linear displacement vs. time curve

35. Set Peak Hold, Rise Time and Hold Time

a. Each of these parameters will need to be set for your material

b. May need to play around with them to get a proper creep curve

36. Add Test Points

a. Add test to this location will add indent test to where crosshairs are located

37. Click the Test tab

38. Can hydrate tissue (Be careful)

39. Turn light off

40. Shut case door

41. Click Play (Green Triangle)

42. When test complete

a. Review results

43. Open Sample > choose sample

a. Can only see one sample at a time

44. Click Excel Output button 
a. To retrieve Excel file

i. My computer $>$ D drive $>$ Samples $>$ Pick name $>$ Date $>$ Find test 


\title{
Paraffin embedding
}

\section{PARAFFIN EMBEDDING (SOFT TISSUE)}

\author{
TIME: 75 MINUTES
}

\section{Equipment/Supplies:}

\begin{tabular}{|l|l|l|}
\hline Item & Amount & \multicolumn{1}{l|}{ Location } \\
\hline 1:10 Formalin & NA & Fume Hood \\
\hline Acid-Free EDTA (Optional) & Various & Various \\
\hline Tissue Tek Cassettes & $\begin{array}{l}\# \\
\text { Specimens }\end{array}$ & $\begin{array}{l}\text { Histology Lower Cabinet } \\
\text { (Rm 1004 West Wall) }\end{array}$ \\
\hline Tap Water & NA & Faucet \\
\hline $\begin{array}{l}\text { Paraplast Paraffin } \\
\text { Embedding Media }\end{array}$ & NA & $\begin{array}{l}\text { Histology Lower Cabinet } \\
\text { (Rm 1004 West Wall) }\end{array}$ \\
\hline Mason Jar & 3 & $\begin{array}{l}\text { Histology Lower Cabinet } \\
\text { (Rm 1004 West Wall) }\end{array}$ \\
\hline Forceps/Tweezers & 1 Pair & Dissection Bench \\
\hline $\begin{array}{l}\text { Stainless steel embedding } \\
\text { mold }\end{array}$ & $\begin{array}{l}\text { \# of } \\
\text { Specimens }\end{array}$ & $\begin{array}{l}\text { Histology Lower Cabinet } \\
\text { (Rm 1004 West Wall) }\end{array}$ \\
\hline Ethanol: 80\%, 95\% \& 100\% & NA & Flammables Cabinet \\
\hline Xylene & NA & Flammables Cabinet \\
\hline Ice & NA & Refrigerator \\
\hline $\mathrm{dH}_{2} 0$ & NA & dH ${ }_{2}$ Jug/Tank \\
\hline
\end{tabular}

Fixation

1. Place each sample in a Tissue-Tek cassette (top and bottom together). Label each cassette with lead pencil. Samples can be kept in the cassettes throughout the whole preservation series (fixation through paraffin embedding).

2. Place the samples in $10 \%$ Neutral Buffered Formalin (NBF). The 48 Hours NBF volume to tissue ratio should be about 10:1 for proper fixation. A large container can be used to simultaneously fix all specimens OR individual containers can be used.

3. Rinse the samples in $\mathrm{dH}_{2} \mathrm{O}$. 


\section{DEHYDRATION/PREPARATION:}

\begin{tabular}{|c|c|}
\hline $\begin{array}{l}\text { 1. Dehydrate in the following series of solutions. Keep all } \\
\text { Tupperware covered to prevent alcohol evaporation: }\end{array}$ & \\
\hline i. $\quad 70 \%$ Ethanol & $45 \mathrm{~min}$ \\
\hline $80 \%$ Ethanol & $45 \min$ \\
\hline iii. $\quad 2 \times 95 \%$ Ethanol & $\begin{array}{l}45 \text { min each } \\
\text { (90 total) }\end{array}$ \\
\hline iv. $\quad 2 \times 100 \%$ Ethanol & $\begin{array}{l}45 \text { min each } \\
\text { (90 total) }\end{array}$ \\
\hline 2. Immerse the sample in Xylene & $45 \min$ \\
\hline $\begin{array}{l}\text { 3. Drain the Xylene and immerse the sample in fresh Xylene. } \\
\text { DO NOT DUMP THE XYLENE DOWN THE DRAIN. Pour it } \\
\text { into a labeled (Used Xylene) empty bottle so that it can be } \\
\text { disposed later as a hazardous waste. }\end{array}$ & $45 \mathrm{~min}$ \\
\hline 4. Drain the Xylene and immerse the sample in fresh Xylene & $45 \min$ \\
\hline $\begin{array}{l}\text { 5. Remove tissue from the Xylene and place the tissue in a } 1 / 2 \\
\text { pint mason jar }\end{array}$ & \\
\hline $\begin{array}{l}\text { 6. Cover the sample in melted paraffin and place the Mason } \\
\text { jar in the incubator set at } 60^{\circ} \mathrm{C} \text {. }\end{array}$ & Overnight \\
\hline $\begin{array}{l}\text { 7. Switch the cassette to a fresh Mason jar with melted } \\
\text { paraffin in it. Place the sample in the incubator }\end{array}$ & 1 Hour \\
\hline $\begin{array}{l}\text { 8. Repeat step } 7 \text { with another fresh change of paraffin. The } \\
\text { samples can be left in the incubator longer than } 1 \text { hour, if } \\
\text { needed }\end{array}$ & 1 Hour+ \\
\hline
\end{tabular}

\section{PARAFFIN EMBEDDING}

1. Melt the paraffin on a hot plate in a beaker.

2. Warm the mold on the hot plate before adding paraffin to it. Pour enough hot paraffin into the mold to cover the bottom of it.

3. Remove the sample from the Mason jar with tweezers. Dump the melted paraffin in the Mason jar into a trash bag.

4. Remove the sample from the cassette. Throw away the lid, but save the cassette bottom. Place the sample in the mold with the cut face down. Pour enough hot paraffin over the sample to cover it.

5. Place the closed end of the cassette bottom on the top of the paraffin.

6. Pour hot paraffin over the cassette.

7. Leave the sample on ice until the paraffin hardens (or place in freezer) 20 minutes

8. Cut along each side of the cassette using the scalpel to remove the embedded sample from the mold, leaving it attached to the cassette. The cassette will serve as the holder for the microtome (and label) 
Poly - I - lysine slide coating

\title{
SLIDE SUBBING (POLY-L-LYSINE) PROTOCOL (Brunelle and Nicholson 2007)
}

\author{
TIME: 75 MINUTES
}

"The following protocol was adapted from (Brunelle and Nicholson 2007) and an open source protocol"

\begin{tabular}{|c|c|c|}
\hline Item & Amount & Location \\
\hline Slide Rack w/ handle & NA & $\begin{array}{c}\text { Histology Lower } \\
\text { Cabinet (Rm } 1004 \\
\text { West Wall) }\end{array}$ \\
\hline Glass Dishes & 5 & $\begin{array}{c}\text { Histology Lower } \\
\text { Cabinet (Rm } 1004 \\
\text { West Wall) }\end{array}$ \\
\hline Glass Slides & NA & \\
\hline Poly-I-lysine & $100 \mathrm{~mL}$ & $\begin{array}{l}\text { Acids Cabinet (Rm } \\
1004 \text { West Wall) }\end{array}$ \\
\hline $\mathrm{NAOH}$ & NA & $\begin{array}{l}\text { Acids Cabinet (Rm } \\
1004 \text { West Wall) }\end{array}$ \\
\hline 95\% Ethanol & NA & Flammables Cabinet \\
\hline Shaker Table & 1 & $\begin{array}{c}\text { Histology Lower } \\
\text { Cabinet (Rm } 1004 \\
\text { West Wall) }\end{array}$ \\
\hline
\end{tabular}

1. Prepare $\mathrm{NAOH}$-ethanol solution

- Dissolve $\mathrm{NAOH}$ in $\mathrm{ddH}_{2} \mathrm{O}$ (if you using tablets) $70 \mathrm{~g} / 280 \mathrm{~mL} 175 \mathrm{~g} / 700 \mathrm{~mL}$ $200 \mathrm{~g} / 800 \mathrm{~mL}$

- Stir until completely dissolved

- Add $95 \%$ ethanol

$420 \mathrm{~mL}$ $1050 \mathrm{~mL}$

$1200 \mathrm{~mL}$

- Stir until completely mixed

- If solution remains cloudy, add water until clear

2. Place slides in metal slide racks ( 30 slides/rack). Do not use defective slides. 
3. Soak slides in the $\mathrm{NaOH}: \mathrm{EtOH}: \mathrm{ddH}_{2} \mathrm{O}$ solution for 2 hours with gentle rotation (using shaker table)

4. Rinse extensively with $\mathrm{dH}_{2} \mathrm{O}$

- Rinse each unit (slide/rack/container) vigorously with $\mathrm{dH}_{2} \mathrm{O}$ for 5 minutes

- Place slide racks in large clean glass container and tilt the container slightly for constant water flow

- Wash under running tap water for 30 minutes

- Do not allow the slides to dry at any time

It is critical to remove all traces of $\mathrm{NaOH}: \mathrm{EtOH}$

5. Prepare poly-I-lysine solution in plastic container

- Mix 3 solutions together in 1 large plastic container and then split into 3 smaller plastic containers

- $100 \mathrm{~mL}$ tissue culture PBS

- $800 \mathrm{~mL} \mathrm{dH} \mathrm{H}_{2} \mathrm{O}$

- $100 \mathrm{~mL}$ poly-I-lysine

6. Soak the slides in the lysine solution for 45 minutes with gentle rotation. Be sure to use a plastic containers, as poly-l-lysine adheres to glass

Poly-l-lysine solution may be reused. Keep the other slide filled racks in $\mathrm{dH}_{2} \mathrm{O}$, while the first 3 are being coated.

7. After the lysine coating, rinse the slides by gently plunging up and down in 2 different changes of $\mathrm{dH}_{2} \mathrm{O}$. Spin dry 5' at $600 \mathrm{rpm}$ or place in incubator (on slide drying rack) at $50^{\circ} \mathrm{C}$. Place drop clothes under to pick up spilling. 


\section{Microtome Slicing}

\section{Equipment/Supplies:}

\begin{tabular}{|c|c|c|}
\hline Item & Amount & Location \\
\hline Paraffin Microtome & NA & Forestry Bldg. 155A \\
\hline $\begin{array}{l}\text { Paraffin Embedded } \\
\text { Samples }\end{array}$ & NA & \\
\hline $\mathrm{dH}_{2} \mathrm{O}$ & & $\mathrm{dH}_{2} \mathrm{O}$ Tank/Jug \\
\hline Poly-I-lysine Coated Slides & & Slide Holder \\
\hline Thermometer & 1 & $\begin{array}{l}\text { Histology Bench Cabinet } \\
\text { (Rm } 1004 \text { West Wall) }\end{array}$ \\
\hline Hot Plate & 1 & Forestry Bldg. 155A \\
\hline Histology Blades & NA & $\begin{array}{l}\text { Histology Bench Cabinet } \\
\text { (Rm } 1004 \text { West Wall) }\end{array}$ \\
\hline Small paint brushes & NA & $\begin{array}{l}\text { Histology Bench Cabinet } \\
\text { (Rm } 1004 \text { West Wall) }\end{array}$ \\
\hline
\end{tabular}

1. Slide coarse adjustment of microtome back

2. Place cassette into holder

3. Place blade into the microtome and lock into place

4. Set desired cutting depth on the microtome and slide the blade up to the cassette, bringing it close but not touching, and lock that into place

5. Start cranking the cutting wheel, and the cassette will move forward your desired cutting depth after each rotation

6. Once the microtome starts cutting, examine the sliced section and make sure you have a complete cross section (You may need to let the microtome make a few slices before you get a good section). Sliced section at this point will be rolled up

7. Place the samples in warm $\mathrm{dH} 2 \mathrm{O}\left(40-45^{\circ} \mathrm{C}\right)$ and allow the rolled up samples to loosen and unroll

8. Scoop out unrolled sections and place on slide. Make 3 slides with 3 sliced sections per slide for each sample being tested

- When preparing the slides, place proximal end of meniscus down on each slide. This will help for orientation when examining the samples under the microscope.

9. Allow slides to air dry for 30 minutes

10. Placed dried slides into the incubator at $45-50{ }^{\circ} \mathrm{C}$ and let sit overnight. This will ensure that the paraffin sections adhere to the slide. (Do not exceed $50^{\circ} \mathrm{C}$, as this may cause sections to crack) 


\section{Deparaffinization}

\section{Equipment/Supplies:}

\begin{tabular}{|c|c|c|}
\hline \multicolumn{1}{|c|}{ Item } & Amount & Location \\
\hline Slide Holder w/ Handle & 6 & $\begin{array}{c}\text { Histology Bench Drawer (Rm } \\
1004 \text { West Wall) }\end{array}$ \\
\hline Tupperware & $\begin{array}{c}\text { Histology Bench Drawer (Rm } \\
1004 \text { West Wall) }\end{array}$ \\
\hline Tap Water & Faucet \\
\hline Ethanol: $70 \%, 95 \%$ \& 100\% & $\begin{array}{c}\text { As much as } \\
\text { necessary }\end{array}$ & Flammables Cabinet \\
\hline Xylene & $\begin{array}{c}\text { As much as } \\
\text { necessary }\end{array}$ & Flammables Cabinet \\
\hline
\end{tabular}

No matter what animal tissue you are sectioning, deparaffinization will work by doing the following:

1. 5 minutes in Histology grade Xylene

2. 5 minutes in another bucket of Histology grade Xylene

3. 5minutes in another bucket of Histology grade Xylene

Now that the paraffin is off the slide, you need to take the excess Xylene off the slide. You do the following:

4. 5 minute in Absolute $\mathrm{ETOH}$

5. 5 minutes in $95 \% \mathrm{ETOH}$

6. 5 minutes in $70 \%$ ETOH

7. Wash with water for 5 minutes.

You can now stain the tissue as necessary. 


\section{Safranin-O and Fast Green Staining}

"The following protocol was adapted using protocols from an IHCworld web page and was created based on previous peer-reviewed work (Camplejohn and Allard 1988; Kahveci et al. 2000; Tran et al. 2000):

\section{Equipment/Supplies:}

\begin{tabular}{|c|c|c|}
\hline Item & Amount & \multicolumn{1}{c|}{ Location } \\
\hline Slide Holder w/ Handle & NA & $\begin{array}{c}\text { Histology Bench Drawer } \\
\text { (Rm 1004 West Wall) }\end{array}$ \\
\hline Tupperware & 1 & $\begin{array}{c}\text { Histology Bench Drawer } \\
(\text { Rm 1004 West Wall) }\end{array}$ \\
\hline $\mathrm{dH}_{2} 0$ & $\mathrm{dH}_{2} 0$ Tank/Jug \\
\hline Tap Water & See Recipe & $\begin{array}{c}\text { Faucet } \\
\text { Cabinet (Rm 1004 West } \\
\text { Wall) }\end{array}$ \\
\hline $\begin{array}{c}\text { Weigerts Iron Hematoxylin } \\
\text { Working Solution (50:50 } \\
\text { Parts A \& B) }\end{array}$ & See Recipe & $\begin{array}{c}\text { Acids Storage Cabinet } \\
\text { (Rm 1004 West Wall) }\end{array}$ \\
\hline Fast Green FCF Solution & See Recipe & $\begin{array}{c}\text { Acids Storage Cabinet } \\
\text { (Rm 1004 West Wall) }\end{array}$ \\
\hline $1 \%$ Acetic Acid Solution & See Recipe & $\begin{array}{c}\text { Acids Storage Cabinet } \\
\text { (Rm 1004 West Wall) }\end{array}$ \\
\hline $0.1 \%$ Safranin O Solution & Flammables Cabinet \\
\hline Ethanol: 80\%, 95\% \& 100\% & & Flammables Cabinet \\
\hline Xylene & &
\end{tabular}

\section{Prepared Solutions}

- Weigerts A

1. Dissolve $5 \mathrm{~g} \mathrm{Hematoxylin} \mathrm{in} 500 \mathrm{~mL} 95 \%$ Ethanol

- Weigerts B

1. Dissolve $5.8 \mathrm{~g}$ Ferric Choloride in $20 \mathrm{~mL} \mathrm{dH}_{2} \mathrm{O}$ to yield $29 \%$ Ferric Chloride Solution

2. Mix Ferric Chloride Solution with $475 \mathrm{~mL} \quad \mathrm{dH}_{2} \mathrm{O}$ and $5 \mathrm{~mL}$ concentrated $\mathrm{HCL}$

- Fast Green FCF Solution

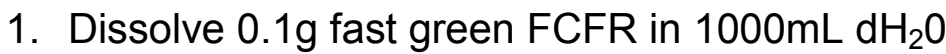

- $1 \%$ Acetic Acid Solution

1. Mix $10 \mathrm{~mL}$ glacial acetic acid with $990 \mathrm{~mL} \mathrm{dH}_{2} \mathrm{O}$

- $\quad 0.1 \%$ Safranin O Solution

1. Dissolve $1 \mathrm{~g}$ Safranin $\mathrm{O}$ in $1000 \mathrm{~mL} \mathrm{dH}_{2} \mathrm{O}$ 
Methods

1. Place the slides in the slide holder.

2. Stain with Weigert's iron hematoxylin working solution for 10 minutes

3. Wash in running tap water for 10 minutes

4. Stain with fast green (FCF) solution for 5 minutes

5. Rinse quickly with $1 \%$ acetic acid solution for no more than $10-15$ seconds

6. Stain in $0.1 \%$ safranin $O$ solution for 10 minutes

7. Dehydrate and clear with $95 \%$ ethanol, absolute ethanol and xylene, using 2 changes each, for 2 minutes each

Results

-GAGs: red

-Nuclei: black

-Cytoplasm: gray-green

-Cartilage, mucin, mast cell granules: orange-red 


\section{Histological Image Analysis}

*Assuming all images have been acquired and a complete meniscal crosssection can be seen (both surfaces) *

\section{Threshold Images}

1. Open Image J Image Program

2. Open a desired image using File $>$ Open

3. With the image appearing on the screen, click $\underline{\text { Image }}>\underline{\text { Adjust }}>\underline{\text { Color }}$ Threshold

4. Move the top selection bar for 'Hue' to a value of $\underline{\mathbf{1 7 0}}$

5. Move the top selection box for 'Saturation' to a value of $\underline{\mathbf{7 5}}$

6. The 'Brightness' bars do not need to be touched.

7. These settings will define where GAG is located so surface measurements can be taken.

8. Figure A.7 shows how image color will change after the color threshold has been applied.

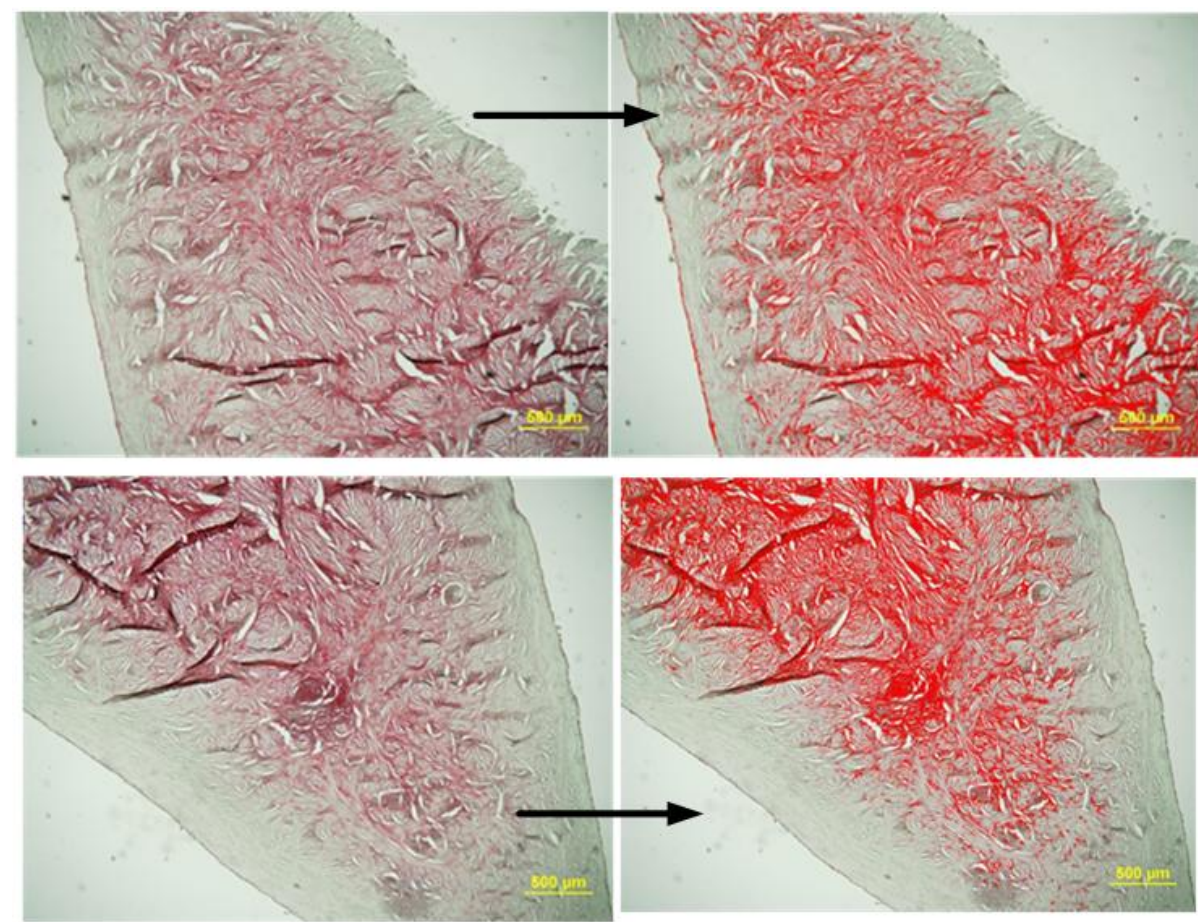

Figure A.6: Images on left are original histology images. Right images are respective histology images after a threshold has been applied. 


\section{Measuring Average Meniscal Surface (no GAG) thickness}

9. The BIOQUANT program will be used to measure the average thickness of the meniscal surface (that does not contain GAG).

a. The lower--right scale bar will be used for calibration

10. Lines will be drawn (in BIOQUANT) to outline one meniscal surface (proximal or distal) and then another line will be drawn along the GAG tide-line (Figure A.3).

11. BIOQUANT will then be used and the average thickness will be measured

12. This average thickness will be recorded for each subsequent image.

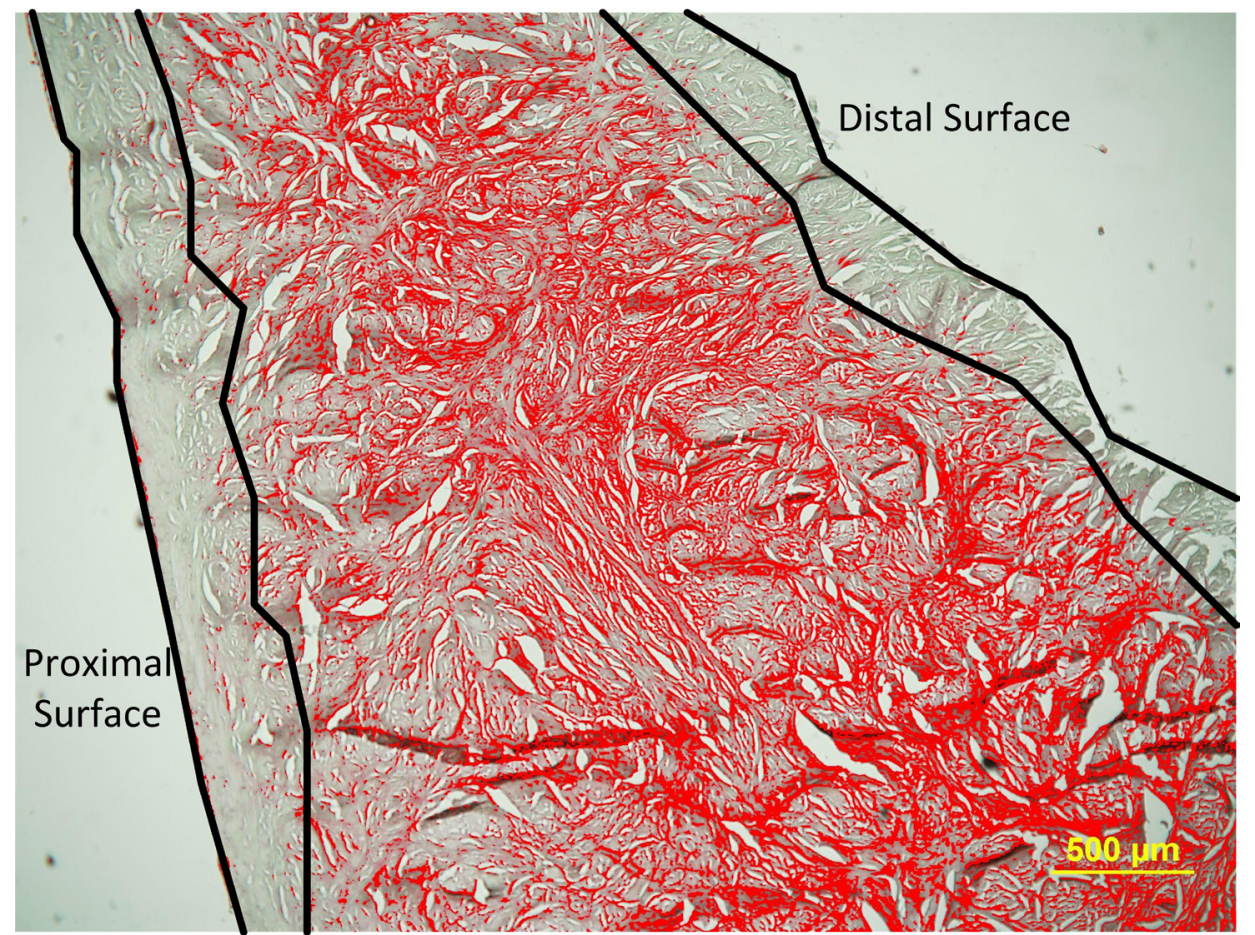

Figure A.7: Image with applied threshold and outlines drawn to measure average thickness of non-GAG meniscal surface.

\section{Measuring ratio of GAG cross-sectional area to Meniscus CSA}

13. Using Image $J$ again, select the 'Polygon Selection' tool

14. Select a 'Region of Interest (ROI)' of the whole meniscal cross-section (Figure A.5) 
a. First double click to start with a line and then click at each corner, on the last connecting corner, click the right-mouse button

b. Try to not include any folded regions

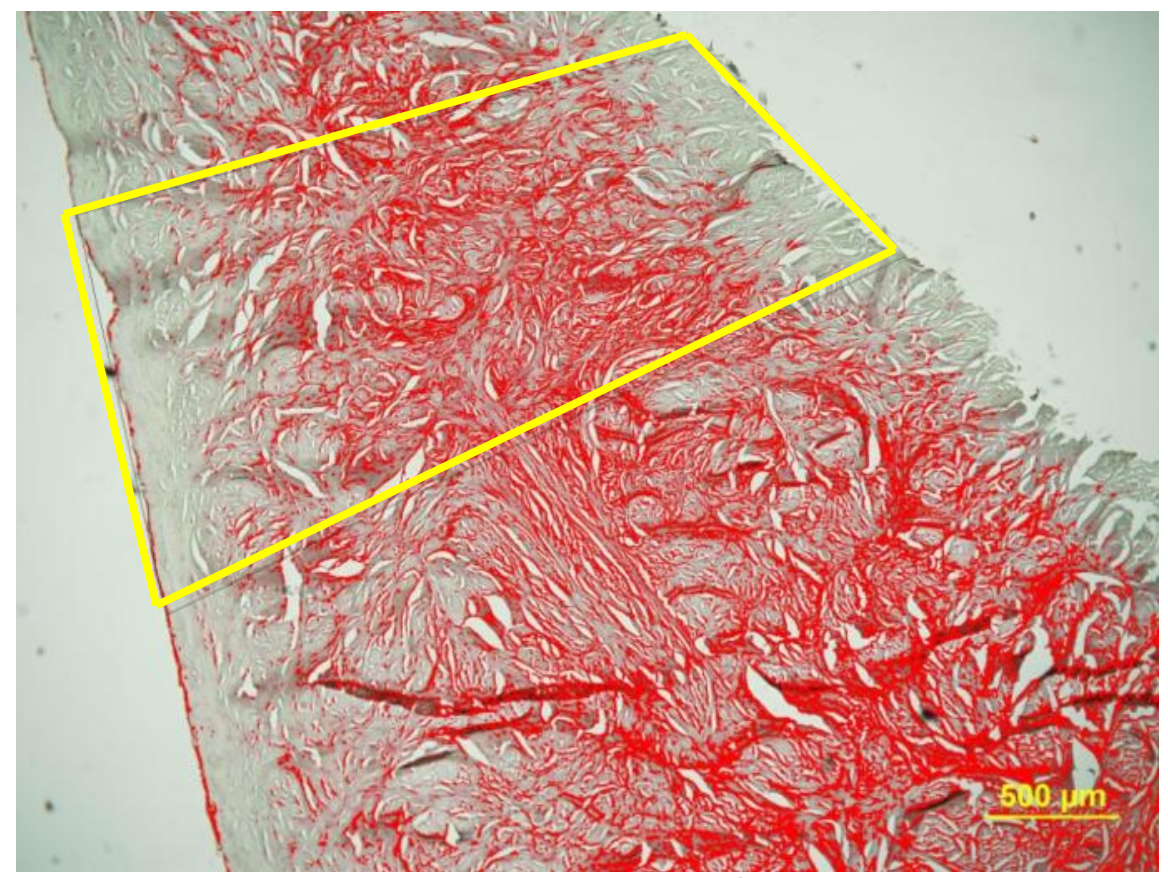

Figure A.8: Histology image with 'outer ROI' highlighted

15. With the correct outer ROI drawn, click "Ctrl $+\mathrm{M}$ " to measure the area of that region

16. Then press "Ctrl + D" to draw that region on the image

17. Now following the same steps as above to draw another inner ROI, surrounding the GAG content (Figure A.6)

a. MAKE SURE YOU OVERLAY THE OUTER ROI HORIZONTAL LINES SO ONLY THE NON-GAG CONTENT IS NOT INCLUDED FROM THE OUTER ROI 


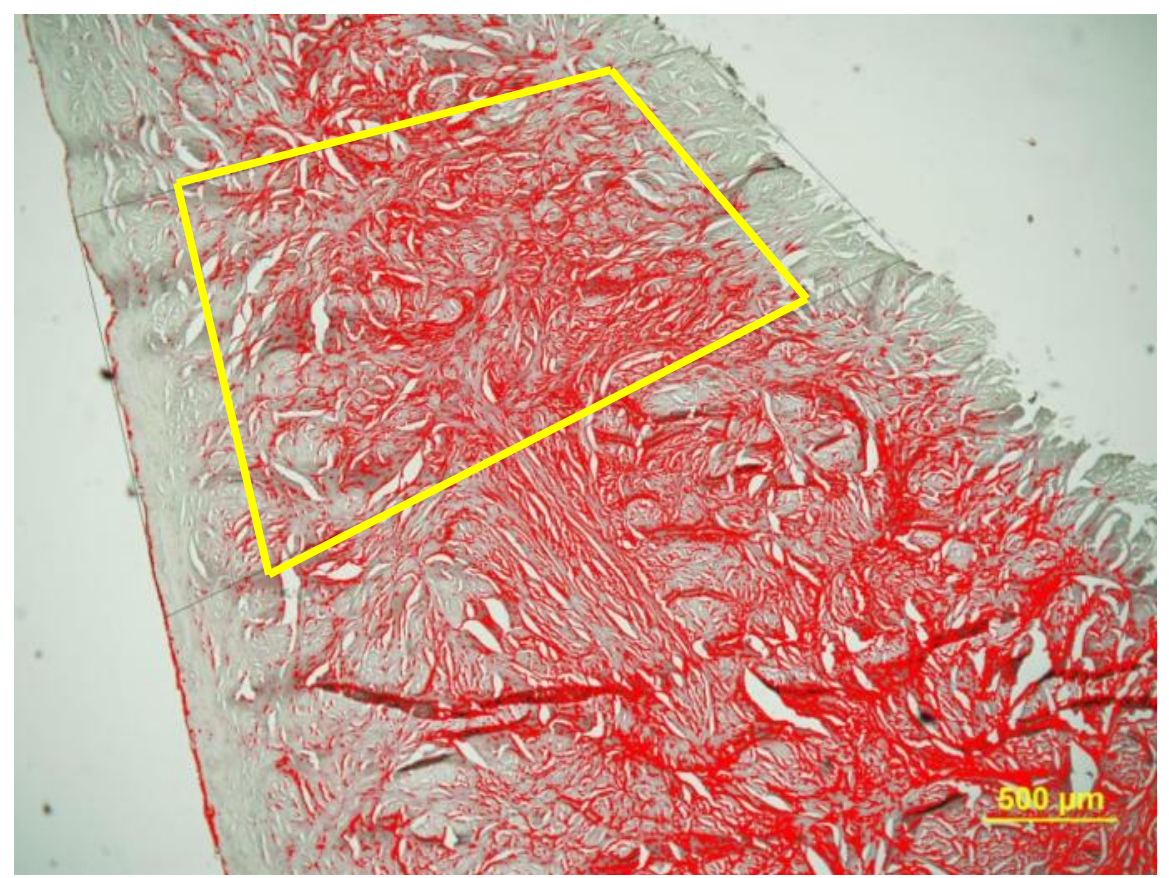

Figure A.9: Histology image with 'inner ROl' highlighted. Making sure to overlay 'outer ROl' lines

18. Both ROls should be similar to Figure A.7, with the shaded and crosshatched region being the GAG region and all cross-hatched being the total meniscal cross-sectional area

19. With the correct inner ROI drawn, click "Ctrl $+\mathrm{M}$ " to measure the area of that region

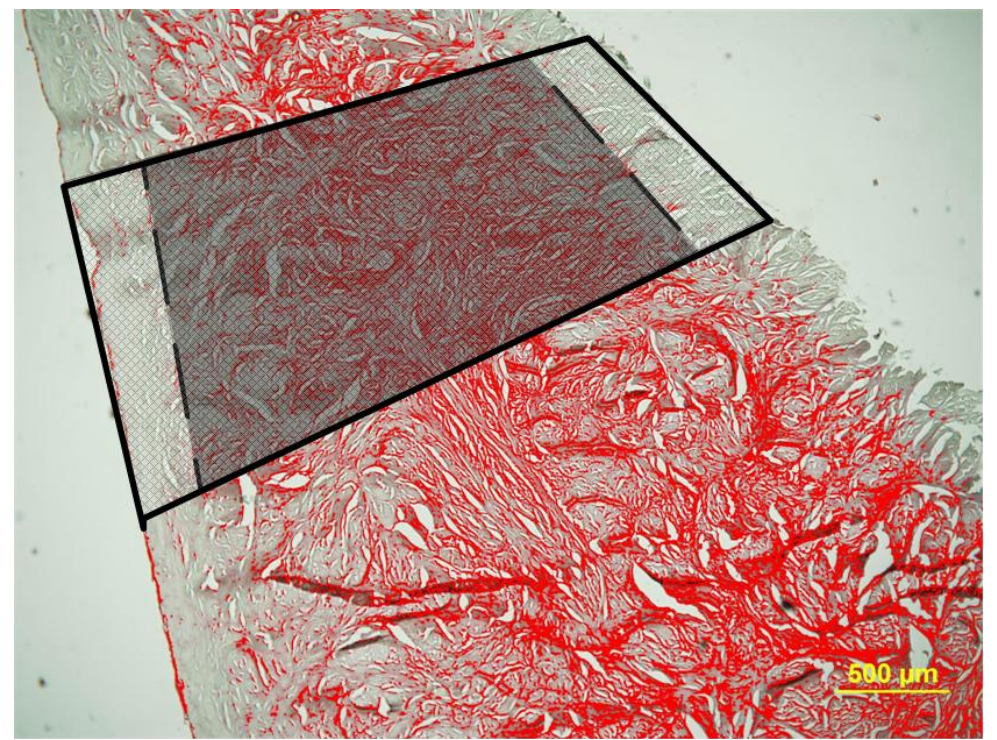

Figure A.10: Image with both inner and outer ROI selected to show intersection 
20. A Results Box should be available with area values for both ROIs

21. For the example in Figure A.7, the GAG-to-meniscus cross section would be:

22. Repeat this for each image

$$
\frac{591065}{788249}=0.75
$$

\section{GAG Intensity Measurement}

**These next steps for "GAG Intensity Measurements" can be done whenever, the threshold images do not need to be used, just the original histology images. ${ }^{* *}$

23. Open an original histology image using Image $\mathrm{J}$ just as described in step \#2

24. Using the Polygon Selection' tool (Figure A.4), select a ROI surround just a portion of red-stained GAG

a. Try to not include any folds, but surround as much GAG as possible 25. With the ROI surrounding GAG selected, Click Analyze $>$ Color Histogram 26. This will give you a 'Results' and 'Histogram' Box

27. Record the Red, Green and Blue values for each image 28. Using the three (RGB) color values, place into Equation 1

$$
\text { GAG Intensity }=\frac{R}{\left(R^{2}+G^{2}+B^{2}\right)^{1 / 2}} \quad \text { Equation } 1
$$

29. The $G A G$ Intensity will be recorded for each image slice. 


\section{Appendix B: Supplementary Material, Raw Data and Matlab Code}

\section{Meniscus Bio-chemical Review}

\section{Table B.1}

Review of previous research on glycosaminoglycans and proteoglycan content with meniscus

\begin{tabular}{|c|c|c|c|c|c|c|c|}
\hline Study & Analysis & $\begin{array}{c}\text { \# of } \\
\text { samples }\end{array}$ & $\begin{array}{l}\text { Meniscus } \\
\text { Location }\end{array}$ & & $\begin{array}{l}\text { Regions } \\
\text { Studied }\end{array}$ & Hyaluronate & $\begin{array}{l}\text { Chondroitin } \\
\text { Sulfate }\end{array}$ \\
\hline $\begin{array}{l}\text { (Adams, } \\
\text { et al., } \\
\text { 1987) }\end{array}$ & Histology & 4 & \multirow{3}{*}{ Medial } & & Body & 1.6 & 14.32 \\
\hline & & Canine & & & "Mixture" & 1.44 & 10.27 \\
\hline & & & & & $\%$ Change & -10.2 & -28.3 \\
\hline & & & \multirow{3}{*}{ Lateral } & & Body & 1.49 & 14.37 \\
\hline & & & & & "Mixture" & 1.44 & 10.1 \\
\hline & & & & & $\%$ Change & -5.6 & -39.5 \\
\hline Study & Analysis & $\begin{array}{c}\text { \# of } \\
\text { samples }\end{array}$ & $\begin{array}{l}\text { Meniscus } \\
\text { Location }\end{array}$ & $\begin{array}{l}\text { Regions } \\
\text { Studied }\end{array}$ & $\begin{array}{c}\text { Water } \\
\text { Content (\% } \\
\text { of wet wt.) }\end{array}$ & $\begin{array}{l}\text { Uronic } \\
\text { acid } \\
\text { ( } \mu \mathrm{g} / \mathrm{mg} \\
\text { dry wt.) }\end{array}$ & $\begin{array}{c}\text { Hexosamin } \\
\text { e ( } \mu \mathrm{g} / \mathrm{mg} \\
\text { dry wt.) }\end{array}$ \\
\hline $\begin{array}{c}\text { (Adams, } \\
\text { et al., } \\
\text { 1981) } \\
\end{array}$ & Histology & 5 & \multirow[t]{2}{*}{ Lateral } & Central & $63.1 \pm 1.2$ & $20.0 \pm 3.2$ & $17.6 \pm 2.2$ \\
\hline \multirow{3}{*}{\multicolumn{2}{|c|}{$\begin{array}{c}\mathrm{A}+\mathrm{P}=\text { Anterior }+ \\
\text { Posterior }\end{array}$}} & Canine & & $A+P$ & $63.8 \pm 0.9$ & $18.2 \pm 3.5$ & $16.0 \pm 3.2$ \\
\hline & & & \multirow{2}{*}{ Medial } & Central & $62.8 \pm 1.4$ & $10.2 \pm 2.0$ & $7.7 \pm 1.9$ \\
\hline & & & & $A+P$ & $63.5 \pm 1.4$ & $15.3 \pm 3.0$ & $12.5 \pm 2.6$ \\
\hline
\end{tabular}


Table B.1, continued

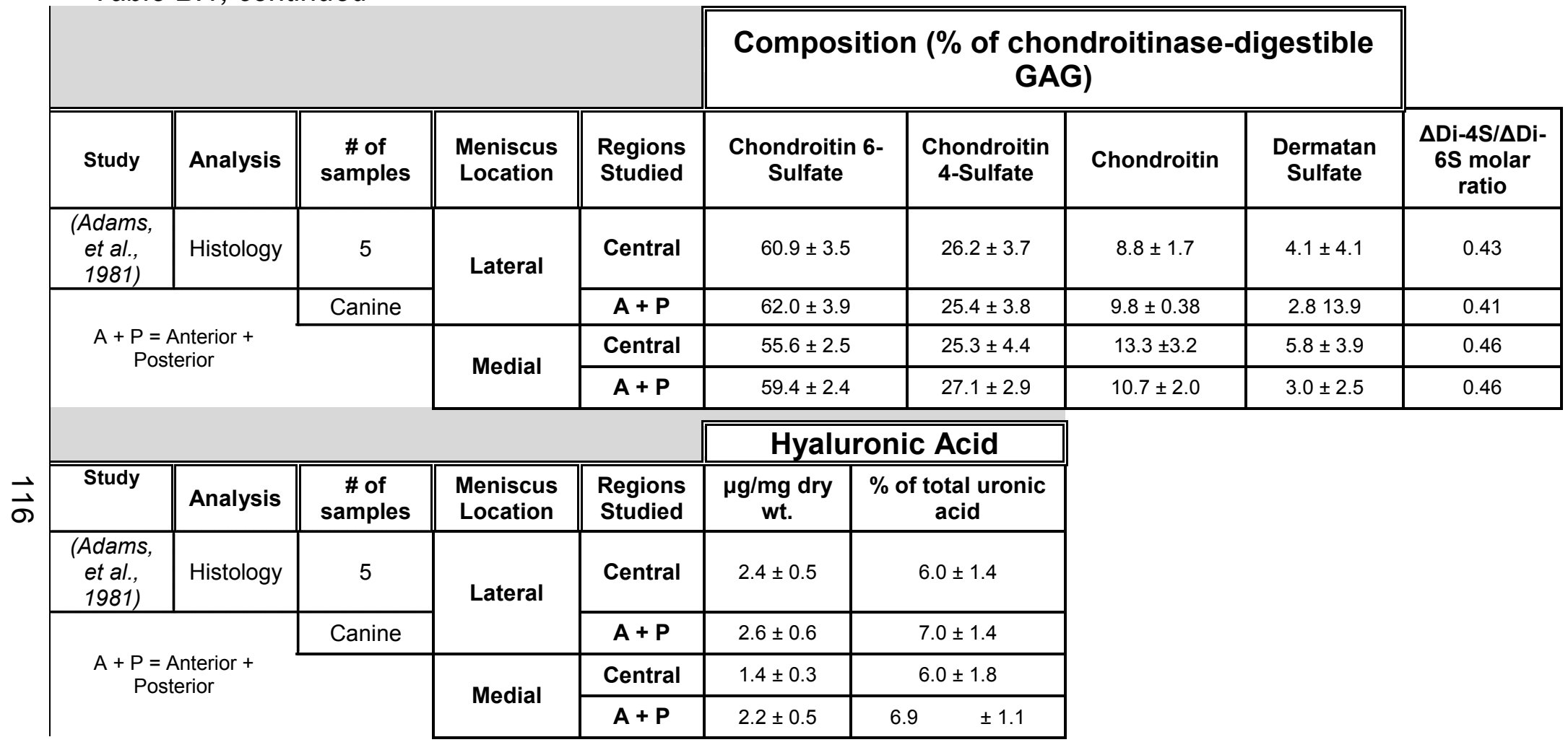




\section{Meniscus Mechanics Review}

Table B.2

Supplementary review of previous mechanical testing conducted on menisci

\begin{tabular}{|c|c|c|c|c|c|c|c|c|c|c|}
\hline Study & $\begin{array}{c}\text { Type of } \\
\text { test }\end{array}$ & $\begin{array}{c}\begin{array}{c}\# \text { of } \\
\text { sample } \\
\mathbf{s}\end{array}\end{array}$ & $\begin{array}{l}\text { Meniscus } \\
\text { Location }\end{array}$ & \multicolumn{3}{|c|}{ Surfaces Studied } & Regions Studied & $\begin{array}{l}\text { Stiffness } \\
(\mathrm{N} / \mathrm{mm})\end{array}$ & $\begin{array}{l}\text { Residual Force } \\
\text { (N) }\end{array}$ & $\begin{array}{l}\text { Indentation } \\
\text { Depth (mm) }\end{array}$ \\
\hline $\begin{array}{l}\text { Sandmann } \\
\text { et al. }\end{array}$ & Indentation & 5 & $\begin{array}{r}\mathrm{Mec} \\
\mathrm{La}\end{array}$ & \multicolumn{3}{|c|}{ Distal } & NA & $11.6-31.1$ & $1.0-3.0$ & 1.25 \\
\hline Study & \multicolumn{2}{|c|}{ Type of test } & $\begin{array}{c}\text { \# of } \\
\text { samples }\end{array}$ & \multicolumn{2}{|c|}{$\begin{array}{l}\text { Meniscus } \\
\text { Location }\end{array}$} & $\begin{array}{l}\text { Surfaces } \\
\text { Studied }\end{array}$ & $\begin{array}{l}\text { Regions } \\
\text { Studied }\end{array}$ & $\begin{array}{l}\text { Elastic Modulus } \\
\quad \pm \mathrm{SD}(\mathrm{MPa})\end{array}$ & & \\
\hline Fithian et al. & \multicolumn{2}{|c|}{ Uniaxial tension } & 56 & \multirow{3}{*}{\multicolumn{2}{|c|}{ Lateral }} & \multirow{3}{*}{ Deep Zone } & Anterior & $159.1 \pm 47.4$ & & \\
\hline & & & & & & & Central & $228.8 \pm 51.4$ & & \\
\hline & & & & & & & Posterior & $294.1 \pm 90.4$ & & \\
\hline & & & & \multirow{3}{*}{\multicolumn{2}{|c|}{ Medial }} & \multirow{3}{*}{ Deep Zone } & Anterior & $159.6 \pm 26.2$ & & \\
\hline & & & & & & & Central & $228.8 \pm 51.4$ & & \\
\hline & & & & & & & Posterior & $294.1 \pm 90.4$ & & \\
\hline
\end{tabular}




\begin{tabular}{|c|c|c|c|c|c|c|c|c|}
\hline Study & Type of test & $\begin{array}{c}\text { \# of } \\
\text { samples }\end{array}$ & $\begin{array}{c}\text { Testing } \\
\text { Orientation }\end{array}$ & $\begin{array}{l}\text { Meniscus } \\
\text { Location }\end{array}$ & $\begin{array}{l}\text { Regions } \\
\text { Studied }\end{array}$ & \multicolumn{3}{|c|}{ Elastic Modulus $\pm \mathrm{SD}(\mathrm{MPa})$} \\
\hline Tissakht et & Uniaxial tension & 31 & & & & \multicolumn{3}{|c|}{ Surface/Zone (Proximodistal Direction) } \\
\hline & & & & & & Proximal & Middle & Distal \\
\hline & & & \multirow{6}{*}{ Radial } & \multirow{3}{*}{ Lateral } & Anterior & $10.00 \pm 4.29$ & $4.07 \pm 1.86$ & $13.01 \pm 8.76$ \\
\hline & & & & & Central & $14.17 \pm 5.88$ & $10.14 \pm 4.65$ & $13.24 \pm 6.96$ \\
\hline & & & & & Posterior & $14.62 \pm 9.62$ & $4.21 \pm 1.26$ & $21.24 \pm 21.24$ \\
\hline & & & & \multirow{3}{*}{ Medial } & Anterior & $6.75 \pm 5.15$ & $3.59 \pm 1.43$ & $9.50 \pm 6.35$ \\
\hline & & & & & Central & $9.31 \pm 7.46$ & $5.60 \pm 2.23$ & $16.51 \pm 9.00$ \\
\hline & & & & & Posterior & $13.53 \pm 8.44$ & $2.03 \pm 0.54$ & $22.62 \pm 7.18$ \\
\hline & & & \multirow{6}{*}{ Circumferential } & \multirow{3}{*}{ Lateral } & Anterior & $124.58 \pm 39.51$ & $88.01 \pm 31.7$ & $112.23 \pm 29.77$ \\
\hline & & & & & Central & $91.37 \pm 23.04$ & $67.68 \pm 10.70$ & $151.80 \pm 44.7 \varepsilon$ \\
\hline & & & & & Posterior & $143.24 \pm 55.04$ & $95.80 \pm 46.83$ & $130.24 \pm 32.65$ \\
\hline & & & & \multirow{3}{*}{ Medial } & Anterior & $106.21 \pm 47.53$ & $79.86 \pm 24.90$ & $87.61 \pm 10.12$ \\
\hline & & & & & Central & $77.95 \pm 25.09$ & $57.97 \pm 19.82$ & $94.54 \pm 19.48$ \\
\hline & & & & & Posterior & $82.36 \pm 22.23$ & $80.72 \pm 23.95$ & $80.35 \pm 27.16$ \\
\hline Study & Type of test & $\begin{array}{l}\text { \# of } \\
\text { samples }\end{array}$ & $\begin{array}{l}\text { Meniscus } \\
\text { Location }\end{array}$ & $\begin{array}{l}\text { Regions } \\
\text { Studied }\end{array}$ & Treatment & $\begin{array}{l}\text { Young's } \\
\left.\text { Modulus ( } \mathrm{E}_{\mathrm{r}}\right) \\
\text { (MPa) }\end{array}$ & $\begin{array}{c}\text { Ultimate } \\
\text { Tensile } \\
\text { Strength (UTS) } \\
\text { (MPa) }\end{array}$ & $\begin{array}{c}\text { Toughness } \\
\left(\mathrm{J} / \mathrm{m}^{3}\right)\end{array}$ \\
\hline $\begin{array}{l}\text { Sanchez- } \\
\text { Adams et al }\end{array}$ & Uniaxial Tension & $\begin{array}{l}\text { Bovine, } \\
n=?\end{array}$ & \multirow{6}{*}{ Medial } & \multirow{2}{*}{ Outer } & Control & 95.00 & 40.00 & 19.00 \\
\hline \multirow{5}{*}{\multicolumn{3}{|c|}{$\begin{array}{l}\text { CABC }=\text { GAG depletion } \\
\text { Control = normal meniscus } \\
\text { \# represents a significant difference } \\
\text { between CABC and Control for } \\
\text { representative \% strain and region } \\
(p<0.05)\end{array}$}} & & & CABC & 110.00 & 45.00 & 20.00 \\
\hline & & & & \multirow{2}{*}{ Middle } & Control & 105.00 & 44.00 & 17.00 \\
\hline & & & & & CABC & 140.00 & 50.00 & 16.00 \\
\hline & & & & \multirow{2}{*}{ Inner } & Control & 90.00 & 31.00 & 9.00 \\
\hline & & & & & CABC & $135.00 \#$ & $46.00 \#$ & $16.00 \#$ \\
\hline
\end{tabular}




\section{Nanoindentation Results - Deep Zone vs. Superficial layer}

Table B.3

Comparison of nanoindentation results (Instantaneous Elastic Modulus) for deep zone and superficial layer of human meniscus. Superficial layer results included averaged proximal and distal surface values

\begin{tabular}{|c|c|c|c|c|c|c|}
\hline & \multicolumn{6}{|c|}{ Instantaneous Elastic Modulus [MPa] } \\
\hline & \multicolumn{2}{|c|}{ Anterior } & \multicolumn{2}{|c|}{ Central } & \multicolumn{2}{|c|}{ Posterior } \\
\hline & Deep & Surface & Deep & Surface & Deep & Surface \\
\hline Lateral & $3.43 \pm 0.30$ & $3.60 \pm 0.43$ & $3.22 \pm 0.33$ & $3.43 \pm 0.20$ & $3.64 \pm 0.28$ & $4.06 \pm 0.37$ \\
\hline Medial & $3.21 \pm 0.37$ & $4.12 \pm 0.43$ & $2.73 \pm 0.21$ & $3.70 \pm 0.33$ & $3.67 \pm 0.41$ & $3.17 \pm 0.18$ \\
\hline
\end{tabular}

Table B.4

Comparison of nanoindentation results (Steady-State Elastic Modulus) for deep zone and superficial layer of human meniscus. Superficial layer results included averaged proximal and distal surface values

\begin{tabular}{|c|c|c|c|c|c|c|}
\hline & \multicolumn{6}{|c|}{ Steady-State Elastic Modulus [MPa] } \\
\hline & \multicolumn{2}{|c|}{ Anterior } & \multicolumn{2}{|c|}{ Central } & \multicolumn{2}{|c|}{ Posterior } \\
\hline & Deep & Surface & Deep & Surface & Deep & Surface \\
\hline Lateral & $1.48 \pm 009$ & $1.52 \pm 0.12$ & $1.46 \pm 0.13$ & $1.63 \pm 0.09$ & $1.55 \pm 0.09$ & $1.69 \pm 0.12$ \\
\hline Medial & $1.40 \pm 0.08$ & $1.63 \pm 0.09$ & $1.30 \pm 0.07$ & $1.67 \pm 0.13$ & $1.33 \pm 0.09$ & $1.47 \pm 0.07$ \\
\hline
\end{tabular}




\section{Three-way Blocked ANOVA Matlab Code}

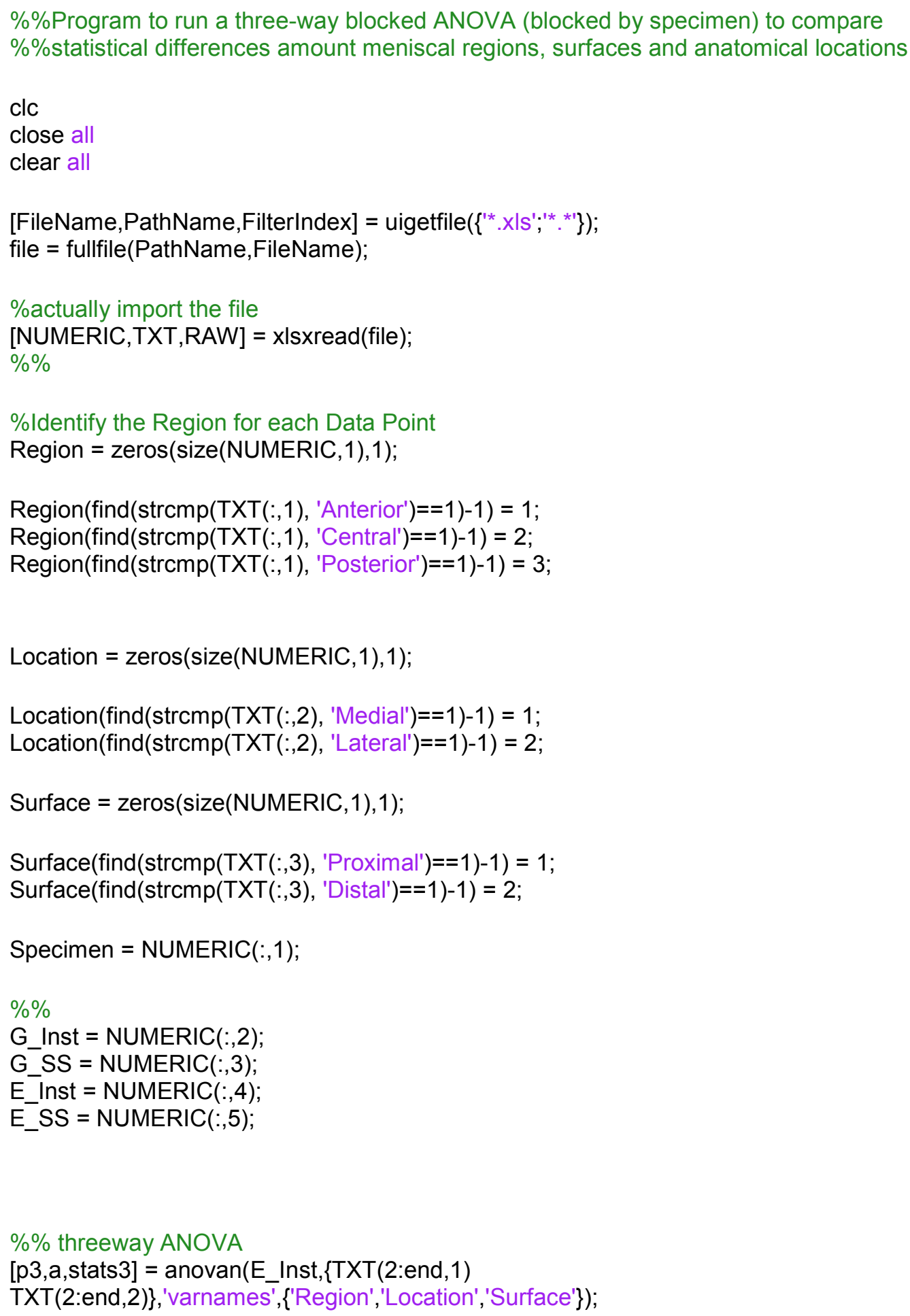


$\%[\mathrm{p} 3, \mathrm{a}$, stats3] $=$ anovan(E_SS, $\{\mathrm{TXT}(2$ :end, 1$) \operatorname{TXT}(2$ :end, 2$)$

TXT(2:end,3)\},'varnames',\{'Region','Location','Surface'\});

[cseas, mseas] = multcompare(stats3,'dimension',2);

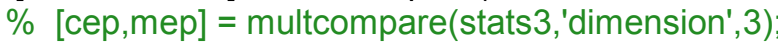

[c_region, $\mathrm{m} \_$region] $=$multcompare $($stats 3$)$; 


\section{Raw Data}

Table B.5: Raw data averages for each deep-zone meniscus nanoindentation

\begin{tabular}{|c|c|c|c|c|c|c|}
\hline Specimen & $\begin{array}{l}\text { Meniscal } \\
\text { Region }\end{array}$ & $\begin{array}{c}\text { Anatomical } \\
\text { Location }\end{array}$ & $\begin{array}{l}\text { Instant. } \\
\text { Shear } \\
\text { Modulus } \\
\text { (MPa) }\end{array}$ & $\begin{array}{c}\text { Steady-State } \\
\text { Shear } \\
\text { Modulus } \\
\text { (MPa) }\end{array}$ & $\begin{array}{l}\text { Instant. } \\
\text { Elastic } \\
\text { Modulus } \\
\text { (MPa) }\end{array}$ & $\begin{array}{l}\text { Steady- } \\
\text { State } \\
\text { Elastic } \\
\text { Modulus } \\
\text { (MPa) }\end{array}$ \\
\hline 3257 & Anterior & Lateral & 1.189 & 0.536 & 3.281 & 1.479 \\
\hline 3257 & Central & Lateral & 0.976 & 0.451 & 2.695 & 1.245 \\
\hline 3257 & Posterior & Lateral & 1.189 & 0.522 & 3.281 & 1.441 \\
\hline 3257 & Anterior & Medial & 1.288 & 0.567 & 3.555 & 1.566 \\
\hline 3257 & Central & Medial & 0.937 & 0.459 & 2.587 & 1.266 \\
\hline 3257 & Posterior & Medial & 1.115 & 0.499 & 3.077 & 1.377 \\
\hline 3265 & Anterior & Lateral & 1.256 & 0.533 & 3.465 & 1.471 \\
\hline 3265 & Posterior & Lateral & 1.221 & 0.503 & 3.369 & 1.387 \\
\hline 3265 & Anterior & Medial & 1.280 & 0.565 & 3.532 & 1.558 \\
\hline 3265 & Posterior & Medial & 2.064 & 0.400 & 5.696 & 1.104 \\
\hline 3341 & Anterior & Lateral & 0.820 & 0.425 & 2.262 & 1.174 \\
\hline 3341 & Central & Lateral & 0.973 & 0.514 & 2.685 & 1.419 \\
\hline 3341 & Posterior & Lateral & 1.707 & 0.694 & 4.712 & 1.916 \\
\hline 3341 & Anterior & Medial & 0.757 & 0.417 & 2.090 & 1.152 \\
\hline 3341 & Central & Medial & 0.946 & 0.467 & 2.612 & 1.288 \\
\hline 3341 & Posterior & Medial & 1.073 & 0.336 & 2.961 & 0.928 \\
\hline 3345 & Anterior & Lateral & 0.850 & 0.399 & 2.347 & 1.101 \\
\hline 3345 & Central & Lateral & 0.895 & 0.421 & 2.470 & 1.163 \\
\hline 3345 & Posterior & Lateral & 0.956 & 0.451 & 2.638 & 1.246 \\
\hline 3345 & Anterior & Medial & 0.824 & 0.411 & 2.275 & 1.134 \\
\hline 3345 & Central & Medial & 1.207 & 0.555 & 3.331 & 1.533 \\
\hline 3345 & Posterior & Medial & 1.014 & 0.488 & 2.799 & 1.348 \\
\hline 61723 & Anterior & Lateral & 1.487 & 0.602 & 4.104 & 1.661 \\
\hline 61723 & Central & Lateral & 1.656 & 0.743 & 4.569 & 2.051 \\
\hline 61723 & Posterior & Lateral & 1.280 & 0.636 & 3.532 & 1.755 \\
\hline 61723 & Anterior & Medial & 1.034 & 0.513 & 2.854 & 1.415 \\
\hline
\end{tabular}


Table B.5, continued

\begin{tabular}{|c|c|c|c|c|c|c|}
\hline 61723 & Central & Medial & 1.200 & 0.521 & 3.312 & 1.438 \\
\hline 61723 & Posterior & Medial & 0.976 & 0.460 & 2.693 & 1.269 \\
\hline 61756 & Anterior & Lateral & 1.541 & 0.619 & 4.254 & 1.708 \\
\hline 61756 & Central & Lateral & 1.352 & 0.522 & 3.733 & 1.440 \\
\hline 61756 & Posterior & Lateral & 1.182 & 0.548 & 3.262 & 1.511 \\
\hline 61756 & Anterior & Medial & 1.231 & 0.507 & 3.397 & 1.400 \\
\hline 61756 & Central & Medial & 0.746 & 0.369 & 2.060 & 1.017 \\
\hline 61756 & Posterior & Medial & 1.901 & 0.582 & 5.248 & 1.605 \\
\hline 61809 & Anterior & Lateral & 1.169 & 0.522 & 3.225 & 1.440 \\
\hline 61809 & Posterior & Lateral & 1.807 & 0.665 & 4.988 & 1.836 \\
\hline 61809 & Anterior & Medial & 0.939 & 0.448 & 2.592 & 1.237 \\
\hline 61809 & Posterior & Medial & 1.277 & 0.639 & 3.526 & 1.763 \\
\hline 61848 & Anterior & Lateral & 1.636 & 0.661 & 4.515 & 1.824 \\
\hline 61848 & Central & Lateral & 1.141 & 0.520 & 3.148 & 1.435 \\
\hline 61848 & Posterior & Lateral & 1.198 & 0.465 & 3.308 & 1.283 \\
\hline 61848 & Anterior & Medial & 1.941 & 0.631 & 5.358 & 1.742 \\
\hline 61848 & Central & Medial & 0.886 & 0.446 & 2.447 & 1.230 \\
\hline 61848 & Posterior & Medial & 1.214 & 0.446 & 3.352 & 1.230 \\
\hline
\end{tabular}

Table B.6: Raw data averages for each meniscal surface nanoindentation

\begin{tabular}{|c|c|c|c|c|c|c|c|}
\hline Specimen & $\begin{array}{l}\text { Meniscal } \\
\text { Region }\end{array}$ & $\begin{array}{l}\text { Anatomical } \\
\text { Location }\end{array}$ & $\begin{array}{l}\text { Meniscal } \\
\text { Surface }\end{array}$ & $\begin{array}{l}\text { Instant. } \\
\text { Shear } \\
\text { Modulus } \\
\text { (MPa) }\end{array}$ & $\begin{array}{l}\text { Steady- } \\
\text { State } \\
\text { Shear } \\
\text { Modulus } \\
\text { (MPa) }\end{array}$ & $\begin{array}{l}\text { Instant. } \\
\text { Elastic } \\
\text { Modulus } \\
\text { (MPa) }\end{array}$ & $\begin{array}{l}\text { Steady- } \\
\text { State } \\
\text { Elastic } \\
\text { Modulus } \\
\text { (MPa) }\end{array}$ \\
\hline 3257 & Anterior & Lateral & Distal & 2.486 & 0.906 & 6.861 & 2.500 \\
\hline 3257 & Anterior & Lateral & Proximal & 1.594 & 0.661 & 4.399 & 1.828 \\
\hline 3257 & Anterior & Medial & Distal & 1.242 & 0.556 & 3.429 & 1.534 \\
\hline 3257 & Anterior & Medial & Proximal & 0.993 & 0.481 & 2.741 & 1.309 \\
\hline 3265 & Anterior & Lateral & Proximal & 0.910 & 0.515 & 2.437 & 1.627 \\
\hline 3265 & Anterior & Medial & Distal & 1.625 & 0.585 & 4.484 & 1.615 \\
\hline 3265 & Anterior & Medial & Proximal & 1.364 & 0.615 & 3.766 & 1.696 \\
\hline 3341 & Anterior & Lateral & Distal & 0.835 & 0.383 & 2.304 & 1.057 \\
\hline 3341 & Anterior & Lateral & Proximal & 0.575 & 0.319 & 1.586 & 0.881 \\
\hline 3341 & Anterior & Medial & Distal & 1.190 & 0.561 & 3.283 & 1.548 \\
\hline
\end{tabular}


Table B.6, continued

\begin{tabular}{|c|c|c|c|c|c|c|c|}
\hline 3341 & Anterior & Medial & Proximal & 1.571 & 0.679 & 4.337 & 1.875 \\
\hline 3345 & Anterior & Lateral & Distal & 1.640 & 0.639 & 4.527 & 1.764 \\
\hline 3345 & Anterior & Lateral & Proximal & 1.067 & 0.451 & 2.944 & 1.245 \\
\hline 3345 & Anterior & Medial & Distal & 1.195 & 0.434 & 3.298 & 1.197 \\
\hline 3345 & Anterior & Medial & Proximal & 2.094 & 0.729 & 5.780 & 2.012 \\
\hline 61723 & Anterior & Lateral & Distal & 2.381 & 0.784 & 6.568 & 2.164 \\
\hline 61723 & Anterior & Lateral & Proximal & 1.049 & 0.476 & 2.895 & 1.312 \\
\hline 61723 & Anterior & Medial & Distal & 3.025 & 0.974 & 8.349 & 2.687 \\
\hline 61723 & Anterior & Medial & Proximal & 2.680 & 0.727 & 7.396 & 2.007 \\
\hline 61756 & Anterior & Lateral & Distal & 1.882 & 0.691 & 5.194 & 1.908 \\
\hline 61756 & Anterior & Lateral & Proximal & 1.599 & 0.633 & 4.412 & 1.746 \\
\hline 61756 & Anterior & Medial & Distal & 0.884 & 0.457 & 2.441 & 1.260 \\
\hline 61756 & Anterior & Medial & Proximal & 1.401 & 0.502 & 3.867 & 1.385 \\
\hline 61809 & Anterior & Lateral & Distal & 1.115 & 0.488 & 3.077 & 1.346 \\
\hline 61809 & Anterior & Lateral & Proximal & 1.062 & 0.477 & 2.931 & 1.317 \\
\hline 61809 & Anterior & Medial & Distal & 0.874 & 0.450 & 2.411 & 1.242 \\
\hline 61809 & Anterior & Medial & Proximal & 1.154 & 0.553 & 3.185 & 1.527 \\
\hline 61848 & Anterior & Lateral & Distal & 0.629 & 0.369 & 1.737 & 1.017 \\
\hline 61848 & Anterior & Lateral & Proximal & 0.735 & 0.405 & 2.029 & 1.119 \\
\hline 61848 & Anterior & Medial & Proximal & 1.410 & 0.630 & 3.892 & 1.749 \\
\hline 61848 & Anterior & Medial & Distal & 1.191 & 0.513 & 3.247 & 1.414 \\
\hline 3257 & Central & Lateral & Distal & 1.694 & 0.652 & 4.707 & 1.799 \\
\hline 3257 & Central & Lateral & Proximal & 1.183 & 0.579 & 3.266 & 1.597 \\
\hline 3257 & Central & Medial & Distal & 1.142 & 0.478 & 3.151 & 1.318 \\
\hline 3257 & Central & Medial & Proximal & 1.025 & 0.477 & 2.829 & 1.316 \\
\hline 3265 & Central & Lateral & Distal & 0.911 & 0.470 & 2.515 & 1.297 \\
\hline 3265 & Central & Lateral & Proximal & 1.014 & 0.518 & 2.799 & 1.429 \\
\hline 3265 & Central & Medial & Distal & 1.223 & 0.532 & 3.676 & 1.468 \\
\hline 3265 & Central & Medial & Proximal & 1.668 & 0.644 & 4.605 & 1.779 \\
\hline 3341 & Central & Lateral & Distal & 1.228 & 0.591 & 3.389 & 1.631 \\
\hline 3341 & Central & Lateral & Proximal & 1.149 & 0.517 & 3.170 & 1.426 \\
\hline 3341 & Central & Medial & Distal & 1.787 & 0.826 & 4.640 & 2.280 \\
\hline
\end{tabular}


Table B.6, continued

\begin{tabular}{|c|c|c|c|c|c|c|c|}
\hline 3341 & Central & Medial & Proximal & 1.195 & 0.614 & 3.298 & 1.695 \\
\hline 3345 & Central & Lateral & Proximal & 1.238 & 0.529 & 3.418 & 1.460 \\
\hline 3345 & Central & Lateral & Distal & 1.622 & 0.800 & 4.478 & 2.207 \\
\hline 3345 & Central & Medial & Distal & 2.280 & 0.920 & 6.291 & 2.539 \\
\hline 3345 & Central & Medial & Proximal & 0.780 & 0.380 & 2.153 & 1.048 \\
\hline 61723 & Central & Lateral & Distal & 1.602 & 0.810 & 4.422 & 2.234 \\
\hline 61723 & Central & Lateral & Proximal & 1.715 & 0.848 & 4.735 & 2.341 \\
\hline 61723 & Central & Medial & Distal & 1.711 & 0.769 & 4.723 & 2.122 \\
\hline 61723 & Central & Medial & Proximal & 1.969 & 0.849 & 5.436 & 2.344 \\
\hline 61756 & Central & Lateral & Distal & 0.858 & 0.444 & 2.367 & 1.226 \\
\hline 61756 & Central & Lateral & Proximal & 0.942 & 0.488 & 2.600 & 1.346 \\
\hline 61756 & Central & Medial & Distal & 0.858 & 0.444 & 2.367 & 1.226 \\
\hline 61809 & Central & Lateral & Distal & 1.271 & 0.534 & 3.507 & 1.479 \\
\hline 61809 & Central & Lateral & Proximal & 1.402 & 0.654 & 3.869 & 1.806 \\
\hline 61809 & Central & Medial & Proximal & 1.092 & 0.518 & 3.020 & 1.429 \\
\hline 61848 & Central & Lateral & Distal & 0.877 & 0.460 & 2.422 & 1.269 \\
\hline 61848 & Central & Lateral & Proximal & 1.182 & 0.524 & 3.261 & 1.447 \\
\hline 61848 & Central & Medial & Proximal & 1.068 & 0.510 & 2.947 & 1.408 \\
\hline 61848 & Central & Medial & Distal & 0.964 & 0.513 & 2.661 & 1.416 \\
\hline 3257 & Posterior & Lateral & Distal & 1.427 & 0.612 & 3.938 & 1.690 \\
\hline 3257 & Posterior & Lateral & Proximal & 1.195 & 0.540 & 3.298 & 1.490 \\
\hline 3257 & Posterior & Medial & Distal & 0.542 & 0.313 & 1.496 & 0.863 \\
\hline 3257 & Posterior & Medial & Proximal & 1.432 & 0.654 & 3.952 & 1.805 \\
\hline 3265 & Posterior & Lateral & Distal & 1.797 & 0.781 & 4.961 & 2.155 \\
\hline 3265 & Posterior & Lateral & Proximal & 1.260 & 0.539 & 3.478 & 1.487 \\
\hline 3265 & Posterior & Medial & Distal & 1.060 & 0.500 & 2.926 & 1.379 \\
\hline 3265 & Posterior & Medial & Proximal & 0.973 & 0.478 & 2.685 & 1.321 \\
\hline 3341 & Posterior & Lateral & Distal & 1.192 & 0.516 & 3.290 & 1.424 \\
\hline 3341 & Posterior & Lateral & Proximal & 1.004 & 0.506 & 2.770 & 1.397 \\
\hline 3341 & Posterior & Medial & Proximal & 1.385 & 0.697 & 3.824 & 1.924 \\
\hline 3345 & Posterior & Lateral & Distal & 2.739 & 0.864 & 7.558 & 2.385 \\
\hline 3345 & Posterior & Lateral & Proximal & 1.130 & 0.517 & 3.120 & 1.427 \\
\hline
\end{tabular}


Table B.6, continued

\begin{tabular}{|c|c|c|c|c|c|c|c|}
\hline 3345 & Posterior & Medial & Distal & 1.006 & 0.496 & 2.775 & 1.368 \\
\hline 3345 & Posterior & Medial & Proximal & 1.327 & 0.585 & 3.661 & 1.615 \\
\hline 61723 & Posterior & Lateral & Distal & 2.596 & 1.076 & 7.164 & 2.969 \\
\hline 61723 & Posterior & Lateral & Proximal & 1.804 & 0.712 & 4.979 & 1.964 \\
\hline 61723 & Posterior & Medial & Distal & 1.224 & 0.569 & 3.378 & 1.571 \\
\hline 61723 & Posterior & Medial & Proximal & 1.258 & 0.505 & 3.471 & 1.394 \\
\hline 61756 & Posterior & Lateral & Distal & 1.032 & 0.487 & 2.849 & 1.345 \\
\hline 61756 & Posterior & Lateral & Proximal & 1.382 & 0.552 & 3.815 & 1.524 \\
\hline 61756 & Posterior & Medial & Distal & 1.070 & 0.467 & 2.954 & 1.290 \\
\hline 61809 & Posterior & Lateral & Distal & 1.368 & 0.519 & 3.776 & 1.432 \\
\hline 61809 & Posterior & Lateral & Proximal & 1.506 & 0.616 & 4.157 & 1.701 \\
\hline 61809 & Posterior & Medial & Distal & 1.222 & 0.548 & 3.372 & 1.513 \\
\hline 61809 & Posterior & Medial & Proximal & 1.364 & 0.607 & 3.765 & 1.677 \\
\hline 61848 & Posterior & Lateral & Distal & 1.091 & 0.478 & 3.011 & 1.319 \\
\hline 61848 & Posterior & Lateral & Proximal & 1.005 & 0.489 & 2.774 & 1.351 \\
\hline 61848 & Posterior & Medial & Distal & 1.075 & 0.490 & 2.966 & 1.353 \\
\hline
\end{tabular}

Table B.7: Raw data from quantitative histological analysis measuring GAG fraction Intensity

\begin{tabular}{|c|c|c|c|}
\hline Specimen & $\begin{array}{l}\text { Anatomical } \\
\text { Location }\end{array}$ & $\begin{array}{l}\text { Meniscal } \\
\text { Region }\end{array}$ & $\begin{array}{c}\text { GAG } \\
\text { Intensity } \\
\text { Fraction }\end{array}$ \\
\hline 3257 & Lateral & Anterior & 0.659 \\
\hline 3257 & Lateral & Central & 0.640 \\
\hline 3257 & Lateral & Posterior & 0.655 \\
\hline 3257 & Medial & Anterior & 0.572 \\
\hline 3257 & Medial & Central & 0.651 \\
\hline 3257 & Medial & Posterior & 0.593 \\
\hline 3341 & Lateral & Anterior & 0.649 \\
\hline 3341 & Lateral & Central & 0.734 \\
\hline 3341 & Lateral & Posterior & 0.623 \\
\hline
\end{tabular}


Table B.7, continued

\begin{tabular}{|c|c|c|c|}
\hline 3341 & Medial & Anterior & 0.579 \\
\hline 3341 & Medial & Posterior & 0.605 \\
\hline 3341 & Medial & Central & 0.586 \\
\hline 3345 & Lateral & Anterior & 0.634 \\
\hline 3345 & Lateral & Central & 0.604 \\
\hline 3345 & Lateral & Posterior & 0.574 \\
\hline 3345 & Medial & Anterior & 0.660 \\
\hline 3345 & Medial & Central & 0.723 \\
\hline 3345 & Medial & Posterior & 0.666 \\
\hline 61756 & Lateral & Anterior & 0.604 \\
\hline 61756 & Lateral & Central & 0.581 \\
\hline 61756 & Lateral & Posterior & 0.555 \\
\hline 61756 & Medial & Anterior & 0.582 \\
\hline 61756 & Medial & Central & 0.587 \\
\hline 61756 & Medial & Posterior & 0.563 \\
\hline 61848 & Lateral & Anterior & 0.663 \\
\hline 61848 & Lateral & Central & 0.668 \\
\hline 61848 & Lateral & Posterior & 0.587 \\
\hline 61848 & Medial & Anterior & 0.653 \\
\hline 61848 & Medial & Central & 0.618 \\
\hline 61848 & Medial & Posterior & 0.590 \\
\hline
\end{tabular}

Table B.8: Raw data from quantitative histological analysis measuring distance from meniscal surface to GAG content

\begin{tabular}{||c||c||c||c|c||}
\hline \multicolumn{1}{||c||}{ Specimen } & Location & Region & \multicolumn{2}{|c|}{ Average Superficial Thickness } \\
\hline \hline & & & Proximal & Distal \\
\hline \hline 3257 & Lateral & Anterior & 400.36 & 481.33 \\
\hline \hline 3257 & Medial & Anterior & 1010.32 & 708.00 \\
\hline \hline 3257 & Lateral & Central & 736.00 & 813.85 \\
\hline \hline 3257 & Ledial & Central & 701.82 & 1393.95 \\
\hline \hline 3257 & Medial & Posterior & 781.70 & 576.41 \\
\hline \hline
\end{tabular}


Table B.8, continued

\begin{tabular}{|c|c|c|c|c|}
\hline 3341 & Lateral & Anterior & 813.13 & 964.31 \\
\hline 3341 & Medial & Anterior & 1284.51 & 890.97 \\
\hline 3341 & Lateral & Central & 574.26 & 805.56 \\
\hline 3341 & Medial & Central & 1021.43 & 1181.28 \\
\hline 3341 & Lateral & Posterior & 865.61 & 642.72 \\
\hline 3341 & Medial & Posterior & 1242.00 & 1619.78 \\
\hline 3345 & Lateral & Anterior & 741.86 & 684.50 \\
\hline 3345 & Medial & Anterior & 517.57 & 501.07 \\
\hline 3345 & Lateral & Central & 713.58 & 816.23 \\
\hline 3345 & Medial & Central & 693.26 & 1222.35 \\
\hline 3345 & Lateral & Posterior & 541.64 & 529.51 \\
\hline 3345 & Medial & Posterior & 512.93 & 1302.62 \\
\hline 61756 & Lateral & Anterior & 751.48 & 805.67 \\
\hline 61756 & Medial & Anterior & 807.84 & 1093.68 \\
\hline 61756 & Lateral & Central & 932.64 & 820.26 \\
\hline 61756 & Medial & Central & 1252.52 & 1263.76 \\
\hline 61756 & Lateral & Posterior & 888.71 & 506.31 \\
\hline 61756 & Medial & Posterior & 1751.02 & 959.87 \\
\hline 61848 & Lateral & Anterior & 508.35 & 708.94 \\
\hline 61848 & Medial & Anterior & 881.16 & 726.64 \\
\hline 61848 & Lateral & Central & 855.74 & 599.41 \\
\hline 61848 & Medial & Central & 813.07 & 391.02 \\
\hline 61848 & Lateral & Posterior & 1048.34 & 655.94 \\
\hline 61848 & Medial & Posterior & 883.64 & 757.16 \\
\hline
\end{tabular}


Table B.9: Raw data from quantitative histological analysis measuring ratio of GAG area to meniscal cross-sectional area

\begin{tabular}{|c|c|c|c|}
\hline Specimen & $\begin{array}{l}\text { Anatomical } \\
\text { Location }\end{array}$ & $\begin{array}{l}\text { Meniscal } \\
\text { Region }\end{array}$ & $\begin{array}{c}\text { GAG-to- } \\
\text { Meniscal Area } \\
\text { Ratio }\end{array}$ \\
\hline 3257 & Lateral & Anterior & 0.680 \\
\hline 3341 & Lateral & Anterior & 0.527 \\
\hline 3345 & Lateral & Anterior & 0.614 \\
\hline 61756 & Lateral & Anterior & 0.478 \\
\hline 61848 & Lateral & Anterior & 0.690 \\
\hline 3341 & Medial & Anterior & 0.364 \\
\hline 3345 & Medial & Anterior & 0.715 \\
\hline 61756 & Medial & Anterior & 0.482 \\
\hline 61848 & Medial & Anterior & 0.466 \\
\hline 3257 & Medial & Anterior & 0.456 \\
\hline 3257 & Lateral & Central & 0.500 \\
\hline 3341 & Lateral & Central & 0.838 \\
\hline 3345 & Lateral & Central & 0.564 \\
\hline 61756 & Lateral & Central & 0.313 \\
\hline 61848 & Lateral & Central & 0.672 \\
\hline 3257 & Medial & Central & 0.563 \\
\hline 3341 & Medial & Central & 0.285 \\
\hline 3345 & Medial & Central & 0.555 \\
\hline 61756 & Medial & Central & 0.238 \\
\hline 61848 & Medial & Central & 0.673 \\
\hline 3257 & Lateral & Posterior & 0.540 \\
\hline 3341 & Lateral & Posterior & 0.477 \\
\hline 3345 & Lateral & Posterior & 0.299 \\
\hline 61756 & Lateral & Posterior & 0.585 \\
\hline 61848 & Lateral & Posterior & 0.576 \\
\hline 3257 & Medial & Posterior & 0.434 \\
\hline 3341 & Medial & Posterior & 0.445 \\
\hline 3345 & Medial & Posterior & 0.720 \\
\hline
\end{tabular}


Table B.9, continued

\begin{tabular}{||c||c||c||c|}
61756 & Medial & Posterior & 0.176 \\
\hline \hline 61848 & Medial & Posterior & 0.485 \\
\hline
\end{tabular}




\section{Appendix C: Copyright Clearance}

\section{Copyright Permission (Figure 1.1)}

You are welcome to it!

David K. Thomas PT

Owner

From: John Moyer <jtmoyer@mtu.edu>;

To: <eldoradopt@yahoo.com>;

Subject: Contact: Using information from Website for Thesis

Sent: Sun, Mar 18, 2012 5:52:31 PM

To: Webmaster

From:

John Moyer

itmoyer@mtu.edu

Message:

I am not sure if this is the proper contact site for this question, but I will start here. I am interested in using a figure from your website (schematic of the human knee, with a blown up view of the menisci and ligaments) for my masters thesis. How would I go about getting permission for this? Thank you!

Akismet Spam Check: passed

Sent from (ip address): 141.219.26.139 (e20-1004-01.coe.ad.mtu.edu) Date/Time:

Coming from (referer): http://www.eldoradopt.com/locations

Using (user agent): Mozilla/5.0 (Windows NT 5.1) AppleWebKit/535.11

(KHTML, like Gecko) Chrome/17.0.963.79 Safari/535.11 


\title{
Copyright Permission (Figure 1.2)
}

\author{
SPRINGER LICENSE \\ TERMS AND CONDITIONS
}

Apr 21, 2012

This is a License Agreement between John T Moyer ("You") and Springer ("Springer") provided by Copyright Clearance Center ("CCC"). The license consists of your order details, the terms and conditions provided by Springer, and the payment terms and conditions.

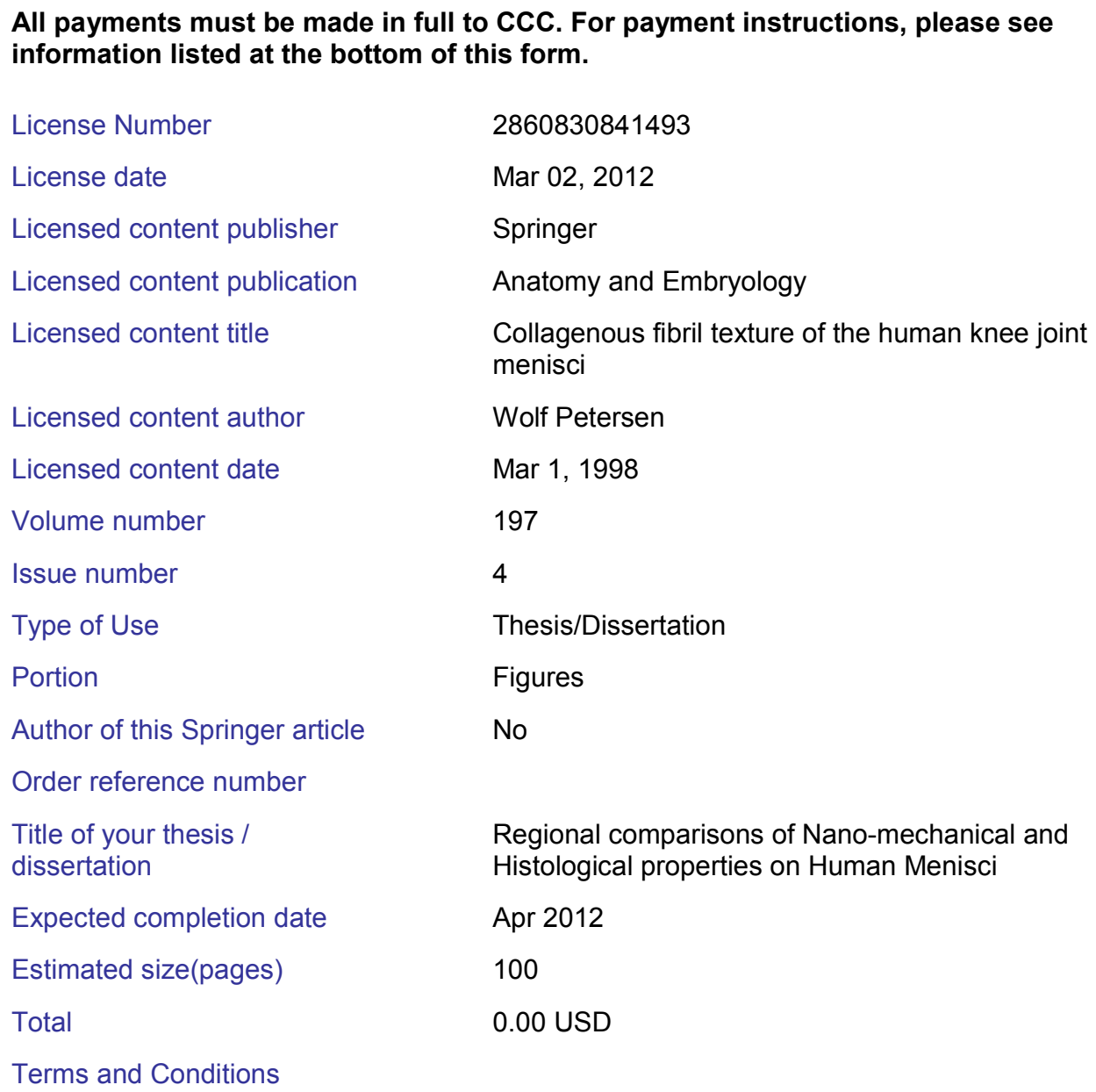




\section{Introduction}

The publisher for this copyrighted material is Springer Science + Business Media. By clicking "accept" in connection with completing this licensing transaction, you agree that the following terms and conditions apply to this transaction (along with the Billing and Payment terms and conditions established by Copyright Clearance Center, Inc. ("CCC"), at the time that you opened your Rightslink account and that are available at any time at http://myaccount.copyright.com).

\section{Terms and Conditions That Apply to All Transactions:}

1. This digital licensing and reprint service enables you, the "User", to obtain licenses to make certain uses of the online content of many copyright holders (each a "Rightsholder"). Licenses granted through this service are granted by the Rightsholder in the content for which you are seeking a license and from whose Website (containing the content) you reached this service. This service is administered by Copyright Clearance Center, Inc. ("CCC") and your use of the content is governed by these terms and conditions, BUT your use will ALSO be governed by the terms and conditions which are set individually by the Rightsholder whose material you seek to use; the Rightsholder's terms and conditions will be made available to you in the course of the licensing process for each transaction. You, as User, will be deemed to have accepted and agreed to all of those terms and conditions, as well as these terms and conditions, if you use the Rightsholder's copyrighted material in any fashion. CCC reserves the right to send electronic mail to you for the purpose of informing you of changes or additions to this service.

2. User hereby acknowledges and agrees that User is responsible for any transaction entered into through this digital licensing and reprint service and identified with User's user name and password (if on account) or User's credit card information (if by credit card). It is User's responsibility to maintain the secrecy of such information, to notify CCC immediately upon learning of any transaction entered into through this service that was done so without User's authorization, and to use the appropriate automated services within this digital licensing and reprint service to alter passwords and standing payment information whenever necessary to preserve secrecy. User represents and warrants that User is at least 18 years old if User is a person (as opposed to a company or other organization); that in any event User is legally capable in User's place of residence or business of entering into the agreement created by these terms and conditions and Rightsholder's terms and conditions; and that the individual opening an account or seeking transactions under this digital licensing and reprint service on behalf of any User that is a business, corporate entity or other organization is duly authorized by User to do so.

3. Use of User-related information collected by this licensing service is governed by CCC's privacy policy. CCC's privacy policy is accessible through CCC's website www.copyright.comand from numerous locations throughout the 
webpages comprising this licensing service.

4. As among User, CCC and the Rightsholder, all materials available for licensing, as well as all rights therein, including copyright rights, remain the sole and exclusive property of the Rightsholder. All trademarks not belonging to the Rightsholder, as well as all software and other elements that you encounter in the course of using this digital licensing and reprint service, as well as all intellectual property rights therein, remain the sole and exclusive property of $\mathrm{CCC}$ and are not licensed to User in any way. While User may exercise the rights licensed immediately upon issuance of the license at the end of the licensing process for the transaction, the license is automatically revoked, and is null and void as if it had never been issued, if complete payment for the license is not received on a timely basis either from User directly or through a payment agent, such as a credit card company. All rights not expressly granted are reserved; any license granted may be further limited (on a Work-byWork basis) as set forth in any restrictions included in the Rightsholder's terms and conditions applicable to the transaction (which will be provided at the end of the licensing process, at User's option, on paper or electronically).

5. User hereby indemnifies and agrees to defend CCC and its employees, agents, representatives, officers and directors, against all claims, liability, damages, costs and expenses, including legal fees and expenses, arising out of any use of licensed material beyond the scope of the rights granted, or any use of any licensed material which has been altered in any way by User, including claims for defamation or infringement of or damage to rights of copyright, publicity, privacy or other tangible or intangible property.As a digital licensing and reprint service on behalf of the Rightsholders, CCC has no duty to indemnify User. Notice of such indemnification as may be available can be found in the Terms and Conditions of the individual Rightsholders.

6. LIMITATION OF LIABILITY OF CCC. UNDER NO CIRCUMSTANCES WILL CCC BE LIABLE FOR ANY DIRECT, INDIRECT, CONSEQUENTIAL OR INCIDENTAL DAMAGES (INCLUDING WITHOUT LIMITATION DAMAGES FOR LOSS OF BUSINESS PROFITS OR INFORMATION, OR FOR BUSINESS INTERRUPTION) ARISING OUT OF (i) THE USE OR INABILITY TO USE ANY LICENSED MATERIAL OR (ii) THE INABILITY TO OBTAIN ADDITIONAL RIGHTS TO LICENSED MATERIALS, EVEN IF CCC HAS BEEN ADVISED OF THE POSSIBILITY OF SUCH DAMAGES. In any event, the total liability of CCC (including its employees, agents, representatives, officers and directors) shall not exceed the total amount actually paid by User for the applicable license. User assumes full liability for the actions and omissions of its principals, employees, agents, affiliates, successors and assigns.

7. NO WARRANTIES FROM CCC. CCC DISCLAIMS ALL WARRANTIES RELATING TO THE COPYRIGHTED MATERIALS OF RIGHTSHOLDER, EITHER EXPRESS OR IMPLIED, INCLUDING WITHOUT LIMITATION IMPLIED WARRANTIES OF MERCHANTABILITY OR FITNESS FOR A PARTICULAR PURPOSE. IN ADDITION, THIS LICENSING SERVICE AND ALL SOFTWARE USED IN CONNECTION THEREWITH ARE DISTRIBUTED ON AN "AS IS" BASIS WITHOUT WARRANTIES OF ANY KIND, EITHER EXPRESS OR IMPLIED, INCLUDING, WITHOUT LIMITATION, WARRANTIES OF TITLE OR IMPLIED WARRANTIES OF MERCHANTABILITY OR FITNESS FOR A PARTICULAR PURPOSE. USER HEREBY ACKNOWLEDGES THAT USE OF THE SERVICE IS 


\section{AT USER'S SOLE RISK.}

8. (a) The term "License Grant" is used in these terms and conditions to describe (i) the entire set of details (including User's name as licensee, the nature of the use for which User seeks a license, and the price of the license), as well as (ii) the Rightsholder's terms and conditions applicable to that licensing transaction and governing the particular use User may make of that copyrighted material, and (iii) CCC's general terms and conditions relating to billing and payment that are applicable to ALL transactions. All elements of the License Grant are printed out or referred to in the license document that is delivered to User at the conclusion of each transaction under this digital licensing and reprint service, and are generally available within the service's Website at any time.

(b) Any failure by User to pay any amount when due, or any use by User of any licensed material beyond the scope of the License Grant, shall be a material breach of the License Grant. Any breach not cured within ten (10) days of notice thereof shall result in immediate termination of such license without further notice. Invoices are due and payable upon their delivery to User (or upon CCC's notice to User that they are available to User for downloading from the Internet); amounts overdue will be subject to a service charge of $1-1 / 2 \%$ per month or, if less, the maximum interest rate allowed by applicable law in User's place of business, such service charge to begin running 30 days after delivery of, or notice of availability of, invoice.

9. CCC hereby objects to any terms contained in any writing prepared by User or its principals, employees, agents or affiliates and purporting to govern or otherwise relate to any licensing transaction, which terms are in any way inconsistent with any of these terms or the Rightsholder's standard terms or with any standard operating procedures of Rightsholder or CCC, whether such writing is prepared prior to, simultaneously with or subsequent to the License Grant, and whether such writing appears on any paper or electronic version of the License Grant or in a separate paper or electronic instrument, unless such writing is countersigned by CCC.

10. User may terminate its account at any time by sending e-mail to: customercare@copyright.com. Upon termination, User will receive a confirmation via e-mail that the request was received, and access to the licensing service from User's account will be suspended within one business day. User is responsible for all charges incurred up to the time the account is deactivated.

11. Unless the Rightsholder's own terms and conditions for the License Grant designate different terms for governing law, venue and jurisdiction and those terms and conditions are determined by a competent court to apply to a particular dispute, (a) the License Grant shall be governed by and construed under the law of the State of New York, USA, without regard to the principles thereof of conflicts of law, (b) any case, controversy, suit, action, or proceeding arising out of, in connection with, or related to the License Grant shall be brought, at CCC's sole discretion, in any federal or state court located in the County of New York, State of New York, USA, or in any U.S. federal or state court whose geographical jurisdiction covers the principal place of business of the Rightsholder, and (c) the parties expressly submit to the personal jurisdiction and venue of each such U.S. federal or state court.

12. User acknowledges and agrees that CCC may alter these terms and conditions in any fashion and at any time, effective immediately, provided that CCC posts notice of any material alteration hereof to the location at which User's monthly 
invoice is made available by CCC on the Internet and any such material alteration will be effective on the date set forth in the notice (and which effective date will be at least 30 days following CCC's first posting thereof). User also acknowledges and agrees that CCC may, on notice to User at the time of invoicing or at the time of any re-invoicing of a past-due amount, assign accounts and/or amounts due either to the applicable Rightsholder or to a financial institution; and that CCC may at any time assign all its rights, duties and responsibilities hereunder or under any License Grant to any other person who shall take responsibility for this licensing facility. Finally, User acknowledges and agrees that CCC may, in its sole discretion, terminate or suspend User's access to all or part of the licensing service for any reason, including without limitation breach of this Agreement or persistent failure to pay license fees on

basis.

Limited

License

With reference to your request to reprint in your thesis material on which Springer Science and Business Media control the copyright, permission is granted, free of charge, for the use indicated in your enquiry.

Licenses are for one-time use only with a maximum distribution equal to the number that you identified in the licensing process.

This License includes use in an electronic form, provided its password protected or on the university's intranet or repository, including UMI (according to the definition at the Sherpa website: http://www.sherpa.ac.uk/romeo/). For any other electronic use, please contact Springer at (permissions.dordrecht@springer.com or permissions.heidelberg@springer.com).

The material can only be used for the purpose of defending your thesis, and with a maximum of 100 extra copies in paper.

Although Springer holds copyright to the material and is entitled to negotiate on rights, this license is only valid, provided permission is also obtained from the (co) author (address is given with the article/chapter) and provided it concerns original material which does not carry references to other sources (if material in question appears with credit to another source, authorization from that source is required as well).

Permission free of charge on this occasion does not prejudice any rights we might have to charge for reproduction of our copyrighted material in the future. 
Altering/Modifying Material: Not Permitted You may not alter or modify the material in any manner. Abbreviations, additions, deletions and/or any other alterations shall be made only with prior written authorization of the author(s) and/or Springer Science + Business Media. (Please contact Springer at (permissions.dordrecht@springer.com permissions.heidelberg@springer.com)

Reservation of Rights Springer Science + Business Media reserves all rights not specifically granted in the combination of (i) the license details provided by you and accepted in the course of this licensing transaction, (ii) these terms and conditions and (iii) CCC's Billing and Payment terms and conditions.

Copyright Notice:Disclaimer You must include the following copyright and permission notice in connection with any reproduction of the licensed material: "Springer and the original publisher /journal title, volume, year of publication, page, chapter/article title, name(s) of author(s), figure number(s), original copyright notice) is given to the publication in which the material was originally published, by adding; with kind permission from Springer Science and Business Media"

Warranties: None

Example 1: Springer Science + Business Media makes no representations or warranties with respect to the licensed material.

Example 2: Springer Science + Business Media makes no representations or warranties with respect to the licensed material and adopts on its own behalf the limitations and disclaimers established by CCC on its behalf in its Billing and Payment terms and conditions for this licensing transaction.

Indemnity

You hereby indemnify and agree to hold harmless Springer Science + Business Media and CCC, and their respective officers, directors, employees and agents, from and against any and all claims arising out of your use of the licensed material other than as specifically authorized pursuant to this license.

No Transfer of License

This license is personal to you and may not be sublicensed, assigned, or transferred by you to any other person without Springer Science + 
Business Media's written permission.

No Amendment Except in Writing

This license may not be amended except in a writing signed by both parties (or, in the case of Springer Science + Business Media, by CCC on Springer Science + Business Media's behalf).

All disputes that may arise in connection with this present License, or the breach thereof, shall be settled exclusively by arbitration, to be held in the Federal Republic of Germany, in accordance with German law.

\section{Other terms and conditions:}

\section{v1.3}

If you would like to pay for this license now, please remit this license along with your payment made payable to "COPYRIGHT CLEARANCE CENTER" otherwise you will be invoiced within $\mathbf{4 8}$ hours of the license date. Payment should be in the form of a check or money order referencing your account number and this invoice number RLNK500731252.

Once you receive your invoice for this order, you may pay your invoice by credit card. Please follow instructions provided at that time.

$\begin{array}{llr}\text { Make } & \text { Payment } & \text { To: } \\ \text { Copyright } & \text { Clearance } & \text { Center } \\ \text { Dept } & & 001 \\ \text { P.O. } & \text { Box } & 843006 \\ \text { Boston, } & \text { MA } & 02284-3006\end{array}$

For suggestions or comments regarding this order, contact RightsLink Customer Support:customercare@copyright.com or +1-877-622-5543 (toll free in the US) or +1978-646-2777.

Gratis licenses (referencing $\$ 0$ in the Total field) are free. Please retain this printable license for your reference. No payment is required. 